Uma arquitetura para simulação flexível de protocolos para computação móvel

Ricardo Couto Antunes da Rocha

\author{
DISSERTAÇÃO APRESENTADA AO \\ INSTITUTO DE MATEMÁTICA E ESTATÍSTICA DA \\ UNIVERSIDADE DE SÃO PAULO \\ PARA OBTENÇÃO DO GRAU DE MESTRE EM \\ CIÊNCIA DA COMPUTAÇÃO
}

Área de Concentração: Sistemas Distribuídos

Orientador: Prof. Dr. Markus Endler

Durante o desenvolvimento deste trabalho, o autor recebeu apoio financeiro da CAPES - São Paulo, SP - Maio de 2001 - 


\title{
Uma Arquitetura para Simulação Flexível de Protocolos para Computação Móvel
}

\author{
Este exemplar corresponde à redação final \\ da dissertação devidamente corrigida \\ e defendida por Ricardo Couto Antunes da Rocha \\ e aprovada pela comissão julgadora.
}

São Paulo, 31 de maio de 2001

Banca Examinadora:

- Prof. Dr. Markus Endler (orientador) - DCC-IME-USP

- Prof. Dr. Marco Dimas Gubitoso - DCC-IME-USP

- Prof. Dr. Antônio Alfredo Ferreira Loureiro - DCC-UFMG 
nada como o firmamento para trazer ao pensamento a certeza de que estou sólido em toda área que ocupo e a imensidão aérea é ter o espaço do firmamento no pensamento e acreditar em voar algum dia.

(O Encontro de Isaac Asimov com Santos Dumont no Céu - Chico Science) 
A mamãe, papai, Nana e Gustavo 


\section{Agradecimentos}

A todos que colaboraram diretamente com meu trabalho:

Ao Markus, pela sua ótima orientação, baseada na empolgação, dedicação, paciência, interesse, estímulo, compreensão, confiança e amizade.

Ao Antônio Loureiro, pela correção minuciosa da minha dissertação e pelas sugestões. Senti o meu trabalho valorizado com sua presença na banca.

Ao Gubi, pelas sugestões ao meu trabalho desde a ocasião da minha qualificação.

Ao Hernan Astudillo, pelas críticas e sugestões na minha qualificação, pela enorme ajuda que me deu discutindo meu trabalho quando eu ainda engatinhava e pela simpatia e amizade.

Aos ex-alunos da disciplina de computação móvel do $2^{\circ}$ semestre de 2000 , que tiveram a coragem de utilizar o meu trabalho e em muito, mas muito mesmo colaboraram para a análise, validação e correção do código do simulador. Agradecimentos especiais a Robson, Alexandre Nardi, Alexis, Mateus, Santiago e Carlos. Foi um tempo de muito trabalho, finais de semana, noites e almoços perdidos, bem pior do que a própria defesa, mas que valeu a pena.

A quem fez da vida em São Paulo possível, familiar e alegre e aos que mantiveram acesa a saudade e a sede da terra maravilhosa que é o Espírito Santo:

A Uirá, Marquinho e Said, meus irmãozinhos de coração, de estudo, de companheirismo, de futebol e postura de vida. Aos amigos que fiz no IME: Marcelo, Francisco, Rogério e Priscila (e Teo), Alexandre Francé, Emmanuel, Robson e Ângela, Lucy, Ariane, Vera, Marcel, Ivone, Mateus, Santos, Nelson, Heitor, Antônio, Jorge, Rogério, Teo, Franklin e tantos outros. Eu havia ido para São Paulo para fazer o mestrado e voltei para o Espírito Santo com algo muito mais valioso: a amizade de vocês.

A Antônio Rosa e minha querida Inês, pela calorosa acolhida e ajuda em São Paulo. A Margareth e Leda, amigas do CEBI como Inês, que durante este tempo estiveram sempre próximas para oferecer carinho e ternura, matéria-prima de que são feitas.

A Rafael, Luíza, Joana, Marinês e Naidia, meus grandes amigos no Espírito Santo, com quem compartilho vida e crenças. Obrigado pelo apoio incondicional que sempre me deram e pela presença que sempre tiveram na minha vida, mesmo quando estava em São Paulo.

Aos meus familiares, que nunca perderam uma oportunidade de dizer o quanto sentiam minha falta, durante minha estadia em São Paulo. 


\section{Resumo}

Os ambientes de computação móvel possuem características que influenciam o projeto de sistemas computacionais sob vários aspectos. Os canais de comunicação sem fio apresentam alta taxa de erros e baixa largura de banda, se comparados às tecnologias atuais de cabeamento. O mobilidade das estações móveis pode causar grandes variações na qualidade da comunicação sem fio e confere ao ambiente de rede uma topologia dinâmica. Além disso, dispositivos móveis possuem recursos limitados de processamento e consumo de energia.

O maior impacto dessas características é no desenvolvimento de protocolos de rede. Nestes ambientes, os protocolos devem implementar mecanismos de correção de erros, controle de acesso ao meio sem fio, gerência de localização variável de estações móveis e utilizar adequadamente os recursos da rede, sobretudo o acesso aos canais de comunicação e o consumo de potência.

Devido a essa complexidade adicional dos protocolos para computação móvel, simuladores têm sido amplamente utilizados com o objetivo de avaliar o desempenho desses protocolos e a adequação dos modelos de simulação para as aplicações reais, sobretudo os modelos de mobilidade. Uma limitação comum a esses simuladores é não permitir a simulação de protocolos de alto nível de forma flexível e adequada.

Esta dissertação apresenta MoBICS (Mobile Computing Simulator), uma ferramenta integrada para teste e avaliação do desempenho de protocolos distribuídos para computação móvel. MoBiCS foi projetado para permitir o desenvolvimento de protótipos de protocolos e facilitar a descrição de cenários de simulação. Para isso, MoBICS provê ao usuário um modelo de programação baseado em micro-protocolos, com o qual é possível descrever protocolos altamente modularizados e organizados em componentes funcionais. No MoBICS ainda é possível programar diferentes modelos de simulação a serem aplicados na simulação do protocolo.

O MовICS utiliza simulações determinísticas como abordagem para teste e avaliação da corretude de protocolos. Neste tipo de simulação é possível reproduzir um cenário crítico de execução e verificar o comportamento do protocolo. Esta abordagem é genérica, aplicável a qualquer protocolo, e não exige nenhuma especificação formal para avaliação da corretude do protocolo. O MoBICS implementa ainda um modo de simulação estocástico, com o qual é possível avaliar o desempenho de protocolos em cenários aleatórios.

Espera-se que MoBiCS possa ser utilizado como elemento central do protótipo da arquitetura do projeto SIDAM e possibilitar o teste integrado dos seus vários componentes arquiteturais.

Além da ferramenta desenvolvida, as contribuições desta dissertação foram a proposta de uma arquitetura de referência para implementação de simuladores de protocolos que implementem diferentes modos de simulação e o desenvolvimento de um arcabouço para a implementação de modos de simulação, com o qual novos modos de simulação podem ser desenvolvidos e incorporados ao MoBiCS. 


\begin{abstract}
Mobile computing environments are characterized by dynamic network topology where connectivity patterns and transmission rates change very fast both because of host mobility and wireless transmission problems or resource shortages at the mobile hosts.

Due to these dynamic characteristics, development and testing of distributed programs and protocols for such environments is even more difficult than for a static network. For example, protocols for mobile computing must implement mechanisms for error correction, wireless media access control, variable location management and adequate use of resources, mainly the wireless channel access and power consumption.

This calls for tools that facilitate the prototyping and testing of distributed protocols for different mobility and connectivity patterns. Many protocol simulators have been developed for mobile computing, performance evaluation and analysis of different simulation models applied to this domain. These simulators differ with respect to simulation performance, flexibility and the network characteristics being modeled. A common limitation of these tools is the support for simulation of high level protocols with flexible and adequate programming abstractions.

This work describes MoBICS (Mobile Computing Simulator), a distributed protocol simulator for mobile computing that facilitates the prototyping and testing of protocols based on high-level programming abstractions and simulation transparency. MOBICS has a protocol programming model based on micro-protocols, that supports the description of highly modularized protocols organized in functional components. The user is also able to program different simulation models that can be applied in the simulation.

MOBICS adopts deterministic simulations as an approach for correctness test of protocols. In this simulation mode, it is possible to reproduce a critical execution scenario and verify the behavior of the protocol. This approach is generic, applied to any protocol and do not require formal specifications. Moreover, MoBICS can simulate protocols in a stochastic mode, in which the user assign a probabilistic behavior pattern to the simulated network elements. This mode is useful for performance evaluation.

The development of MoBICS is part of a larger project called SIDAM (Distributed Information Systems for Mobile Agents), which aims at investigating the problems related to the development of distributed information systems. MoBICS will be used as a central component of the SIDAM architecture and enable an integrated test of its several architectural components.

Besides the simulation tool, the contributions of this work are a reference architecture for development of protocol simulators that support different simulation modes and a framework for implementing new simulation modes, that can be added to the MOBICS.
\end{abstract}




\section{Sumário}

1 Introdução 1

2 Trabalhos Relacionados $\quad 4$

2.1 Ambientes para Implementação Modular de Protocolos . . . . . . . . . . . . 4

2.1.1 ADAPTIVE .......................... 4

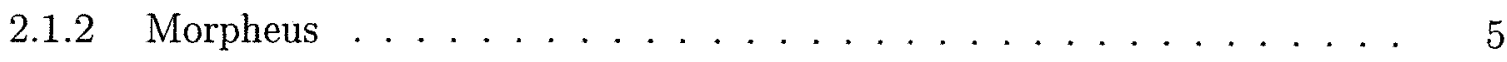

2.1.3 x-Kernel e Coyote . . . . . . . . . . . . . . . . 6

2.2 Simuladores para Computação Móvel . . . . . . . . . . . . . . . . . . 7

2.2 .1 GloMoSim ...................... 8

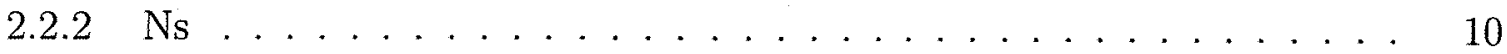

2.2 .3 Outros Simuladores . . . . . . . . . . . . . . . 11

2.3 Verificação da Corretude de Protocolos . . . . . . . . . . . . . . . . 12

3 Protocolos para Computação Móvel $\quad 14$

3.1 Modelo de Sistema e Definições . . . . . . . . . . . . . . . . . . . . 14

3.2 A Mobilidade nas Camadas de Protocolos . . . . . . . . . . . . . . . . 16

3.2 .1 Física e Enlace . . . . . . . . . . . . . . . . . 16

3.2 .2 Rede ............................... 17

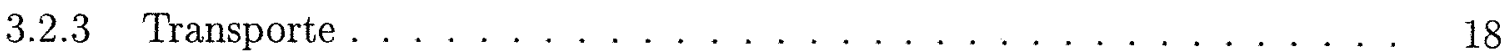

3.2 .4 Aplicação . . . . . . . . . . . . . . . . . . 18

3.3 Protocolos Distribuídos . . . . . . . . . . . . . . . . . . . . . 19

3.3.1 Um Exemplo: Protocolo de Entrega Confiável de Respostas a Clientes Móveis ..................... . . 20

4 Arquitetura de Referência $\quad 23$

4.1 Objetivos e Decisões de Projeto . . . . . . . . . . . . . . . . . . 23 
4.1.1 Desenvolvimento de Protocolos . . . . . . . . . . . . . . . 24

4.1.2 Simulação de Ambientes de Computação Móvel . . . . . . . . . . . 25

4.2 Arquitetura de Software para Simulação Flexível de Protocolos . . . . . . . . 26

4.2 .1 Camada de Aplicação . . . . . . . . . . . . . . . . . . . . 27

4.2 .2 Camada de Protocolos Distribuídos . . . . . . . . . . . . 27

4.2 .3 Camada de Elementos de Rede . . . . . . . . . . . . . . . 27

4.2 .4 Camada de Simulação . . . . . . . . . . . . . . . . 28

4.3 Simulação Determinística . . . . . . . . . . . . . . . . . . . . . 30

4.3 .1 Exemplo de Simulação Determinística . . . . . . . . . . . . . . 32

4.3 .2 Discussão . . . . . . . . . . . . . . . . . . . 33

4.4 Modelo de Programação de Protocolos . . . . . . . . . . . . . . . . . . . 34

4.5 Programação de Modelos de Simulação . . . . . . . . . . . . . . . . . . . . 35

4.5.1 Programação de Modelos de Mobilidade . . . . . . . . . . . . . . 36

$\begin{array}{llr}5 & \text { O Simulador MobiCS } & 38\end{array}$

5.1 Visão Geral do MobiCS . . . . . . . . . . . . . . . . . . . . . . 38

5.2 Uso do MobiCS . . . . . . . . . . . . . . . . . . . . . . . 39

5.3 Programação de Protocolos no MobiCS . . . . . . . . . . . . . . . . . . . 40

5.3.1 Pacote mobics.ppi.message e a Declaração de Mensagens . . . . . . 42

5.3.2 Pacote mobics.ppi.protocol e a Programação de Protocolos . . . . 44

5.3 .3 Discussão ........................ . . 47

5.4 Criação do Ambiente Simulado . . . . . . . . . . . . . . . . . 47

5.5 Modos de Simulação . . . . . . . . . . . . . . . . . . . . . 49

5.5 .1 Modo Determinístico . . . . . . . . . . . . . . . 49

5.5 .2 Modo Estocástico . . . . . . . . . . . . . . . . 51

5.6 Programação de Modelos de Simulação . . . . . . . . . . . . . . . . . 52

5.6 .1 Modelos de Simulação para Canais de Comunicação . . . . . . . . . 52

5.6 .2 Modelos de Simulação para Elementos . . . . . . . . . . . . . . 53

5.6 .3 Modelo de Mobilidade . . . . . . . . . . . . . . 55

5.6 .4 Discussão .............................. 56

6 Exemplo de Uso do MobiCS 58

6.1 Implementação do Protocolo RDP . . . . . . . . . . . . . . . . . . 58

6.1 .1 Declaração das Mensagens . . . . . . . . . . . . . . . . . 59 
6.1 .2 Implementação dos Micro-Protocolos . . . . . . . . . . . . 60

6.2 Simulação Determinística do RDP . . . . . . . . . . . . . . . . . . . 61

6.3 Simulação Estocástica do RDP . . . . . . . . . . . . . . . . . 63

6.3 .1 Modelo de Simulação . . . . . . . . . . . . . . . . . . . 64

6.3 .2 Implementação da Simulação . . . . . . . . . . . . . 65

6.3 .3 Resultados da Simulação . . . . . . . . . . . . . . . . . . . 67

$\begin{array}{lll}7 & \text { Implementação do MobiCS } & 70\end{array}$

7.1 Visão Geral . . . . . . . . . . . . . . . . . . . . . . . . 70

7.2 Implementação dos Elementos de Rede . . . . . . . . . . . . . . . 72

7.2 .1 Máquinas de Rede . . . . . . . . . . . . . . . . . 72

7.2 .2 Canais de Comunicação . . . . . . . . . . . . . . . 73

7.3 Arcabouço de Implementação de Modos de Simulação . . . . . . . . . . . . 74

7.3.1 Classe AbstractSimulatedElement . . . . . . . . . . . . . 74

7.3 .2 Classe simulator . . . . . . . . . . . . . . . . 75

7.3 .3 Classe Simulation . . . . . . . . . . . . . 76

7.3 .4 Criação dos Objetos . . . . . . . . . . . . . . . 76

7.3 .5 Discussão . . . . . . . . . . . . . . . . 77

7.4 Camada de Simulação . . . . . . . . . . . . . . . . . 77

7.4 .1 Arquitetura Geral . . . . . . . . . . . . . . . . . . 78

7.4 .2 Modo Determinístico . . . . . . . . . . . . . . . . . 79

7.4 .3 Modo Estocástico . . . . . . . . . . . . . . . . . . . . . . 80

8 Avaliação $\quad 83$

8.1 Experiência de Uso do MobiCS . . . . . . . . . . . . . . . . . . . . 83

8.1.1 Modelo de Programação de Protocolos . . . . . . . . . . . . . 83

8.1 .2 Simulação Determinística . . . . . . . . . . . . . . . . . 84

8.1 .3 Simulação Estocástica . . . . . . . . . . . . . . . . 85

8.2 Comparação com outros Simuladores . . . . . . . . . . . . 85

$\begin{array}{llr}9 & \text { Conclusões e Trabalhos Futuros } & 89\end{array}$

A Implementação do Protocolo RDP 92

A.1 Declaração das Mensagens . . . . . . . . . . . . . . . . . . . . . . 92

A.2 Declaração dos Protocolos e Micro-Protocolos . . . . . . . . . . . . 93 
A.3 Implementação do Protocolo RDPMss . . . . . . . . . . . . . . . . . . 94

A.4 Simulação Determinística . . . . . . . . . . . . . . . . . . . . . . 98

A.5 Simulação Estocástica . . . . . . . . . . . . . . . . . . . 100

A.5.1 Classe MyStochSimulation . . . . . . . . . . . . . 100

A.5.2 Classe MigrationEventModel . . . . . . . . . . . . . . . 102

A.5.3 Classe MyMh . . . . . . . . . . . . . . . . . . . . 103 


\section{Lista de Figuras}

2.1 Trecho de Pseudo-código de um Micro-protocolo no Coyote . . . . . . . . 7

2.2 Arquitetura de Camadas de Protocolos de GloMoSim . . . . . . . . . . . . 8

2.3 Exemplo de Implementação de Protocolo no GloMoSim . . . . . . . . . . . . 9

2.4 Exemplo de Esboço de Protocolo Implementado para Simulação no ns . . . . 10

3.1 Modelo de Sistema para Computação Móvel . . . . . . . . . . . . . . . 15

3.2 Arquitetura de Camadas de Protocolos TCP/IP . . . . . . . . . . . 16

3.3 Reenvio de pacotes para $M h$, do home agent para o foreign agent . . . . . 17

3.4 Protocolos Distribuídos na Arquitetura de Camadas de Rede . . . . . . . . 19

3.5 Exemplo de Funcionamento do Protocolo RDP . . . . . . . . . . . . . 21

4.1 Arquitetura de Software em Camadas . . . . . . . . . . . . . . . 26

4.2 Interação entre as Camadas de Elementos de Rede e de Simulação . . . . . . 29

4.3 Exemplo de cenário para simulação determinística . . . . . . . . . . . 32

4.4 Diagrama de Interação entre Micro-Protocolos . . . . . . . . . . . . . 35

5.1 Implementação de Protocolos e Simulações a partir do MoBiCS . . . . . . 39

5.2 Diagrama de Seqüência de Implementação e Simulação de um Protocolo . . . 40

5.3 Exemplo de Mapeamento de um Protocolo para classes Java . . . . . . . . 41

5.4 Diagrama UML das Classes do Pacote mobics.ppi.message . . . . . . . . 43

5.5 Diagrama UML das Classes do Pacote mobics.ppi.protocol . . . . . . . 44

5.6 Exemplo de Uso de $\mathrm{rSend} \ldots \ldots \ldots$. . . . . . . . . . . . . . 46

5.7 Diagrama de Sequência de Envio de Mensagens . . . . . . . . . . . . 46

5.8 Exemplo de Criação de Elementos Simulados . . . . . . . . . . . . . . . 49

5.9 Exemplo de Script Determinístico . . . . . . . . . . . . . . . . 50

5.10 Atribuição de um Modelo de Simulação a um Elemento Simulado . . . . . . 52

5.11 Componentes de um Gerador de Eventos . . . . . . . . . . . . . . . 53 
6.1 Diagrama de Comunicação entre os Módulos do RDP . . . . . . . . . . . . 59

6.2 Implementação da Mensagem Ack_Mh . . . . . . . . . . . . . . . . . . . 60

6.3 Estrutura da Classe RDPMss . . . . . . . . . . . . . . . . . . 61

6.4 Implementação do Tratador da Mensagem Ack . . . . . . . . . . . . . . 62

6.5 Cenário de Teste Determinístico do Protocolo RDP . . . . . . . . . . . 63

6.6 Implementação do Script Determinístico do Cenário do RDP . . . . . . . . . 64

6.7 Saída Parcial da Simulação Determinística . . . . . . . . . . . . . . . 65

6.8 Matriz de Vizinhança entre Células . . . . . . . . . . . . . . . . . 67

6.9 Número relativo de mensagens ForwardRes em função da probabilidade de migração . . . . . . . . . . . . . . . . . . . 68

6.10 Tamanho médio de Plist em função do número de requisições por migração . 68

7.1 Diagrama de Classes do Arcabouço . . . . . . . . . . . . . . . . . 75

7.2 Diagrama de Seqüência de Criação de Objetos . . . . . . . . . . . . . . . 77

7.3 Arquitetura Geral da Camada de Simulação . . . . . . . . . . . . . . 78

7.4 Diagrama de Estados dos Elementos Simulados no Modo Determinístico . . . 79

7.5 Algoritmo de Cálculo do Atraso de Envio de Mensagem por Canal sem Fio . 81

A.1 Diagrama de Classes das Mensagens do Protocolo RDP . . . . . . . . . . . 92

A.2 Diagrama de Classes de Declaração dos Micro-Protocolos e Instâncias do Protocolo RDP . . . . . . . . . . . . . . . . . . 93 


\section{Lista de Tabelas}

4.1 Eventos trocados entre a Camada de Elementos de Rede e as Camadas Superiores 28

4.2 Eventos trocados entre a Camada de Simulação e de Elementos de Rede . . . 30

5.1 Mapeamento dos Conceitos do Modelo de Programação de Protocolos para o Modelo de Programação Java . . . . . . . . . . . . . . . . . . . . . 41

6.1 Mensagens utilizadas pelo protocolo RDP. . . . . . . . . . . . . . 59

7.1 Organização da Biblioteca MobıCS . . . . . . . . . . . . . . 71

8.1 Tabela Comparativa entre Diferentes Simuladores . . . . . . . . . . . . . 86 


\section{Capítulo 1}

\section{Introdução}

Com a miniaturização dos circuitos e dispositivos eletrônicos e a sua acelerada queda de preços, computadores portáteis como palmtops e PDA's (Personal Digital Assistants) estão se tornando cada vez mais populares. Esses dispositivos podem ser utilizados com tecnologias de comunicação sem fio, como por exemplo WaveLAN, para compor ambientes comumente chamados de ambientes de computação móvel. Nestes ambientes, os dispositivos são chamados de estações móveis e podem migrar sem perder sua conexão com a rede.

Os ambientes de computação móvel possuem várias características que os diferenciam das redes de computadores convencionais. Os canais de comunicação sem fio apresentam alta taxa de erros e baixa largura de banda, se comparados às tecnologias atuais de cabeamento. Enquanto nas tecnologias de redes fixas a velocidade de transmissão de dados chega a $10 \mathrm{Mbps}$ em Ethernet, 100 Mbps em FDDI e FastEthernet e 155 e 622 Mbps em ATM, em redes sem fio baseadas no atual padrão IEEE 802.11 essa taxa é limitada em $1 \mathrm{Mbps}$ [71, 91]. A mobilidade das estações pode causar grandes variações na qualidade da comunicação sem fio e confere ao ambiente de rede uma topologia dinâmica. Além disso, dispositivos móveis possuem recursos limitados de processamento e consumo de energia. Por outro lado, ambientes de computação móvel viabilizam a implementação de várias aplicações conscientes da localização (mobilityaware) como a descoberta automática de serviços e serviços dependentes de contexto, tais como [25].

Todas essas características influenciam o projeto de sistemas computacionais sob vários aspectos [56], tais como a implementação de banco de dados, interfaces com usuário, segurança e protocolos de comunicação.

No caso de algoritmos distribuídos, é necessário implementar várias modificações nos algoritmos projetados para redes convencionais, a fim de que sejam garantidas a eficiência e corretude da interação distribuída. Nos ambientes de computação móvel, os algoritmos distribuídos devem ser capazes de manter a interação com um número variável de participantes, uma vez que as desconexões são constantes. Além disso, as desconexões voluntárias não devem ser tratadas com a semântica de uma falha. Algoritmos distribuídos devem ainda ser implementados para minimizar o uso dos canais de comunicação sem fio. Em [8] há uma discussão detalhada sobre influência das características dos ambientes de computação no projeto de algoritmos distribuídos. 
Algoritmos distribuídos são implementados em aplicações ou protocolos de comunicação de alto nível, também chamados protocolos distribuídos. Os protocolos distribuídos possuem várias características que os diferenciam dos protocolos ponto-a-ponto. Nos protocolos distribuídos o estado do algoritmo é mantido distribuído entre os participantes da interação. Assim, uma eventual desconexão pode causar a perda parcial deste estado. Os protocolos distribuídos são altamente influenciados pela mobilidade. Enquanto que nos protocolos ponto-a-ponto a mobilidade influi apenas na modificação do estado de acessibilidade entre dois hosts, nos protocolos distribuídos a mobilidade pode provocar uma reorganização do estado distribuído do algoritmo e modificar a forma como as mensagens são encaminhadas. Por exemplo, há vários algoritmos distribuídos $[4,89,94]$ que se baseiam em topologias de interconexão entre participantes. Esses algoritmos precisam se reorganizar sempre que houver uma modificação na topologia da rede. Por este motivo, a validação dos algoritmos distribuídos é mais complexa do que a dos protocolos ponto-a-ponto e a escolha do modelo de mobilidade pode influenciar diretamente o resultado da simulação.

A simulação é uma abordagem amplamente utilizada para avaliação de protocolos de rede, sobretudo protocolos para computaçao móvel, cujo critério de avaliação é tipicamente a escalabilidade. Existem vários simuladores para computação móvel $[18,21,24,68,76,81$, $82,96]$, que diferem entre si quanto aos aspectos de flexibilidade, desempenho de simulação e poder de modelagem. Uma limitação comum a esses ambientes é não permitir a simulação de protocolos de alto nível, como protocolos distribuídos, de forma flexível e adequada. Em alguns casos, isso ocorre por excesso de detalhamento do ambiente simulado ou pela falta de abstrações de programação de alto nível. Não existem ferramentas integradas para teste, validação e análise de desempenho que possam ser aplicadas em protocolos distribuídos para computação móvel. Apesar da influência da mobilidade nestes protocolos, a maioria das ferramentas não disponibiliza abstrações para a definição e implementação de modelos de mobilidade adequados à análise dos protocolo.

Esta dissertação apresenta MOBICS ${ }^{1}$ (Mobile Computing Simulator), um simulador de protocolos distribuídos para computação móvel, que integra em uma única ferramenta a prototipagem, teste, validação e avaliação de protocolos distribuídos. $O$ simulador facilita a programação de protótipos de protocolos, tendo como base um modelo de programação modular e orientado a eventos, baseado no conceito de micro-protocolos.

MoBICS implementa dois modos de simulação: determinístico e estocástico. No modo de simulação determinístico, o usuário pode simular o protocolo em um cenário determinístico descrito em um script. Neste modo, o usuário deverá programar situações críticas de execução do protocolo, com o objetivo de realizar testes, depurar e validar o protocolo. No modo de simulação estocástico ${ }^{2}$, o usuário pode simular o protocolo em um cenário aleatório, submetendo-a a simulações exaustivas a fim de analisar o seu desempenho. MoBICS define várias abstrações com as quais o usuário pode programar o seu próprio modelo de simulação e aplicá-lo à simulação estocástica. Por exemplo, o usuário pode implementar e configurar o seu próprio modelo de mobilidade.

\footnotetext{
${ }^{1}$ Pronuncia-se mobix.

${ }^{2} \mathrm{O}$ termo estocástico possui o mesmo sentido de probabilístico e indica algo que é governado pela probabilidade [38]. No caso deste modo, o comportamento do ambiente simulado é descrito probabilisticamente.
} 
MOBICS implementa transparência de simulação para o programador. Isso significa que os protótipos de protocolos podem ser simulados nos diferentes modos de simulação, sem que seja necessária nenhuma modificação ou configuração nos protocolos.

A partir do projeto do MoBICS, foi desenvolvida uma arquitetura de referência que generaliza a arquitetura do MOBICS e permite a construção de simuladores de protocolos nos quais diferentes modos de simulação podem ser desenvolvidos e incorporados, com total transparência de simulação para os programadores de protocolos. A arquitetura de referência estabelece ainda conceitos e requisitos que devem ser implementados pelos simuladores e adota uma abordagem para avaliação da corretude de protocolos baseada em simulações determinísticas.

Além da ferramenta de simulação e da arquitetura de referência, outra contribuição desta dissertação foi o desenvolvimento de um arcabouço ${ }^{3}$ para implementação de modos de simulação com o qual novos modos de simulação podem ser facilmente desenvolvidos e incorporados ao simulador.

MoBICS foi desenvolvido no contexto do projeto SIDAM ${ }^{4}$ (Sistemas de Informação Distribuídos para Agentes Móveis) [33] com o qual pretende-se utilizar uma arquitetura de computação móvel para implementar "serviços de informação descentralizados para consulta por agentes móveis" [29]. A aplicação de referência para o projeto é um sistema on-line de disseminação de informações sobre tráfego. No contexto do projeto, foram desenvolvidos alguns protocolos $[34,32]$ que estão sendo simulados com o MoвıCS. Além disso, espera-se que o simulador possa ser utilizado como elemento central do protótipo da arquitetura SIDAM e possibilitar o teste integrado dos seus vários componentes arquiteturais.

\section{Organização desta Dissertação}

Esta dissertação está organizada da seguinte forma: o capítulo 2 descreve os principais trabalhos na literatura relacionados com o tema desta dissertação, incluindo alguns simuladores para redes móveis sem fio e alguns ambientes de desenvolvimento de protocolos. $\mathrm{O}$ capítulo 3 apresenta o modelo de sistema de computação móvel adotado e discute brevemente a influência da mobilidade nas diversas camadas de protocolos. Esta seção também apresenta a classe de protocolos que será simulada pelo ambiente, chamada protocolos distribuídos. O capítulo 4 apresenta a arquitetura de referência proposta em relação aos seus requisitos de projeto, arquitetura de software e conceitos propostos. O capítulo 5 descreve o simulador MoBICS, do ponto de vista de um usuário, e no capítulo 6 é descrito um exemplo de simulação de protocolo usando o MoBICS. O capítulo 7 apresenta os principais detalhes de implementação do simulador. O capítulo 8 apresenta uma avaliação da implementação feita, enquanto que algumas conclusões e propostas de trabalhos futuros são apresentadas no capítulo 9 .

\footnotetext{
${ }^{3}$ Framework

${ }^{4} \mathrm{O}$ projeto SIDAM é patrocinado pela FAPESP (Fundação de Amparo à Pesquisa do Estado de São Paulo) - Proc. No. 98/06138-2
} 


\section{Capítulo 2}

\section{Trabalhos Relacionados}

Há dois principais problemas relacionados ao projeto e implementação da arquitetura de simulação proposta. O primeiro problema é desenvolver um modelo de programação que permita a prototipagem de protocolos. O segundo problema é a implementação de um simulador que faça uso dessa arquitetura e simule o ambiente de computação móvel desejado. Este capítulo descreve os principais trabalhos encontrados na literatura que propõem direta ou indiretamente soluções para esses dois problemas. A seção 2.1 descreve vários ambientes para implementação modular ou prototipagem de protocolos e que definem modelos de programação de protocolos orientados a diferentes aspectos, como configurabilidade e eficiência. A seção 2.2 enumera e descreve as características dos principais simuladores de computação móvel existentes, com ênfase na arquitetura e nos aspectos de ambientes de computação móvel simulados. O capítulo ainda apresenta na seção 2.3 uma breve discussão sobre as abordagens para validação de protocolos baseadas em simulação, uma vez que este também é um dos objetivos da arquitetura.

\subsection{Ambientes para Implementação Modular de Pro- tocolos}

Devido ao aumento da complexidade dos ambientes de rede, vários ambientes têm sido desenvolvidos para oferecer uma infra-estrutura para implementação de protocolos. O principal objetivo desses ambientes é facilitar a prototipagem e o desenvolvimento de protocolos eficientes. Esta seção descreve três desses ambientes: ADAPTIVE, Morpheus e Coyote. Esses ambientes foram escolhidos por promoverem modularização, abstrações de programação e configurabilidade às implementações.

\subsubsection{ADAPTIVE}

ADAPTIVE [19] (A Dynamically Assembled Protocol Transformation, Integration and Evaluation) é um ambiente flexível para o desenvolvimento de protocolos considerando di- 
versos requisitos de qualidade de serviço (QoS) em redes de alto desempenho. O ambiente possui um conjunto de ferramentas com as quais é possível compor e experimentar diferentes protocolos, modificando as sessões e arquiteturas de processos, de maneira a prover funcionalidade, desempenho e flexibilidade.

As sessões são "instâncias" executáveis de um protocolo de comunicação, contendo informações de contexto e tarefas em processamento. Em ADAPTIVE pode-se configurar uma sessão através da escolha de diferentes mecanismos para uma determinada tarefa do protocolo, como por exemplo, a política de retransmissão de pacotes. A configuração da arquitetura de processos é feita verticalmente através da escolha da família de protocolos a ser utilizada (TCP/IP, por exemplo) e/ou horizontalmente, através da escolha de protocolos específicos para cada camada (como entre TCP e UDP). Essas configurações podem ser estáticas, definidas em tempo de compilação, ou dinâmicas. Esta segunda forma permite a adaptação às mudanças nos requisitos da aplicação (QoS), características da rede (causadas por congestionamento, por exemplo) ou disponibilidade de recursos do sistema.

As ferramentas de ADAPTIVE permitem medir o desempenho de diferentes configurações de protocolos e comparar diferentes soluções de acordo com os requisitos da aplicação.

\subsubsection{Morpheus}

Morpheus [1] é uma linguagem de programação orientada a objetos destinada à implementação de protocolos com alto desempenho. Um protocolo é uma classe que estende uma das classes básicas definidas por Morpheus. Dessa forma, Morpheus possibilita a modularização, a reutilização de código e a transparência de detalhes com a ocultação de informação.

Há cinco classes básicas em Morpheus: Protocol, UnderSap, OverSap, UnderSession e OverSession. Protocol representa a implementação de um protocolo; cada instância dessa classe representa um diferente protocolo implementado. UnderSap e OverSap ${ }^{1}$ representam a interface entre dois diferentes protocolos (objetos da classe Protocol). UnderSap está associado ao protocolo que utiliza um serviço da rede e OverSap ao protocolo que provê o serviço. As classes UnderSession (lado do cliente) e OverSession (lado do servidor) representam sessões, ou seja, fluxos de dados entre objetos UnderSap e OverSap. Elas implementam as operações de entrega e recebimento de mensagens. Há ainda três classes frequentemente utilizadas pelos protocolos mas que não são extensíveis: Message, Map (tabela hash) e Event (eventos). Um objeto Protocol é composto de vários objetos UnderSap, OverSap, UnderSession e OverSession.

Em Morpheus, um protocolo está associado a um perfil (shape), que define a tarefa que ele desempenha. Os protocolos podem implementar três possíveis perfis: multiplexor (para protocolos de multiplexação e demultiplexação), worker (detecção de erro, retransmissão, reordenação, duplicação de mensagens, etc) e router (manipula endereços de máquinas).

Um compilador se encarrega de traduzir um código Morpheus para um código de alto desempenho, baseando-se no conhecimento do tipo da aplicação alvo (identificando em qual perfil o protocolo se aplica), no conhecimento da arquitetura de hardware utilizada e uti-

\footnotetext{
${ }^{1}$ SAPs são Service Access Points, interfaces de serviços de comunicação.
} 
lizando técnicas específicas de otimização, como expansão em linha de chamadas de funções.

\subsection{3 x-Kernel e Coyote}

x-Kernel [55] é um sistema operacional orientado a comunicação que adota uma organização modular de protocolos. A arquitetura do x-Kernel possibilita a construção e composição hierárquica de protocolos de rede, a partir de uma interface de programação de protocolos composta de três operações: demux, que passa uma mensagem para uma sessão de protocolo de mais alto nível, push, responsável pelo envio de mensagens para uma sessão de protocolo de mais baixo nível e pop, que implementa o recebimento de uma mensagem de uma camada de mais baixo nível, como resultado de um demux. x-Kernel usa o modelo de execução de uma thread por mensagem e possui ainda uma biblioteca com a implementação dos protocolos mais comuns.

Coyote $[13,15]$ é um sistema para construção de protocolos modulares e configuráveis que estende o $\mathrm{x}$-Kernel na medida em que permite a composição de protocolos em um nível adicional: o de composição horizontal ou modular. O objetivo do Coyote é permitir a implementação de protocolos com maior expressibilidade, facilidade de manutenção, eficiência, reutilização de código e configurabilidade. No modelo de programação do Coyote, protocolos são compostos de módulos chamados micro-protocolos, que implementam uma semântica específica do protocolo. A flexibilidade de composição de módulos torna possível a experimentação de diversas alternativas de implementação, mantendo a funcionalidade do protocolo.

A interação entre micro-protocolos é feita através de eventos. Para cada micro-protocolo pode-se definir um conjunto de eventos tratáveis, condições para recebimento de eventos e uma sequência de ações associadas ao recebimento de cada evento. Há dois tipos de eventos: os pré-definidos, tipicamente relacionados a mensagens recebidas de outras camadas de protocolos, e os definidos pelo usuário, que são gerados no corpo dos micro-protocolos implementados. Um sistema em tempo de execução é responsável por captar todos os eventos gerados e executar seus correspondentes tratadores. Há um tipo especial de evento chamado evento de tempo, que possibilita a execução de ações relacionadas à passagem de tempo e ações a serem executadas periodicamente.

O trecho de pseudo-código da figura 2.1 trata dois eventos: Message_Pushed_From_CP, que é um evento pré-definido correspondente ao recebimento de uma mensagem $x$-Kernel de um protocolo de camada superior, e Beacon.Timer, um evento de tempo repetitivo (a cada $100 \mathrm{~ms}$ ) inicializado no campo initialize.

No âmbito do projeto Coyote, foi implementado um conjunto de micro-protocolos para computação móvel [14], adotando diversas implementações para coordenação de handoff, detecção de handoff, prevenção de oscilação no handoff em regiões sobrepostas de células, desconexão e protocolos para qualidade de serviço. 


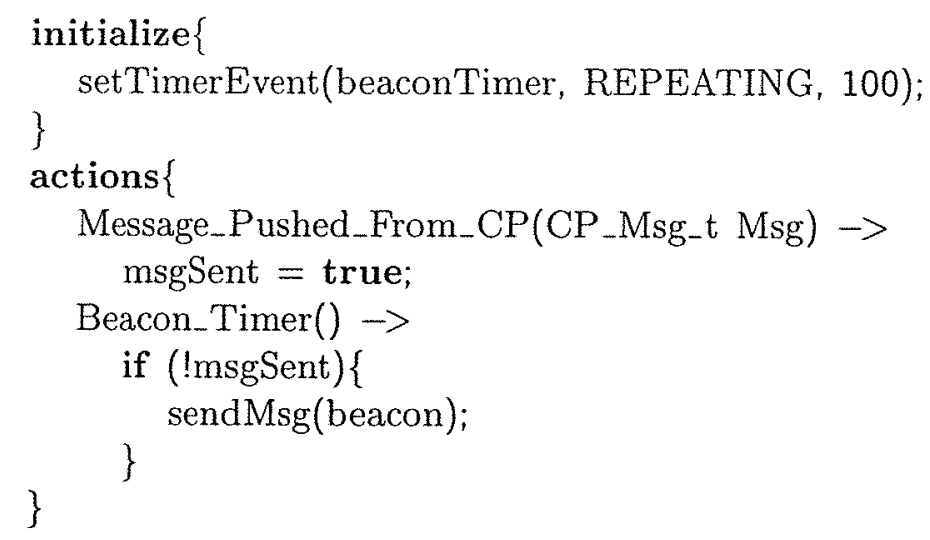

Figura 2.1: Trecho de Pseudo-código de um Micro-protocolo no Coyote

\subsection{Simuladores para Computação Móvel}

Muitos simuladores já foram desenvolvidos para computação móvel. Eles podem ser classificados de acordo com a flexibilidade em simuladores de rede e simuladores de protocolos.

Simuladores de rede (como $[18,24,68]$ ) são desenvolvidos para simular um ambiente específico de rede e protocolos, em relação a diferentes padrões de topologias e/ou de comportamento dos elementos da rede. Por exemplo, em [18] e [82] são apresentados simuladores de rede que permitem o teste de diferentes estratégias de atualização da localização de estações móveis em redes celulares. Geralmente, os simuladores de rede modelam o ambiente em um grau menor de detalhamento e implementam algoritmos de simulação mais eficientes, baseando-se no conhecimento das características do ambiente simulado. Além disso, a interface com o usuário é projetada para permitir uma melhor visualização apenas das informações relevantes para simulação realizada.

Simuladores de protocolos, por outro lado, são implementados para serem flexíveis e permitir a implementação e o teste de protocolos para um ambiente de rede simulado. Devido ao seu caráter genérico, o desempenho de simulação desses simuladores é tipicamente inferior ao dos simuladores de rede. Em contrapartida, a abordagem de implementação desses simuladores permite o uso de abstrações flexíveis e reutilizáveis, na maioria das vezes baseadas em arquiteturas orientadas a objetos. Em um mesmo simulador pode-se encontrar aspectos de simuladores de rede e de simuladores de protocolos.

O simulador MoBICS, implementado a partir da arquitetura proposta, faz parte da classe dos simuladores de protocolos, que tem como principais representantes, para computação móvel, os simuladores ns e o GloMoSim. As duas seções seguintes descrevem os aspectos arquiteturais, o modelo de programação de protocolos e os modelos de simulação desses dois simuladores. A seção 2.2.3 enumera e descreve brevemente outros simuladores desenvolvidos especialmente para computação móvel. 


\subsubsection{GloMoSim}

GloMoSim [77, 96] (Global Mobile system Simulator) é um simulador de redes sem fio baseado em bibliotecas, desenvolvido no Laboratório de Computação Paralela da Universidade da Califórnia em Los Angeles. O GloMoSim implementa um conjunto de protocolos para redes sem fio, organizados em uma arquitetura em camadas, mostrada na figura 2.2. Esses protocolos são organizados em módulos que definem um aspecto específico dos protocolos de comunicação sem fio.

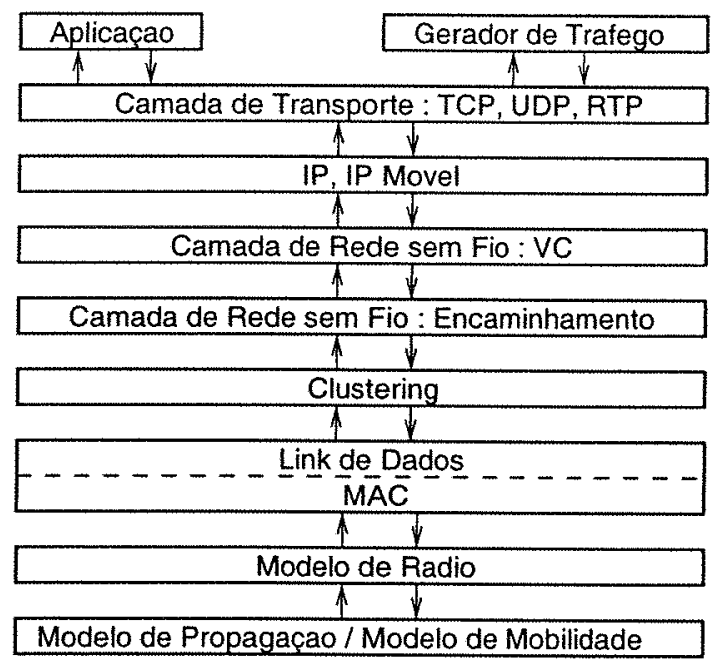

Figura 2.2: Arquitetura de Camadas de Protocolos de GloMoSim

A biblioteca é implementada em Parsec [10], uma linguagem de simulação paralela baseada em C. Novos protocolos e módulos programados em Parsec podem ser adicionados à biblioteca para compor diferentes simulações. Os novos módulos devem estar em conformidade com uma API definida pelo GloMoSim para a comunicação entre as camadas da figura 2.2.

O núcleo de Parsec implementa uma máquina de simulação de alto desempenho, que utiliza vários protocolos para simulação paralela e distribuída. Essa característica permite a utilização do GloMoSim para simulação de redes de computação móvel de larga escala. Além disso, Parsec permite tornar a maior parte dos detalhes de simulação transparentes ao programador. Em alguns casos, entretanto, o usuário precisa definir o mapeamento de entidades para processadores e especificar a topologia de comunicação requerida pelo algoritmo de simulação paralela.

Para programar um protocolo, o usuário deve utilizar o modelo de programação de Parsec. Neste modelo, protocolos são implementados em módulos monolíticos chamados entidades. Cada entidade define a posição na camada de protocolos do GloMoSim, as mensagens trocadas com as demais camadas e o algoritmo do protocolo, que define as ações que devem ser executadas no recebimento de cada mensagem.

A figura 2.3 mostra um esboço de um protocolo da camada MAC implementado em Parsec. O exemplo especifica duas das mensagens que o protocolo pode tratar: ClearedToSend e 


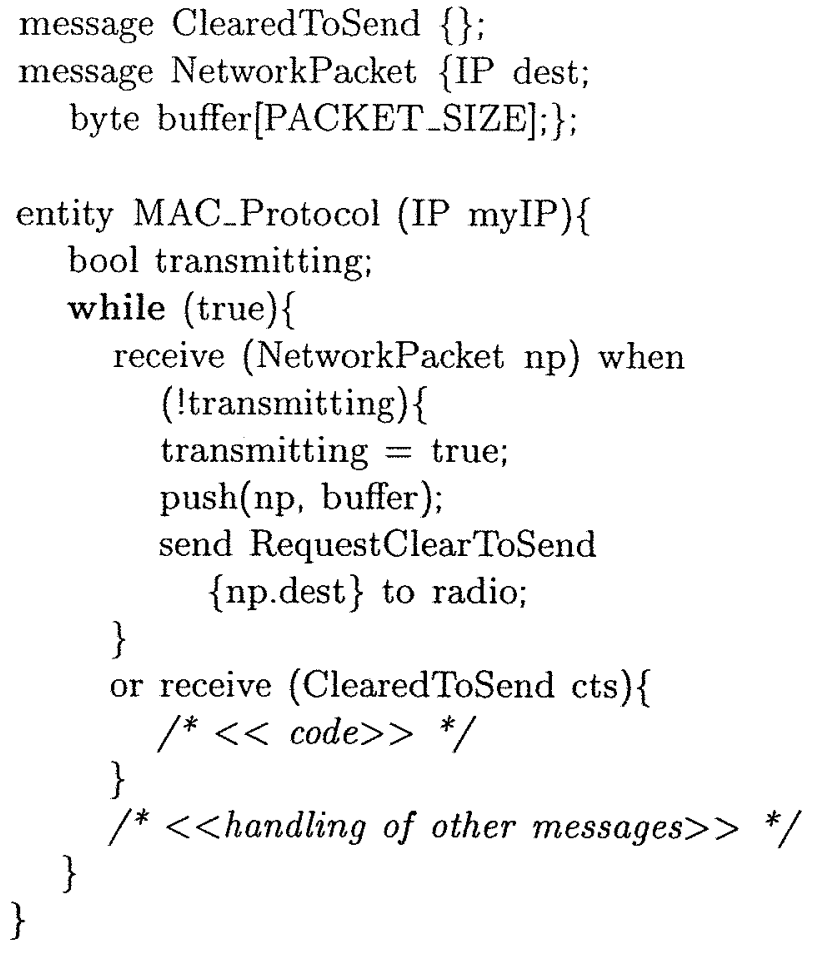

Figura 2.3: Exemplo de Implementação de Protocolo no GloMoSim

NetworkPacket. No corpo da declaração do protocolo, o programador especifica as ações do protocolo que processam cada uma das mensagens.

Para atender aos requisitos de escalabilidade, em GloMoSim uma máquina na rede simulada não é mapeada em uma entidade Parsec. Ao invés disso, toda a rede é decomposta em partições que são simuladas por uma única entidade Parsec. Nessa abordagem, a modularidade é obtida através da incorporação de entidades dentro de entidades. Esse encapsulamento permite um melhor desempenho de simulação mas exige que o programador tenha consciência desse detalhe arquitetural durante a implementação do protocolo.

Parsec contém uma ferramenta visual chamada PAVE, que permite o projeto de programas Parsec através de uma interface gráfica e a configuração dos modelos de simulação.

Um arquivo de entrada define os parâmetros da simulação de acordo com o modelo de simulação para computação móvel do GloMoSim. Neste modelo, os parâmetros de simulação são o número de estações móveis, a estratégia de distribuição das estações no ambiente e o modelo de mobilidade, escolhido a partir de dois modelos bem definidos. O usuário ainda indica nesse arquivo quais são as informações (traces) que ele deseja coletar na saída da simulação, dentro de um conjunto extenso de informações definidos pelo GloMoSim.

Vários trabalhos recentes, como [48, 83], fizeram uso de GloMoSim para simular e avaliar de desempenho de protocolos para computação móvel. Alguns desses trabalhos identificaram limitações no ambiente para a simulação adequada de protocolos específicos. Por exemplo, na simulação apresentada em [48], o modelo de mobilidade do GloMoSim foi modificado porque 
mostrou-se insuficiente para uma avaliação efetiva do protocolo.

\section{$2.2 .2 \quad \mathrm{Ns}$}

Ns [21, 92] é um simulador de eventos discretos flexível e de caráter geral amplamente utilizado para simulação de protocolos de rede. Ele foi desenvolvido na Universidade da Califórnia em Berkeley como parte do projeto VINT, do qual ainda participam LBNL ${ }^{2}$, UCS/ISI ${ }^{3}$ e Xerox PARC. O ns pode ser utilizado também como um emulador de rede, fazendo com que uma rede simulada interaja com uma rede real. O pacote do ns ainda inclui geradores de padrões de falhas, tráfego e topologia de rede e uma ferramenta de animação de rede chamada nam [35].

Ns utiliza um modelo de programação em dois níveis: o núcleo de simulação é implementado em $\mathrm{C}++$, que interage com módulos programados em OTcl, uma extensão orientada a objetos de $\mathrm{Tcl}$. O núcleo em $\mathrm{C}++$ implementa a funcionalidade da rede, as primitivas e a máquina de simulação, enquanto que OTcl é utilizado para definir, configurar e controlar as simulações. Todo objeto simulado é implementado por um objeto $\mathrm{C}++$, que confere eficiência à implementação e que pode ser estendido para criar características específicas e adicionar funcionalidades ao simulador. Esses objetos são mapeados para objetos OTcl, que o usuário pode configurar e incorporar à sua simulação, o que confere abstração sobre detalhes de implementação do objeto $\mathrm{C}++$. Com esse modelo de dois níveis e orientado a objetos, ns visa atender os requisitos de desempenho e flexibilidade.

Um protocolo é programado em uma classe $\mathrm{C}++$, que estende a classe Agent, e implementa os métodos Agent.command (...) e Agent.recv (...). A figura 2.4 mostra a interface da classe de um protocolo implementado em ns [43]. O método Agent. command (...) define as ações de inicialização do protocolo, e é chamado externamente por scripts OTcl durante a simulação. O método Agent.recv (...) define as tarefas que o protocolo executa após o recebimento de cada uma das mensagens a ele associadas.

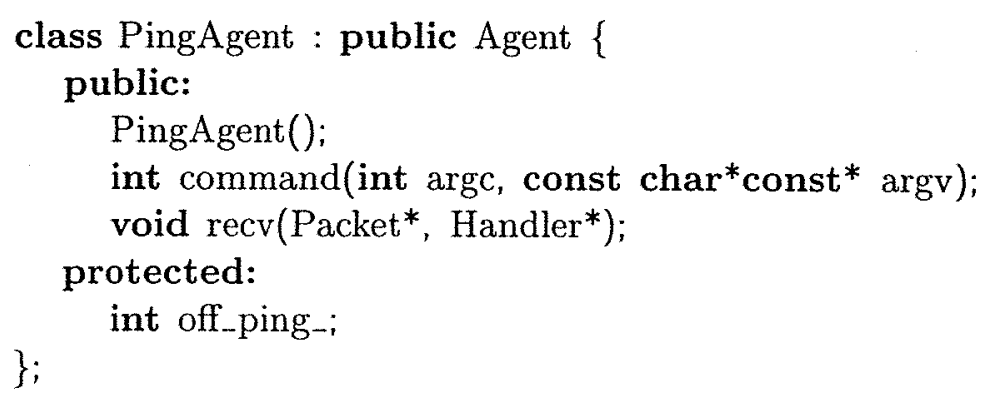

Figura 2.4: Exemplo de Esboço de Protocolo Implementado para Simulação no ns

Depois de implementada, a classe em $\mathrm{C}++$ precisa ser mapeada para uma classe OTcl, com a qual o usuário pode definir a interface do protocolo no ns pela qual ele é configurado. A

\footnotetext{
${ }^{2}$ Lawrence Berkeley National Laboratory

${ }^{3}$ Information Science Institute da University of Southern California
} 
incorporação do protocolo no ns exige ainda a inclusão de informações específicas do simulador para que o protocolo compilado possa interagir com um código OTcl.

Embora a versão 2 no ns, chamada ns-2, permita a implementação e simulação de protocolos de comunicação para meio sem fio em redes locais, ela ainda não contemplava mobilidade de estações e outras características necessárias para a simulação de um ambiente de computação móvel completo. Um grupo de pesquisadores do projeto Monarch [47], da Carnegie Mellon University, implementou uma extensão [22] ao ns-2 que ampliou o seu uso para simulação de protocolos para computação móvel. Esta extensão implementou vários protocolos, modelos de comunicação sem fio e de mobilidade.

Nesta extensão, a mobilidade é descrita na forma de movimentos explícitos das estações, em termos de posição cartesiana e velocidade. O usuário pode utilizar um programa OTcl para descrever a mobilidade, descrevendo explicitamente a mobilidade dos nós ou criando abstrações sobre o modelo básico definido. O modelo de mobilidade adotado é o "random waypoint" [59]. Há ainda um gerador de migrações, que define movimentos aleatórios baseados em parâmetros definidos pelo usuário.

Muitos trabalhos de pesquisa fizeram uso de ns para simular protocolos para computação móvel, sobretudo para redes ad hoc. Os trabalhos $[45,50,54,58,62,67,70,73,88,90]$ são exemplos recentes de uso do ns.

\subsubsection{Outros Simuladores}

Além do ns e do GloMoSim, existem vários outros de simuladores para computação móvel, como [18, 24, 37, 49, 68, 76, 81, 82]. Diferentemente dos simuladores apresentados, estes são simuladores de rede, projetados para simular ambientes e/ou características bem específicas. Há ainda simuladores que foram desenvolvidos apenas para simular protocolos específicos, como $[23,75,95]$.

WiPPET [76] é um simulador de redes sem fio projetado para avaliar algoritmos de gerência de recursos de transmissão de rádio-freqüência e protocolos de transporte. WiPPET é implementado com o arcabouço $\mathrm{TeD} / \mathrm{C}++[79]$, que executa sobre uma máquina de simulação que utiliza um algoritmo Time Warp. $\mathrm{C}++$ é usada para implementar os detalhes funcionais dos elementos simulados e a interface da camada TeD com a camada de simulação do WiPPET. MetaTeD é uma linguagem de alto nível para a descrição de redes de telecomunicações. Ela define abstrações próprias para este domínio de aplicação. WiPPET define um conjunto de objetos $\mathrm{TeD}$ que modelam mobilidade, modelo de propagação de rádio e protocolos. Esses objetos interagem com objetos $\mathrm{C}++$ para compor uma simulação. O modelo de mobilidade pode conter uma descrição bem detalhada do ambiente, como a geometria do terreno no qual as estações migram. A mobilidade pode ser descrita por trajetórias pré-computadas a partir de arquivos de entrada ou pela descrição de padrões de mobilidade.

MobSim $++[68]$ permite simular redes de telecomunicações com o objetivo de avaliar os efeitos de alocação de recursos em redes celulares. Devido ao domínio das características avaliadas, MobSim ++ modela detalhadamente o ambiente de rede, fazendo o uso de metodologias de paralelização para tornar a simulação eficiente, e se baseia em um núcleo de simulação 
que usa Time Warp.

SWiMNet [18] é um simulador projetado para a avaliação do desempenho de redes estruturadas PCS com relação a chamadas e bloqueios de chamadas feitas por estações móveis. $\mathrm{O}$ simulador estabelece um modelo de mobilidade fixo, no qual as estações móveis são classificadas em quatro classes, de acordo com seu padrão de migração: Worker, Wanderer, Static e Traveler.

Hodge [49] descreve um ambiente de simulação de redes móveis sem fio, que tem como objetivo modelar o desempenho de aplicações cliente-servidor em função da mobilidade, tecnologias sem fio empregadas e características de erro dos canais. O simulador desenvolvido adota um modelo rígido de mobilidade, no qual células são divididas em zonas lógicas, que definem taxas de erros e mobilidades próprias.

MCE [81] é uma plataforma de software para o desenvolvimento e simulação de aplicações em uma rede móvel sem fio. $\mathrm{Na}$ arquitetura de MCE uma aplicação convencional pode ser executada sobre a rede emulada, sem que seja necessária nenhuma alteração de código. Estações móveis e estações base são simuladas por processos executando em uma máquina UNIX e a migração de estações é simulada por migração de processos entre máquinas. $O$ simulador define uma interface de programação com primitivas de localização, de envio mensagens entre estações móveis e de simulação da aplicação.

\subsection{Verificação da Corretude de Protocolos}

Há basicamente três abordagens para a verificação da corretude de protocolos: execução de testes, verificação formal e simulações exaustivas. Cada uma das abordagens contribui para a validação de protocolos com um diferenciado grau de garantia da corretude.

Existem simuladores $[12,51]$ que testam a corretude de um protocolo utilizando uma abordagem de simulação baseada na validação de especificações de protocolos. Essa categoria de simuladores verifica a consistência lógica da especificação de um protocolo, geralmente descrito em uma linguagem formal, e a satisfação de propriedades que expressam os comportamentos esperados do protocolo.

A maioria desses simuladores se baseiam em algoritmos para análise de alcançabilidade (reachability analysis) que testam se todos ou uma parcela representativa dos possíveis estados (de um protocolo distribuído), alcançáveis a partir de um estado inicial, satisfazem as propriedades desejadas do protocolo. Exemplos de simuladores nesta categoria são SPIN (para a linguagem Promela) [51] e Verif (para a TDF LOTOS) [12].

Esses simuladores dificilmente podem ser utilizados para a classe de protocolos que se pretende simular, devido ao grande número de variáveis associadas ao ambiente de computação móvel, tais como localização e qualidade da comunicação sem fio.

Outra abordagem utiliza geradores de testes para casos críticos de execução dos protocolos [46], que podem ser simulados, por exemplo, no ns. Entretanto, esta técnica não é flexível o suficiente para permitir o teste de qualquer protocolo. 
Um dos requisitos da arquitetura de referência e do simulador foi propor uma abordagem para verificação da corretude de protocolos. A abordagem adotada é baseada em simulações determinísticas, nas quais o simulador reproduz cenários determinísticos de testes que são definidos pelo usuário. Se comparadas às diferentes abordagens para validação de protocolos, essa técnica apresenta características das abordagens baseadas em testes e em simulações exaustivas. No caso desta última abordagem, simulações estocásticas podem ser utilizadas em complementação às simulações determinísticas.

\section{Resumo}

O projeto de um ambiente de simulação que atenda aos requisitos adotados nesta dissertação deve incorporar facilidades de ambientes de desenvolvimento de protocolos, simuladores de protocolos para computação móvel e abordagens para validação de protocolos. Há vários trabalhos na literatura que contemplam cada uma dessas áreas de pesquisa. Entretanto não existe nenhum trabalho que incorpore todos esses requisitos em um ambiente, e permita a prototipagem e a validação de protocolos distribuídos para computação móvel.

Os principais requisitos para a arquitetura de referência e implementação do MoBICS foram a disponibilização de um modelo de programação de protocolos adequado à prototipagem, flexibilidade e extensibilidade, que permita a simulação de um ambiente de computação móvel no nível de detalhamento adequado para protocolos distribuídos e com uma abordagem para validação adequada a esta classe de protocolos.

O capítulo 8 apresenta uma comparação entre MoBICS e os trabalhos apresentados neste capítulo, destacando as diferenças com outros simuladores e as contribuições do simulador. 


\section{Capítulo 3}

\section{Protocolos para Computação Móvel}

Este capítulo descreve o modelo de sistema para computação móvel adotado neste trabalho. Este modelo define basicamente as características do ambiente de computação móvel e a classe de protocolos que devem ser simulados. A seção 3.1 apresenta o modelo de sistema e define os termos utilizados no restante da dissertação. A seção 3.2 discute a influência da mobilidade nas diferentes camadas de uma arquitetura geral de protocolos. A seção 3.3 discute a programação de algoritmos distribuídos para computação móvel e define o conceito de protocolos distribuídos. O simulador MOBICS foi projetado para simular esta classe de protocolos. A seção 3.3.1 apresenta um exemplo de protocolo distribuído chamado RDP, que será utilizado no capítulo 6 para exemplificar o uso do simulador.

\subsection{Modelo de Sistema e Definições}

Há dois possiveis modelos de sistema para computação móvel: redes móveis estruturadas e redes ad hoc. Em redes ad hoc, uma estação móvel pode se comunicar diretamente com outra estação móvel localizada dentro do seu raio de ação ou utilizar outra estação móvel como intermediária da comunicação. O modelo de sistema para computação móvel adotado nesta dissertação é o modelo de redes móveis estruturadas no qual uma estação móvel se comunica com outra utilizando a rede fixa como intermediária. Os principais termos e definições associados a este modelo e utilizados ao longo desta dissertação são os seguintes:

Rede Fixa - porção da rede formada por elementos de rede convencionais conectados fisicamente.

Máquina Fixa - dispositivo conectado fisicamente à rede, com localização geográfica e endereço de rede fixos.

Estação Móvel ou Mh (Mobile Host) - dispositivo cuja localização e ponto de conexão (endereço) à rede podem variar.

Estação Base ou Mss (Mobile Support Station) - máquina fixa responsável pela comunicação de todos os $M h$ s, dentro de uma determinada região (célula). 
Célula - área geográfica sob a responsabilidade de um $M s s$.

Canal sem fio - canal de comunicação entre um $M s s$ e um $M h$, através do qual este se comunica com o restante do sistema. Um $M s s$ e um $M h$ trocam mensagens em um canal sem fio por meio de sinais de rádio.

Hand-off - processo de transferência da responsabilidade sobre um $M h$ entre dois Msss, quando este migra de uma célula para outra. Este processo engloba todas as trocas de mensagens, alterações de estados de conexões e/ou elementos da rede envolvidos na migração do $M h$.

A figura 3.1 mostra um exemplo de cenário para computação móvel, baseado neste modelo de sistema. Msss estão fisicamente conectados à rede fixa, podendo trocar dados entre si com alta taxa de transmissão. Um $M h$ pode estar em dois estados: disponivel e indisponivel. No estado disponivel um $M h$ pode enviar e receber mensagens pela rede caso esteja na região de uma célula. No estado indisponível um $M h$ não pode receber nem enviar mensagens, independente de sua localização. A mudança do estado de disponibilidade é uma operação voluntária utilizada pelo $M h$ para diminuir o consumo de energia, quando em estado crítico.

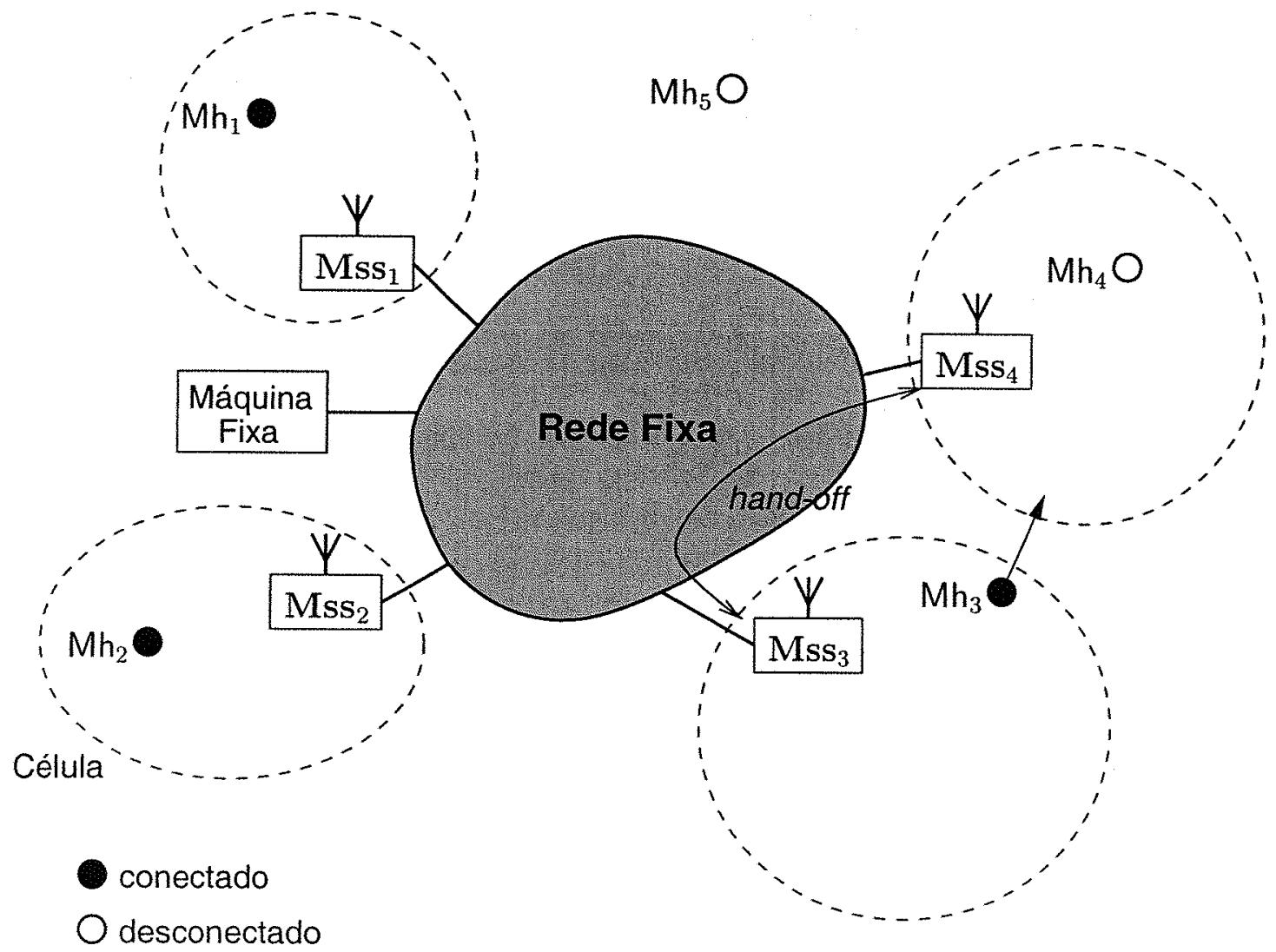

Figura 3.1: Modelo de Sistema para Computação Móvel

Quando um $M h$ entra em uma célula ele envia uma mensagem Greet(OldMss) ao Mss, onde OldMss é o endereco último Mss responsável por ele. Assim que a mensagem Greet é 
recebida, o Mss inicia o processo de handoff do $M h$. Na figura 3.1, o handoff ocorre entre $M s s_{3}$ e $M s s_{4}$, quando o $M h_{3}$ realiza a migração indicada. Quando um $M h$ volta de um estado de indisponibilidade, um $M h$ também envia uma mensagem Greet.

\subsection{A Mobilidade nas Camadas de Protocolos}

As características dos ambientes de computação móvel introduzem vários fatores que influenciam os protocolos de rede.

O canais sem fio possuem alta taxa de erros e requerem o uso de mecanismos de controle de alocação de canais e multiplexação de frequência. Para permitir a mobilidade das estações, os protocolos devem implementar mecanismos para gerenciar a localização variável e a mudança na qualidade da comunicação. Os dispositivos móveis possuem recursos limitados e por isso é necessário gerenciar a adaptação de protocolos e aplicações à variação da disponibilidade dos recursos do sistema. Uma discussão extensa sobre essas características pode ser obtida em [56] e [71].

Devido a essas características, o protocolos convencionais para redes fixas não são adequados para ambientes de computação móvel, por não tratarem muitos dos problemas mencionados anteriormente, apresentarem um desempenho insatisfatório e deixarem de prover vários serviços interessantes neste ambiente.

As seções seguintes discutem brevemente a influência da mobilidade nas camadas de protocolos na arquitetura TCP/IP, mostrada na figura 3.2 .

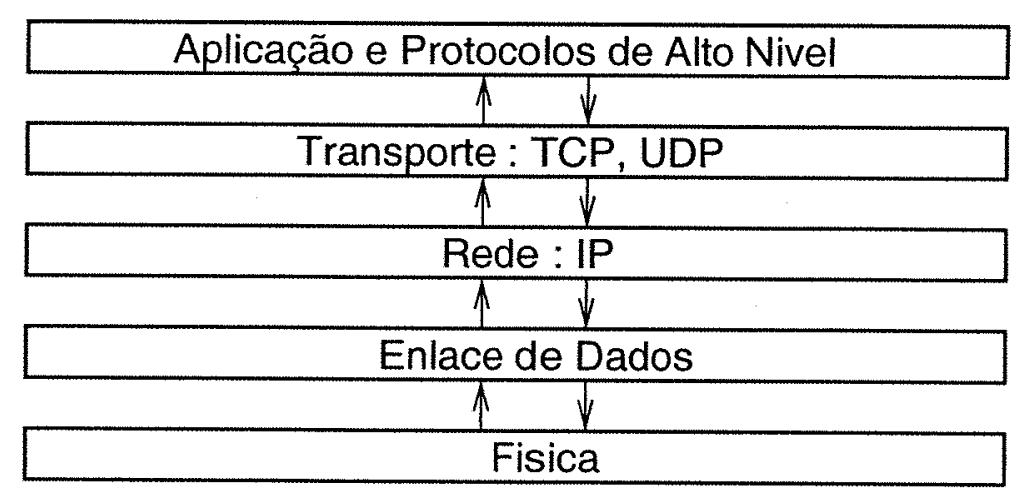

Figura 3.2: Arquitetura de Camadas de Protocolos TCP/IP

\subsubsection{Física e Enlace}

As camadas físicas e de enlace de dados implementam a comunicação pelo meio físico e o controle de comunicação ponto-a-ponto. Estas camadas compreendem os protocolos responsáveis pela transmissão pelo meio físico (multiplexação, alocação de frequências), correção de erros e gerência de energia. 
Os ambientes de computação móvel exigem o uso de técnicas especializadas de acesso ao meio (camada MAC). Os protocolos utilizam técnicas como FDMA (Frequency Division Multiplexing Access), TDMA (Time Division Multiplexing Access) ou CDMA (Code Division Multiplexing Access). Slotted Aloha [16] e CDPD [57] (Cellular Digital Packet Data) são exemplos de protocolos que utilizam essas técnicas de acesso ao meio. Em [84] há uma discussão detalhada sobre cada uma dessas técnicas e a motivação para o seu uso.

\subsubsection{Rede}

A camada de rede define o endereçamento de máquinas na rede e implementa o envio de mensagens entre máquinas baseada nesse endereço, em uma tarefa chamada de encaminhamento de pacotes.

No ambiente de computação móvel, os protocolos desta camada definem como as mensagens serão endereçadas e entregues para estações móveis e para isso usualmente definem novas formas de endereçamento.

O IP Móvel [78], iniciativa da IETF (Internet Engineering Task Force), é o principal exemplo de protocolo desta camada para computação móvel, e que já foi incorporado nas versões mais recentes do IP como IPv4 e IPv6. No IP móvel, um endereço IP de uma estação móvel é formado por dois números: endereço IP do home agent, origem da estação móvel, $\mathrm{e}$ do endereço care-of, que é atual ponto de acesso à rede da estação móvel.

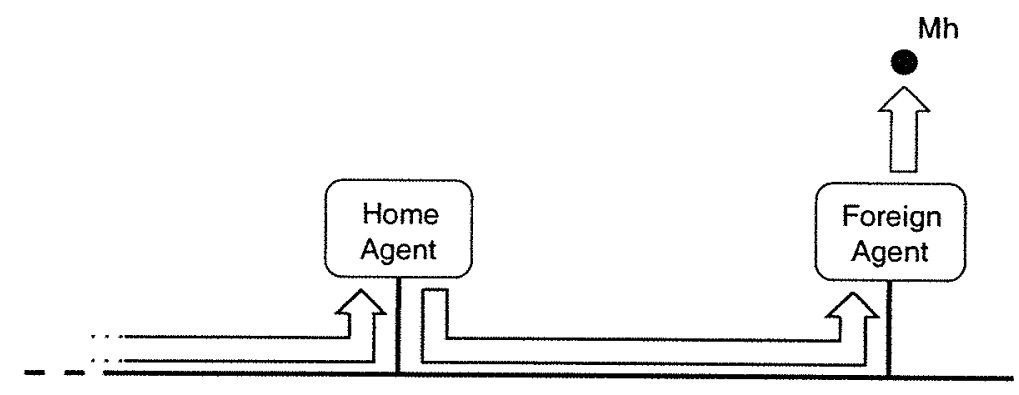

Figura 3.3: Reenvio de pacotes para $M h$, do home agent para o foreign agent

O home agent é responsável por reenviar todos os pacotes de uma conexão para o atual endereço de care-of da estação móvel (figura 3.3). A estação base na qual a estação móvel se conecta é chamada de foreign agent e a associação de um home agent com o atual endereço care-of da estação móvel é chamada de binding. Quando ocorre a migração para outro ponto de acesso, o endereço care-of muda e essa informação é atualizada no home agent para refletir a nova localização da estação móvel.

Dessa forma, todo pacote tendo a estação móvel como destinatária é enviado para o seu home agent, que o reenvia para a localização corrente da estação móvel. Com esta solução, aplicaçōes convencionais e protocolos na camada de transporte funcionam sobre a camada de rede sem que seja necessária nenhuma modificação. 
Johnson e Maltz [60] propõe uma versão de IP móvel que permite a adaptação de camadas de mais alto nível à mobilidade. Para isso, o protocolo informa para essas camadas a largura de banda, latência, taxa de erros e custo do serviço da corrente conexão. Nesta proposta, um hand-off também é propagado para as camadas de mais alto nível.

\subsubsection{Transporte}

A camada de transporte implementa a gerência de envio de mensagens fim a fim, efetuando funções como ordenação de pacotes, retransmissões, mecanismo de fluxo e controle de congestionamento.

A heterogeneidade de uma rede móvel sem fio implica em grandes variações na taxa de comunicação durante o envio de pacotes. Esta variação é interpretada por uma conexão convencional TCP como sendo causada por um congestionamento, fazendo com que o protocolo reaja de forma inapropriada através do reenvio de pacotes. Isso acarreta uma queda de desempenho ainda maior na conexão.

I-TCP [11] (TCP Indireto) é uma implementação de TCP para redes móveis sem fio que resolve esse problema fazendo com que a mobilidade seja percebida e tratada na camada de transporte, que então pode reagir adequadamente a mudanças no desempenho de uma conexão.

O TCP indireto utiliza um modelo indireto de interação entre estações base e móveis. Uma conexão é divida em uma parte fixa e uma parte móvel. Em uma conexão TCP com estações móveis, um pacote transita por duas diferentes implementações do protocolo de transporte, a implementação convencional e o I-TCP que conecta uma estação móvel a uma estação base, e que é específica para uma comunicação sem fio.

\subsubsection{Aplicação}

As camadas de nível acima do nível de transporte implementam mecanismos que oferecem semântica de conectividade fim a fim de alto nível. A chamada remota de protocolos (RPC) é um exemplo esse tipo de mecanismo de alto nível.

Para que tais mecanismos sejam implementados eficientemente em ambientes de computação móvel, eles devem ter consciência da mobilidade, conforme destaca [7].

Da mesma forma, aplicações podem fazer uso da consciência de mobilidade para implementar adaptações de acordo com a variação da qualidade da comunicação ou da localização do dispositivo. As adaptações associadas à localização permitem às aplicações prover vários novos serviços específicos de localização como, por exemplo, encontrar os hospitais mais próximos de um usuário móvel.

Esta dissertação tem como enfoque a simulação de protocolos de alto nível que implementam algoritmos distribuídos. A seção seguinte discute em detalhes as principais questões relacionadas à implementação dessa classe de protocolos e o modelo de sistema para protocolos adotado na dissertação. 


\subsection{Protocolos Distribuídos}

Protocolos Distribuídos são algoritmos distribuídos que implementam a comunicação e/ou coordenação entre várias máquinas dentro de uma rede, como $[2,3,5,32,34,44,93]$. Há basicamente duas abordagens para a implementação de protocolos distribuídos em ambientes de computação móvel [93]. Na primeira abordagem, a mobilidade e as desconexões são gerenciadas pelas camadas de transporte ou rede e são transparentes para as camadas superiores. Nesta abordagem, os algoritmos distribuídos em geral não precisam levar em consideração os impactos da computação móvel nas interações entre os elementos distribuídos e um protocolo projetado para uma rede convencional pode ser utilizado diretamente em uma rede móvel.

Na segunda abordagem, também chamada modelo indireto [9], a mobilidade não é transparente para o algoritmo, que pode tratar as desconexões e as migrações. Um algoritmo poderia, por exemplo, definir seu próprio mecanismo de localização e entrega de mensagens para estações móveis. Há basicamente três vantagens nesta abordagem:

1. A entrega de mensagens pode ser otimizada para minimizar o uso dos canais de comunicação sem fio.

2. Pode-se promover entrega confiável ou atômica de mensagens, com diferentes políticas de ordem de entrega (causal, total).

3. Algoritmos distribuídos que utilizam a noção de grupo e topologia, podem ser implementados levando em consideração as desconexões e a topologia dinâmica intrínseca à computação móvel.

Os protocolos de rede em geral não atribuem uma semântica adequada à indisponibilidade de estações móveis. No IP móvel, por exemplo, não há semântica de desconexão, ou seja, ele não diferencia uma máquina desconectada de uma máquina não encontrada. Isso influencia diretamente os algoritmos distribuídos implementados sobre a camada de rede, que assim não dispõem de informação suficiente para avaliar quais são os participantes da interação que estão realmente disponíveis. Neste caso, a segunda abordagem mostra-se mais eficaz. Em [8] há uma discussão aprofundada sobre o projeto de algoritmos distribuídos em ambientes de computação móvel.

\begin{tabular}{|c|}
\hline APLICAÇÃO \\
\hline $\begin{array}{r}\text { PROTOCOLOS } \\
\text { DISTRIBUIDOS }\end{array}$ \\
\hline TRANSPORTE E REDE \\
\hline FÍSICO E ENLACE \\
\hline
\end{tabular}

Figura 3.4: Protocolos Distribuídos na Arquitetura de Camadas de Rede

A figura 3.4 mostra a posição ocupada pelos protocolos distribuídos na arquitetura de camadas de protocolos adotada. Como tipicamente a abstração de interação neste nível é a 
mensagem, é razoável colocar tais protocolos na camada imediatamente superior às camadas de rede e transporte. Entretanto, no modelo indireto os protocolos das camadas de rede e de transporte devem tornar visíveis todas as desconexões e possibilitar que as camadas superiores implementem seus próprios mecanismos de entrega de mensagens para estações móveis. Do ponto de vista da camada de protocolos distribuídos, comunicações ponto-a-ponto são consideradas confiáveis, embora um destinatário móvel nem sempre seja acessível. A seção 3.3.1 descreve um protocolo distribuído que implementa a entrega confiável de respostas a clientes móveis.

Esta dissertação adota o modelo indireto para protocolos distribuídos. Embora o simulador implementado possa também ser utilizado para outras classes de protocolos, o seu objetivo é a simulação de protocolos distribuídos com fortes requisitos de confiabilidade.

\subsubsection{Um Exemplo: Protocolo de Entrega Confiável de Respostas a Clientes Móveis}

O protocolo RDP (Result Delivery Protocol) [31] é um protocolo desenvolvido no contexto do projeto SIDAM que otimiza e garante a entrega confiável de respostas de servidores a cliente móveis, com a mesma semântica do RPC. Esta seção descreve uma versão inicial [34] desse protocolo, na qual um cliente móvel cria e mantém proxies em várias estações base, correspondentes a cada uma das requisições pendentes. Este protocolo será utilizado no capítulo 6 para exemplificar o uso do MOBICS na implementação e simulação de protocolos distribuídos.

\section{Visão Geral}

Para cada requisição, o protocolo RDP cria um proxy no $M s s$ responsável pelo $M h$ cliente no momento em que a requisição é enviada. O proxy desempenha o papel de representante do $M h$ na rede fixa e é responsável pelo recebimento, armazenamento e reenvio das respostas dos servidores para a localização corrente do $M h$.

Em cada proxy, a variável currentLoc armazena o endereço do $M s s$ responsável pelo $M h$ após o último hand-off. Para cada $M h$, associa-se uma lista de proxys ( $p$ List), que armazena o endereço de todos os $M s s s$ que contêm algum proxy criado pelo $M h$ e para o qual a resposta correspondente do servido ainda está pendente.

Quando a resposta de um servidor é recebida por um proxy $M s s_{p r x y}$ em um Mss, o $M s s_{p r x y}$ reenvia a resposta em uma mensagem forward_res para o $M s s_{\text {resp }}$ armazenado em currentloc. Após receber a confirmação do recebimento pelo $M h$, o $M_{s} s_{p r x y}$ envia uma mensagem remPList para todos os Msss para que apaguem a referência ao proxy na sua lista de proxys.

A difusão de remPList a todos os Msss garante a remoção do proxy mesmo que durante o seu envio o $M h$ migre para outra célula. A figura 3.5 ilustra um cenário de execução do protocolo, onde são indicadas as trocas de mensagens entre servidor, $M s s s$, Mh e proxy (linha tracejada), e geradas pelo protocolo quando $M$ h envia uma requisição. 


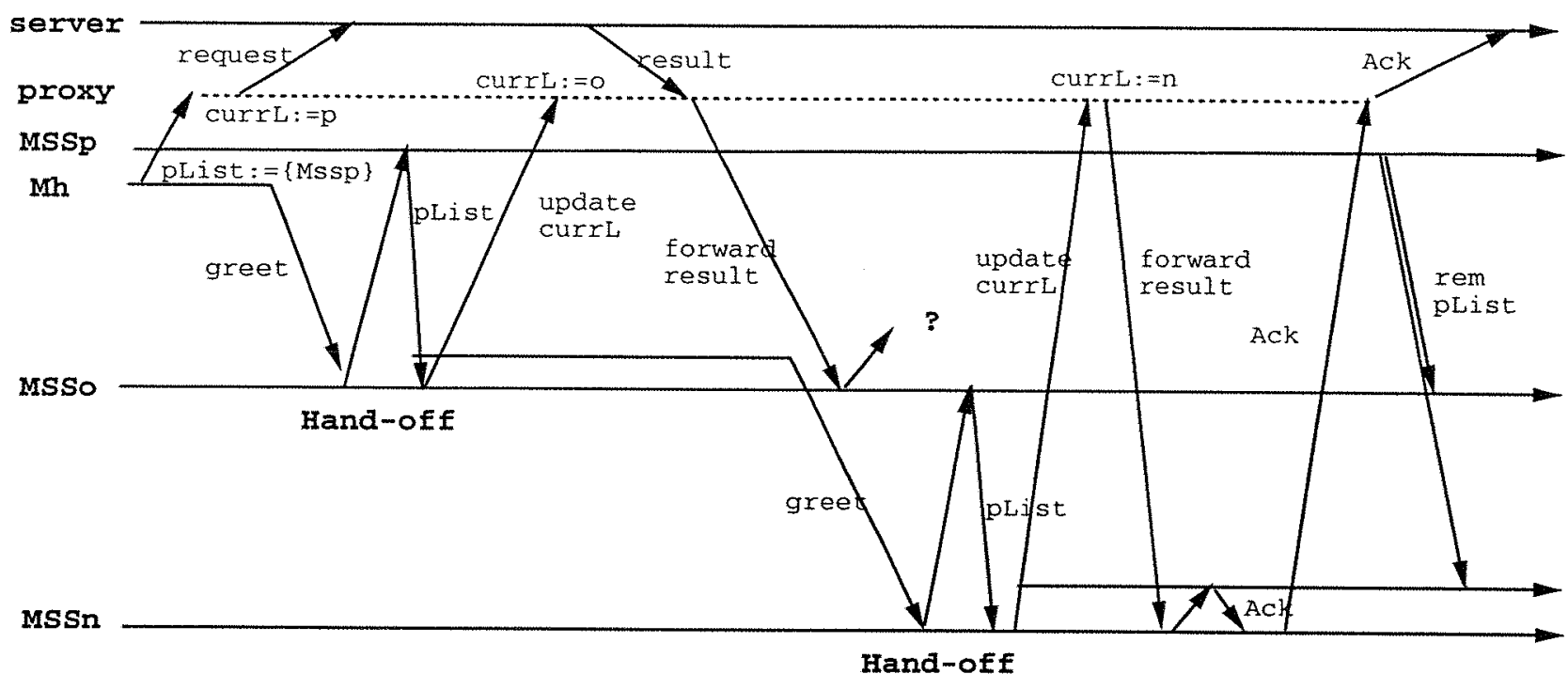

Figura 3.5: Exemplo de Funcionamento do Protocolo RDP

\section{Hand-off}

Quando o $M h$ migra da célula do $M s s_{o}$ para a célula do $M s s_{n}$, o protocolo de handoff no $M s s_{n}$ envia uma mensagem dereg para $M s s_{o}$, requisitando a lista de proxys do $M h$ naquele $M s s$. No recebimento de dereg, $M s s_{o}$ envia uma mensagem $p L i s t$ com a lista de proxys do $M h$, removendo-o da sua lista de $M h$ locais.

Ao receber a lista de proxys do $M h, o M s s_{n}$ torna-se responsável pelo $M h$, colocando-o na sua lista de $M h$ s locais, e enviando seu endereço na mensagem updateCurr Loc para os $M s s_{\text {prxy }}$ dos proxys. Cada $M s s_{\text {prxy }}$ atualiza a localização do $M h$, armazenando o endereço do $M s s_{n}$ na variável currentLoc do proxy.

No cenário da figura 3.5 , o $M h$ migra antes de receber a mensagem forward_res do $M s s_{o}$. Neste caso, a mensagem forward_res é reenviada quando o $M s s_{o}$ receber a mensagem updateCurrLoc, correspondente ao novo hand-off do $M h$. Isto garante que o $M h$ eventualmente receberá a resposta do servidor.

\section{Discussão}

Há vários aspectos do protocolo RDP que sugerem uma análise mais aprofundada. O cenário mostrado na figura 3.5 é apenas um dos vários cenários dinâmicos nos quais o protocolo precisa garantir a entrega correta do resultado da requisição. No cenário descrito, o hand-off do protocolo é completado com sucesso antes que outras mensagens sejam recebidas pelos elemento envolvidos. Entretanto, os cenários nos quais a atomicidade do hand-off é violada são os mais interessantes para serem testados e aqueles que sugerem a maior ocorrência de erros no protocolo. Além disso, o número de situações possíveis nos cenários aumenta bastante quando o hand-off não é atômico. 
Em geral, é difícil garantir a corretude de um protocolo em todas essas situaçōes. Por isso, muitos protocolos e simuladores adotam como requisito a atomicidade no hand-off ou consideram um limite para a mobilidade das estações.

Do ponto de vista do desempenho, o protocolo adiciona sobrecarga na rede em dois aspectos, se comparado ao correspondente protocolo em redes fixas. Quando uma estação móvel migra com frequência, o número de mensagens forward_res aumenta, como consequência das mensagens perdidas durante o envio para estações móveis não mais locais ou indisponíveis para comunicação. O tamanho da lista de proxys é outra componente da sobrecarga causada na rede pela migração das estações móveis. Quanto maior for a taxa de requisições de uma estação móvel e sua migração, maior será o número de proxys trocados por estações base durante o hand-off.

O capítulo 6 apresenta suscitamente um exemplo no qual esses aspectos do protocolo foram avaliados com o MOBICS.

\section{Resumo}

No projeto da arquitetura de simulação foi adotado o modelo de redes estruturadas no qual uma estação móvel se comunica com outra utilizando como intermediária uma máquina na rede fixa chamada estação base. Além disso, a arquitetura foi projetada para a simulação de algoritmos distribuídos, implementados em protocolos de alto nível, chamados protocolos distribuídos. A mobilidade influencia diretamente o desempenho desses protocolos e torna difícil a validação dos protocolos pois produz um número muito grande de cenários para teste. 


\section{Capítulo 4}

\section{Arquitetura de Referência}

Este capítulo descreve detalhadamente a arquitetura de referência para a simulação flexível de protocolos que é um dos principais resultados desta dissertação. Uma arquitetura de referência é uma arquitetura generalizada que define uma infra-estrutura e interfaces comuns para sistemas em um mesmo domínio de aplicação [40]. Uma arquitetura de referência pode ser instanciada para criar uma arquitetura de software para um sistema específico. $O$ capítulo está organizado da seguinte forma: a seção 4.1 apresenta os objetivos da arquitetura de referência e as consequentes decisões de projeto. A seção 4.2 descreve a arquitetura de software em camadas que deve ser implementada pelos simuladores. Para isso, a seção descreve a funcionalidade de cada uma das camadas de softwares e como elas interagem entre si. A seção 4.4 propõe um modelo de programação de protocolos a partir do qual protocolos podem ser implementados e simulados. Por fim, a seção 4.5 , apresenta e discute a abordagem adotada para a programação de modelos de simulação.

\subsection{Objetivos e Decisões de Projeto}

O objetivo da arquitetura de referência proposta é facilitar a construção de simuladores de protocolos que permitam o desenvolvimento de protótipos de protocolos distribuídos para computação móvel, incluindo as fases de implementação, depuração e avaliação de desempenho. Para atingir esse objetivo, a arquitetura de referência propõe conceitos, modelos e uma arquitetura de software que devem ser implementadas em tais simuladores. As decisões de projeto da arquitetura podem ser classificadas em duas categorias. A primeira, explorada na seção 4.1.1, tem como preocupação oferecer as facilidades necessárias para o desenvolvimento e avaliação de protótipos de protocolos. A segunda, explorada na seção 4.1.2, tem como preocupação permitir a definição e a simulação de várias características de ambientes de computação móvel, de forma flexível e configurável.

As duas seções seguintes discutem, para cada uma dessas categorias, os principais requisitos de projeto e suas conseqüências diretas para a definição da arquitetura. 


\subsubsection{Desenvolvimento de Protocolos}

Para possibilitar o rápido desenvolvimento e avaliação de protótipos de protocolos são necessárias facilidades que permitam ao programador fazer um mapeamento direto entre algoritmo e implementação, executar rápidas experimentações e testes do protótipo, bem como avaliar o seu desempenho. Essas facilidades foram classificadas em quatro requisitos, descritos nas subseções seguintes: prototipagem, programabilidade, modularização e avaliação.

\section{Prototipagem}

O primeiro requisito da arquitetura é oferecer ferramentas adequadas para a prototipagem de protocolos. Nesses protótipos devem ficar ocultos todos os detalhes que não digam respeito diretamente ao algoritmo do protocolo ou que sejam detalhes marginais. Em especial, do ponto de vista do programador deve haver uma ocultação de detalhes de transmissão de dados, a disponibilização de abstrações de programação de alto nível e transparência de simulação.

Como conseqüência desses requisitos, o simulador deve adotar uma arquitetura de software em camadas, que promova a transparência de detalhes entre camadas e a separação de funcionalidade. Esta separação de funcionalidade e transparência deve ocorrer em três níveis: simulação, programação de protocolos e especificação do ambiente simulado. Esses niveis devem ser independentes, apesar de colaborarem entre si durante uma simulação. A arquitetura de software em camadas está descrita na seção 4.2.

A linguagem de implementação dos protocolos também influencia diretamente a facilidade de programação de protótipos. Devido às facilidade de modularização, composição e extensão, sugere-se a adoção de uma linguagem orientada a objetos. Em [17] há uma discussão extensa sobre as vantagens do uso do paradigma de orientatação a objetos, inclusive quando utilizado em aplicações de simulação.

\section{Programabilidade}

Outro requisito da arquitetura é oferecer flexibilidade para programação de protocolos e permitir o uso de estruturas de dados tão complexas quanto necessário na programação dos protocolos.

Como conseqüência, a arquitetura prevê a utilização de uma linguagem de programação de propósito geral para a programação de protocolos, ao invés da criação de uma linguagem específica para descrever elementos e protocolos simulados. As vantagens dessa decisão são o rápido aprendizado pelo programador, o uso de bibliotecas pré-definidas e a existência de abstrações adequadas. Por isso, tanto a programação de protocolos como a implementação dos modelos de simulação deverão fazer uso de uma mesma linguagem de programação.

O uso de linguagens de simulação, como o SimScript [6], não é adequada ao domínio deste problema pois com essas linguagens não é possível incorporar protocolos genéricos sem modificar a programação do ambiente simulado. Tais linguagens são úteis, portanto, para programar simulações específicas e com modelos de simulação bem determinados. A 
transparência e separação entre os níveis da arquitetura destacados no requisito prototipagem também não podem ser atingidas se uma linguagem de simulação específica for adotada.

\section{Modularização}

A modularização é um requisito importante para reduzir a complexidade dos sistemas de software. No caso específico desta arquitetura de referência, a modularidade é usada para permitir que protocolos complexos possam ser dividos em módulos configuráveis e parametrizáveis. Para provê-la, a arquitetura sugere um modelo de programação de protocolos baseado no conceito de micro-protocolos, discutido na seção 4.4 .

\section{Avaliação}

A corretude e o desempenho são os dois aspectos principais de avaliação de um protocolo. A arquitetura de referência deve ser capaz de facilitar esses dois aspectos de avaliação dentro de um único simulador. Conforme já comentado no capítulo 2, as técnicas para avaliação da corretude de protocolos baseadas em especificação formal e em geradores de casos de testes e simulações exaustivas não são adequados para um ambiente com o requisito de permitir a rápida prototipagem de protocolos. Como alternativa, a arquitetura prevê a utilização de um modo de simulação deterministico para teste de protocolos, no qual quaisquer comportamentos e situações determinísticas podem ser testadas. Este modo de simulação é discutido com profundidade na seção 4.3. Para possibilitar a incorporação deste modo de simulação, projetou-se uma arquitetura de software genérica na qual diferentes modos de simulação podem ser desenvolvidos e incorporados sem que seja necessário modificar as outras camadas de software.

\subsubsection{Simulação de Ambientes de Computação Móvel}

Outro objetivo da arquitetura de referência é oferecer um conjunto de facilidades que permitam a modelagem e simulação de ambientes de computação móvel. Para isso a arquitetura adota os requisitos de flexibilidade, extensibilidade e abstrações, discutidos a seguir. A importância destes requisitos na simulação de protocolos é discutida em maior profundidade em $[20,21]$.

\section{Flexibilidade}

O primeiro requisito da arquitetura é oferecer ao usuário do simulador a possibilidade de escolha do modelo de simulação mais adequado para o protocolo a ser simulado ou o tipo de análise a ser feita. Como conseqüência, a arquitetura propõe um modelo genérico de programação e incorporação de modelos de simulação, descrito na seção 4.5. 


\section{Extensibilidade}

Um simulador implementado a partir da arquitetura de referência deve possibilitar a adição de características aos elementos do ambiente simulado e a criação de comportamentos específicos. Por exemplo, em protocolos para computação móvel é importante poder modificar a semântica de detecção do protocolo de hand-off para qualquer uma das alternativas apresentadas em [14]. Para garantir tal extensibilidade, a arquitetura prevê a implementação da funcionalidade dos elementos simulados em um modelo orientado a objetos, que possibilite a redefinição e a especialização de comportamentos, bem como a adição de novas classes de elementos.

\section{Abstrações}

Outro requisito da arquitetura de referência com respeito à modelagem de simulações, é fornecer abstrações para que o usuário programe e configure modelos de simulação, especialmente modelos de mobilidade. A seção 4.5 discute detalhadamente a importância desse tipo de abstração e como ela está incorporada na arquitetura proposta.

\subsection{Arquitetura de Software para Simulação Flexível de Protocolos}

O principal componente da arquitetura de referência é uma arquitetura de software composta de quatro camadas: aplicação, protocolos, elementos de rede e simulação. A figura 4.1 mostra como as camadas estão organizadas.

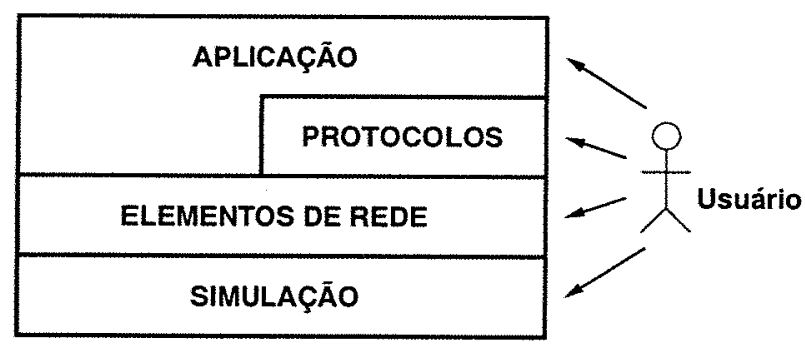

Figura 4.1: Arquitetura de Software em Camadas

As camadas interagem entre si por meio de eventos bem definidos, que garantem o encapsulamento dos detalhes específicos de cada camada. Os eventos trocados entre a camada de simulação e a de elementos de rede são de especial interesse. Eles foram definidos de maneira que as informações específicas de simulação fossem ocultadas. Isso torna possível a implementação de diferentes camadas de simulação sem que seja necessária qualquer modificação na camada de elementos de rede, conforme descreve a seção 4.2.4. As subseções seguintes descrevem em detalhes cada uma dessas camadas. 


\subsubsection{Camada de Aplicação}

A camada de aplicação implementa a aplicação distribuída que utiliza os serviços do protocolo sendo testado. A camada pode ser tanto um programa que descreve o comportamento de um usuário de um dispositivo móvel como um protótipo de uma aplicação real que utiliza os serviços providos pelos protocolos. Alternativamente, o próprio usuário pode assumir a função da camada e realizar chamadas às primitivas e serviços das camadas de protocolos e de elementos de rede.

A camada de aplicação também deve ser capaz de lidar com eventos gerados nas camadas inferiores a fim de permitir adaptações às mudanças de estados dos protocolos e/ou dos elementos simulados. Essa tarefa pode ser realizada a partir da definição de tratadores para esses eventos. Os eventos que podem ser captados pela camada são os mesmos eventos exportados pela camada de elementos de rede e descritos na seção 4.2.3.

\subsubsection{Camada de Protocolos Distribuídos}

A camada de protocolos é formada pelo(s) protocolo(s) distribuído(s) implementado(s) pelo usuário e incorporados aos elementos de rede. Esses protocolos proveêm serviços para a camada de aplicação e coordenam a interação distribuída entre os elementos simulados. Esta camada é capaz de receber requisições de uma aplicação e captar os eventos gerados pela camada de elementos de rede.

Um protocolo define um conjunto de tratadores de eventos. Cada tratador implementa as ações que o protocolo deve realizar na ocorrência de um determinado evento e que inclusive podem causar a geração de novos eventos. Os eventos podem ser mensagens, eventos de tempo, eventos de hand-off ou mudanças no estado do elemento de rede. A seção 4.4 descreve detalhadamente o modelo de programação de protocolos adotado para esta arquitetura.

\subsubsection{Camada de Elementos de Rede}

A camada de elementos de rede implementa a funcionalidade do elemento simulado e as interfaces com as quais o usuário configura o elemento durante a simulação. A funcionalidade de um elemento inclui tanto a funcionalidade do hardware do elemento simulado como o seu software básico, como o sistema operacional e protocolos de mais baixo nível. Por exemplo, esta camada deve implementar os protocolos da camada física e de enlace, bem como a funcionalidade das estações móveis, estações base, máquinas fixas, canais de comunicação e quaisquer outros objetos necessários para simular o ambiente de rede.

A camada de elementos de rede interage com as camadas superiores através dos eventos mostrado na tabela 4.1.

O evento Config pode ser gerado tanto por um protocolo como por uma aplicação para modificar a configuração do hardware ou do software de baixo nível. Por exemplo, um protocolo pode requisitar o desligamento de alguma função do hardware (como a unidade de disco) de acordo com o consumo de energia de uma estação móvel. Os eventos NetResChange 


\begin{tabular}{|c|c|}
\hline Tipo de Evento & Significado \\
\hline$\downarrow$ MsgSend (Source, Dest, Data) & $\begin{array}{l}\text { Uma mensagem deve ser enviada para o elemento de } \\
\text { rede Dest }\end{array}$ \\
\hline$\downarrow$ Config (Param, Value) & $\begin{array}{l}\text { O parâmetro Param do elemento (associado ao seu } \\
\text { hardware ou software básico) é modificado para Value }\end{array}$ \\
\hline Dest, Data) & Uma mensagem foi recebida de Source \\
\hline$\uparrow$ MovedTo (Loc) & Mh moveu para uma nova localização Loc \\
\hline$\uparrow$ Connectivity(S & $\begin{array}{l}\text { I estado de conectividade do } M h \text { mudou para Status } \\
\text { (por exemplo, on/off) }\end{array}$ \\
\hline$\uparrow$ NetResChange(Res, Param, Value) & $\begin{array}{l}\text { O parâmetro Param de um recurso da rede Res (por } \\
\text { exemplo, o canal de comunicação sem fio) mudou para } \\
\text { Value }\end{array}$ \\
\hline$\uparrow$ LocResChange(Res, Param, Value) & $\begin{array}{l}\text { O parâmetro Param de um recurso local Res do elemen- } \\
\text { to (por exemplo, energia restante na bateria) mudou } \\
\text { para Value }\end{array}$ \\
\hline
\end{tabular}

\section{Legenda: $\downarrow$ Eventos recebidos de uma camada superior \\ $\uparrow \quad$ Eventos exportados para a camada superior}

Tabela 4.1: Eventos trocados entre a Camada de Elementos de Rede e as Camadas Superiores

e LocResChange permitem informar quando ocorre uma alteração no estado de algum recurso na rede ou recurso local. Essa informação pode ser utilizada para prover adaptação das camadas superiores e possibilitar assim uma certa gerência de qualidade de serviço (QoS) nos protocolos e aplicações.

O evento Connectivity indica a mudança do estado de conectividade de uma estação móvel, quando ela se desconecta ou se reconecta à rede, seja de forma voluntária ou involuntária. O evento MovedTo indica a migração da estação móvel para uma área atendida por outra estação base. Esse evento inicia o processo de hand-off nos protocolos, que eventualmente pode ser propagado até a camada de aplicação e que ocorre sempre que houver uma mudança da estação base responsável pela estação móvel.

\subsubsection{Camada de Simulação}

A camada de simulação implementa a máquina de simulação, que determina o momento de execução dos eventos das demais camadas.

A camada atribui timestamps aos eventos e determina o instante no qual os eventos serão processados pelos diferentes elementos simulados, sem violar a causalidade entre os eventos. A implementação da camada de simulação determina a equivalencia entre o tempo real e o tempo simulado (warp time, tempo real) e o controle de processamento dos eventos (sequencial, paralelo, tempo real).

Todos os eventos dependentes do tempo ou que exigem uma ordem de execução são escalonados pela camada de simulação. Esses eventos podem ser classificados em três tipos:

- Eventos de simulação, que descrevem eventos internos à camada de simulação, de acordo 
com o modelo de simulação utilizado. Esses eventos representam ações dos elemento simulados que não podem ser controladas pelas demais camadas, tais como migrações e envio de mensagens pela rede simulada.

- Processamento de mensagens, que indicam o recebimento de uma mensagem por um elemento de rede. A camada controla o momento em que essa mensagem deve ser processada pelo protocolo.

- Eventos de tempo, que são eventos escalonados por elementos de outras camadas que notificam a passagem de um período de tempo simulado.

A interação entre a camada de elementos de rede e de simulação só é necessária quando um elemento simulado realiza algum processamento dependente do tempo. Isso ocorre precisamente em dois casos: quando o elemento de rede é uma máquina que realiza um processamento, como uma estação base ou móvel, ou quando implementa um canal de comunicação, com tempos de envio de mensagens associados. No caso de um canal sem fio, é possível definir um modelo de simulação que determina como a qualidade da comunicação varia em função da localização da estação móvel. A figura 4.2 mostra a separação e independência de responsabilidades entre as duas camadas e como elas interagem no exemplo de uma comunicação entre uma estação base e uma estação móvel.

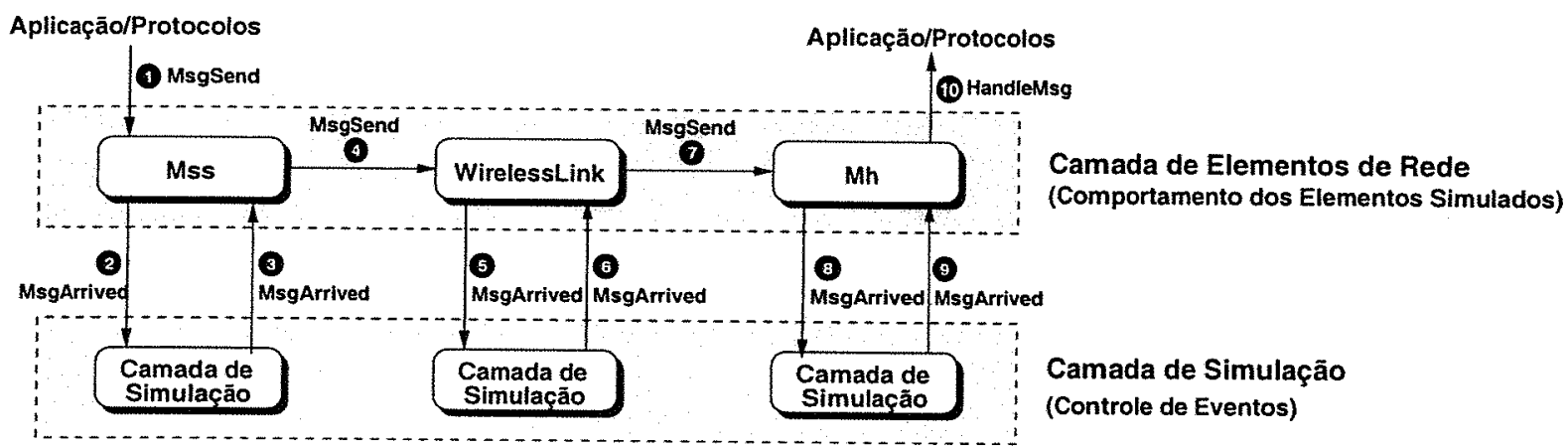

Figura 4.2: Interação entre as Camadas de Elementos de Rede e de Simulação

As camadas de elementos de rede e de simulação interagem através dos eventos mostrados na tabela 4.2, para um elemento simulado $\mathrm{E}$.

O evento MsgArrived é recebido pela camada de simulação pela interface de rede quando uma mensagem deve ser entregue a uma máquina simulada ou enviada por um canal de comunicação.

Quando o elemento simulado E é um canal de comunicação, a camada de simulação simplesmente adiciona ao timestamp do evento MsgArrived o atraso associado ao envio da mensagem pelo canal. Este atraso é determinado pelo modelo de simulação associado ao canal de comunicação definido pelo usuário. Eventualmente, o cálculo desse atraso pode exigir a interação com a camada de simulação de outros elementos, caso se trate de uma mensagem enviada por um canal sem fio. A seção 7.4.3 descreve como esse atraso para 


\begin{tabular}{|l|l|}
\hline Tipo de Evento & Significado \\
\hline \hline$\downarrow$ MsgArrived (Source, Dest, Data) & Foi recebida uma mensagem para o elemento Dest, envi- \\
& ada por Source \\
$\downarrow$ SetTimer(T, WakeUpEvent) & E escalona o evento WakeUpEvent para o tempo simulado \\
& $\mathrm{T}$ \\
$\uparrow$ Timer(WakeUpEvent) & Ocorrência do evento de tempo WakeUpEvent \\
$\uparrow$ MsgArrived(Source, Dest, Data) & Uma mensagem enviada por Source para Dest deve ser \\
& processada por E \\
$\uparrow$ MovedTo (Loc) & O elemento E moveu para uma nova localização Loc \\
$\uparrow$ Connectivity(Status) & O estado de conectividade de Emudou para Status \\
\hline \hline
\end{tabular}

Legenda: $\downarrow$ Eventos recebidos

$\uparrow$ Eventos exportados

Tabela 4.2: Eventos trocados entre a Camada de Simulação e de Elementos de Rede

canais sem fio é calculado no MOBICS, a partir do modelo de comunicação definido pelo usuário.

Como pode-se perceber, nenhum dos eventos descritos anteriormente contém informações dependentes da implementação da camada de simulação. Isto significa que há total transparência de simulação para as demais camadas, garantindo assim a independência entre as camadas. Conseqüentemente, essa arquitetura torna possível a implementação e incorporação de diferentes camadas de simulação ao simulador, sem que sejam necessárias modificações nas demais camadas.

No caso do MOBICS, dois modos de simulação diferentes foram implementados: um modo estocástico e um modo determinístico de simulação. O capítulo 5 descreve detalhadamente como esses dois modos foram implementados e como eles foram incorporados em um mesmo ambiente de simulação. O modo determinístico de simulação, discutido na seção seguinte, também é um dos componentes da arquitetura de referência e conseqüência dos requisitos assumidos na seção 4.1 .1

\subsection{Simulação Determinística}

A simulação determinística é a abordagem proposta na arquitetura para teste e avaliação da corretude de protocolos. Neste modo, o simulador executa um script de simulação que descreve um cenário específico no qual o protocolo distribuído deve ser testado. Um script descreve dois tipos de informação:

- O comportamento dinâmico dos elementos simulados, tais como migrações, falhas e desconexões, e das aplicações, como o envio de mensagens e requisições.

- A ordem global de ocorrência dos eventos descritos no script.

O único comportamento que não é possível descrever no script é o comportamento dos protocolos distribuídos, pois este é definido pela sua implementação. Através do script é 
possível reproduzir qualquer padrão de eventos de um ambiente de computação móvel. Desta forma, é possível realizar testes e avaliar a corretude dos protocolos verificando se ele produz os resultados esperados nas situações descritas nos scripts. Tipicamente, o usuário do simulador programará scripts que reproduzam situações críticas de execuções dos protocolos sob teste.

Como um script contém uma sequência bem definida de traços de simulação, a simulação determinística pode ser considerada um tipo de simulação trace-driven [61].

Neste modo de simulação não há noção de tempo, ou seja, não existe relação entre o tempo real requerido para processar as ações sendo executadas e o correspondente tempo simulado. Conseqüentemente, os elementos simulados se comportam como se possuíssem uma capacidade infinita de processamento e as ações executadas fossem instantâneas.

Para definir a ordem de processamento dos eventos, o modo determinístico utiliza pontos de sincronização globais e locais, que permitem sincronizar o processamento de eventos de diferentes elementos simulados. Sem esses pontos de sincronização, seria impossível especificar qualquer ordem causal entre os eventos executados nos elementos simulados.

\section{Pontos de Sincronização Globais e Locais}

No modo de simulação determinístico, uma simulação é executada em passos. Cada passo contém um conjunto de ações que podem ser executadas concorrentemente por cada um dos elementos simulados. A execução dos eventos de um passo de simulação só é iniciada quando a execução de todos os eventos do passo anterior (e os seus eventos decorrentes) estiver terminada. O comando de script end_step determina o fim de um passo de simulação e o inicio de um novo passo. Como este comando define uma sincronização entre todos os elementos simulados, ele é chamado de um ponto de sincronização global.

Um ponto de sincronização local define quando um elemento simulado irá processar uma ou mais mensagens recebidas. O comando accept define um ponto de sincronização local para o processamento de um mensagem ou uma classe de mensagens. Quando um elemento executa accept $\left(m_{1}\right)$, os comandos subsequentes do script para o mesmo elemento serão executado somente após a mensagem $m_{1}$ ter sido entregue pela camada de simulação à camada de elementos de rede (evento MsgArrived). Caso a mensagem $m_{1}$ não esteja na fila de mensagens do elemento, o comando accept $\left(\mathrm{m}_{1}\right)$ impedirá a execução de qualquer outro comando até que esta mensagem seja recebida. Todas as mensagens causalmente precedentes a $\mathrm{m}_{1}$, e armazenadas na mesma fila de mensagens, são processadas. Se a camada de simulação detectar que não há nenhum elemento simulado processando eventos quando um elemento estiver bloqueado no accept, então o comando é desbloqueado para evitar deadlock.

\section{Geração de Timeouts}

Muitos protocolos definem um tempo máximo (timeout) de espera por mensagens. Para implementar tais protocolos, é necessário que sejam programados o envio do evento SetTimer e o tratamento do correspondente evento Timer recebido da camada de simulação. Uma vez 
que eventos de tempo essencialmente são eventos gerados pelo ambiente (relógio) e neste modo de simulação todos os comportamentos são especificados pelo usuário, os timeouts devem aparecer explicitamente nos scripts. No MoBICS, timeouts podem ser programados com comandos accept semelhantes aos usados para mensagens.

Do ponto de vista da camada de elementos de rede e protocolos, um evento de timeout gerado explicitamente no script é equivalente a um evento de timeout quando a máquina de simulação utiliza um tempo simulado.

\subsubsection{Exemplo de Simulação Determinística}

Nesta seção apresentaremos um cenário específico de simulação para uma versão simplificada do protocolo IP Móvel [78] e um script determinístico escrito de maneira a garantir o seu teste neste cenário.

No cenário da figura 4.3, um $M h$ envia uma requisição (req) a um servidor e espera a chegada do resultado da requisição (res). O protocolo IP Móvel gerencia a mobilidade do $M h$, trocando mensagens entre o home agent e os $M s s s$ no papel de foreign agent quando o $M h$ migra. Para efeito de simplificação, essas mensagens não estão indicadas na figura.

Deseja-se reproduzir no simulador, a situação na qual o servidor processa req e envia res depois que o $M h$ migrou de MSSo para MSSn.

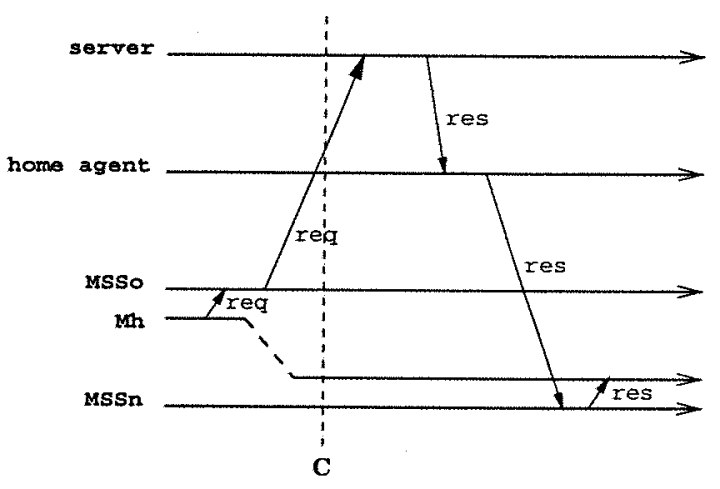

Figura 4.3: Exemplo de cenário para simulação determinística

Para descrever o cenário, o usuário pode definir o corte $\mathrm{C}$ indicado na figura 4.3. Antes do corte, o $M h$ envia req para o MSSo e depois do corte o servidor recebe req. Para simular o corte, o usuário deve incluir um comando end_step no script determinístico da seguinte forma: 


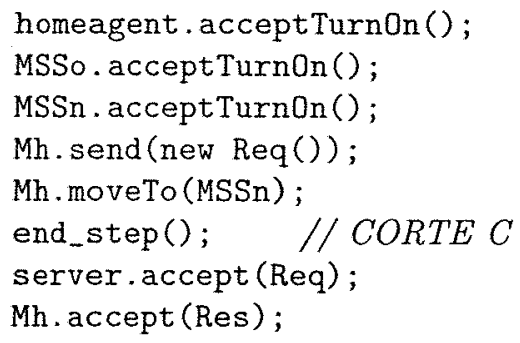

No exemplo, o comando acceptTurnon() faz com que o respectivo elemento processe todas as mensagens recebidas, sem que seja necessário colocar accepts em todos os passos de simulação para todos os elementos. Quando a mensagem Req é recebida pelo MSSo, ele a processa e gera uma nova mensagem Req destinada a server. Como o tempo de processamento de Req pelo MSSo não é conhecido, é preciso usar o comando end_step para garantir que server só receberá a mensagem e gerará a resposta Res após a migração do Mh para MSSn.

Por meio deste cenário, o usuário pode testar se o IP Móvel atualiza corretamente o careof-address do Mh e a mensagem Res de fato chega ao seu destinatário. Caso isso não tenha ocorrido, ou server não tenha enviado a resposta, na execução do comando Mh. accept (Res) o simulador gerará uma exceção, indicando ao usuário que o comando não pôde ser completado.

\subsubsection{Discussão}

Uma simulação determinística é capaz de reproduzir um cenário de computação móvel com qualquer ordem local e/ou global de ocorrência de eventos de simulação. Por isso, a simulação determinística é uma ferramenta útil para a depuração e avaliação da corretude de um protocolo distribuído, uma vez que pode ser utilizada para a reproduzir cenários críticos de execução de um protocolo e verificar a satisfação das suas propriedades.

Entretanto, programar scripts que descrevam a maioria das situações críticas para os protocolos pode ser tão difícil quanto programar um protocolo correto. Além disso, tornase impraticável programar um script quando há muitos elementos simulados envolvidos no cenário. Por outro lado, testes e avaliação de corretude de protocolos baseada em outros métodos também são dispendiosos pois exigem a especificação formal dos protocolos e o uso de ferramentas para análise dos resultados da simulação.

A simulação determinística pretende oferecer um mecanismo a ser explorado para teste e avaliação da corretude de protocolos. Para que ela possa ser utilizada efetivamente para simular cenários mais complexos é necessário o uso de geradores automáticos de casos de testes em scripts, o que no entanto foge ao escopo deste trabalho.

Deste ponto de vista, a simulação determinística é uma técnica que deve ser utilizada em complementação a outras técnicas de validação de protocolos. No caso do MoBICS, as simulações estocásticas mostraram ser úteis para complementar a simulação determinística na identificação de erros nos protocolos, conforme destaca a seção 8.1.3. 


\subsection{Modelo de Programação de Protocolos}

O modelo de programação de protocolos adotado neste trabalho é baseado no modelo de programação de protocolos compostos proposto em [13]. Neste modelo, um protocolo é composto de um conjunto de módulos chamados micro-protocolos, que implementam uma funcionalidade bem definida do protocolo. Para o caso de protocolos para computação móvel, é comum adotar uma organização baseada em três componentes funcionais ${ }^{1}$ :

- Wired: responsável pela troca de mensagens pela rede fixa.

- Wireless: responsável pela troca de mensagens pelos canais de comunicação sem fio.

- Hand-off: responsável pela comunicação entre os elementos de rede durante o processo de hand-off, e que pode incluir o envio de mensagens pela rede fixa e pelo canal sem fio.

Cada um desses módulos pode ser implementado por um micro-protocolo. Essa organização foi utilizada em [2] para descrever um protocolo de multicast para computação móvel. A principal vantagem dessa organização é a separação explícita dos aspectos funcionais de um protocolo de acordo com as seguintes características:

- Uso do meio de comunicação: As componentes Wired e Wireless organizam o protocolo em componentes que enviam mensagem pela rede fixa e que utilizam o meio sem fio. A utilização desses dois meios de comunicação define o desempenho de um protocolo.

- Mobilidade: Esta organização separa explicitamente os componentes que tratam da interação estática do algoritmo, composta pelos micro-protocolos Wired e Wireless, e a componente dinâmica (micro-protocolo Hand-off), que trata a mobilidade das estações móveis. Com essa separação é possível identificar o componente do algoritmo afetado pela mobilidade.

Desta forma, é possível avaliar o impacto e a relação de custo-benefício quando o protocolo é utilizado com características extremas um ambiente: redes estáticas convencionais e em redes altamente dinâmicas (como redes ad hoc).

A figura 4.4 ilustra a interação entre micro-protocolos e os principais conceitos relacionados ao modelo de programação. Um protocolo é uma estrutura que encapsula vários micro-protocolos, que podem trocar eventos entre si e compartilhar estruturas de dados. Cada micro-protocolo contém um estado interno e um conjunto de funções chamadas tratadores de eventos ou handlers, que implementam as ações que devem ser executadas na ocorrência de um determinado evento. A interface de um micro-protocolo é o conjunto de eventos que o mesmo é capaz de tratar (eventos importados) ou gerar (eventos exportados).

\footnotetext{
${ }^{1}$ Esta organização não se aplica aos protocolos para redes ad hoc.
} 


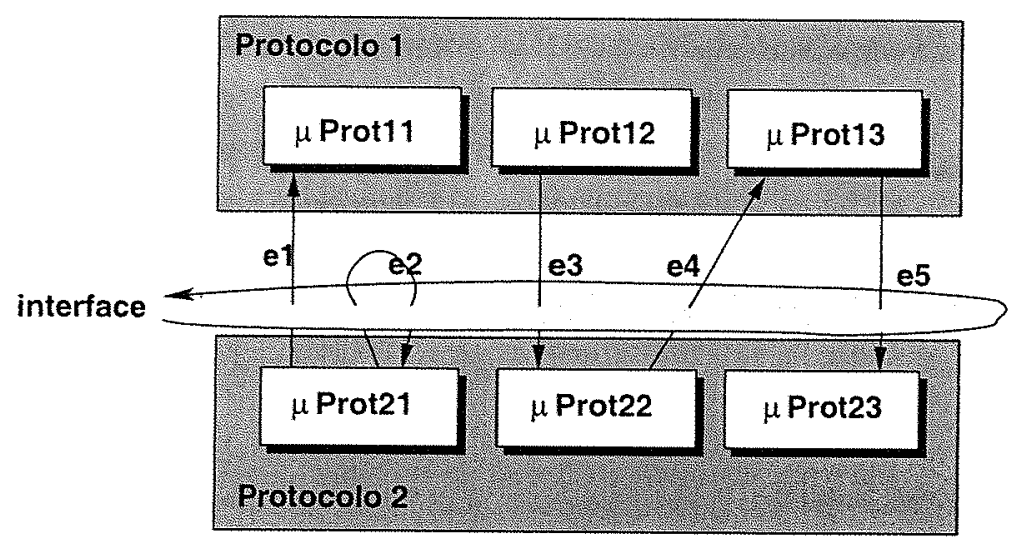

Figura 4.4: Diagrama de Interação entre Micro-Protocolos

Há dois tipos de eventos: mensagens, que podem ser enviadas por outro micro-protocolo ou camada, e eventos de tempo que são escalonados por micro-protocolos na camada de simulação para indicar a passagem de um intervalo específico de tempo. Estes eventos equivalem aos eventos MsgArrived e Timer, discutidos anteriormente.

Os simuladores implementados a partir da arquitetura de referência proposta, devem traduzir os conceitos de protocolos, micro-protocolos, tratadores de eventos e interfaces, para estruturas da linguagem de programação adotada para implementação de protocolos. No caso do MoBICS, esses conceitos foram mapeados para construções da linguagem Java.

\subsection{Programação de Modelos de Simulação}

O modelo de simulação implementa a métrica de avaliação e o padrão abstrato de comportamento dinâmico do sistema simulado em função do tempo. Para um simulador, o modelo de simulação define os parâmetros de uma simulação e como os eventos simulados são gerados a partir deles. Por exemplo, um modelo de simulação poderia definir que um de seus parâmetros é a taxa de requisições feitas a um serviço implementado por um protocolo, e durante a simulação o simulador geraria requisições ao protocolo baseadas nesse parâmetro. A escolha adequada do modelo de simulação permite a reprodução do comportamento real do ambiente simulado e com um nível de complexidade coerente com as características do protocolo.

Um dos requisitos da arquitetura de referência proposta é permitir que o usuário programe os modelos de simulação adequados à avaliação do seu protocolo. Essa flexibilidade na modelagem é, segundo Law [66], a principal característica para um software de simulação. O usuário deve escolher o modelo de simulação baseado nas seguintes características:

- Especificidades do Protocolo: as características dinâmicas do ambiente de rede podem produzir um impacto diferente no desempenho de diferentes protocolos. Por exemplo, a topologia de rede é uma variável relevante na avaliação de protocolos de 
difusão e não produz nenhuma influência em protocolos de correção de erros. Dependendo da simulação pretendida, pode-se promover diferentes níveis de abstração para as características do ambiente simulado, para que os protocolos sejam avaliados apenas em função dos eventos dinâmicos relevantes.

- Ambiente de Rede: modificações nas características do ambiente podem produzir um impacto no desempenho de um mesmo protocolo, como por exemplo, a utilização de diferentes modelos de comunicação sem fio e de diferentes protocolos em camadas inferiores.

- Modelo de Mobilidade: não há um modelo de mobilidade genérico e flexível que seja aplicável a qualquer aplicação para computação móvel. A escolha do modelo de mobilidade deve ser orientada às características do ambiente a ser simulado.

Para permitir a programação dos modelos de simulação, a arquitetura de referência define dois conceitos:

Evento de Simulação é uma atividade atômica realizada por uma máquina simulada e cuja ocorrência independe de qualquer outro elemento do ambiente simulado, como por exemplo uma migração. Um evento de simulação é composto pelo seu identificador, que incorpora o tipo do evento e seus parâmetros, e pelo timestamp que indica o tempo simulado no qual ele deve ocorrer.

Gerador de Eventos é um elemento interno à camada de simulação de uma máquina simulada que gera eventos durante uma simulação. Cada gerador de eventos possui um conjunto de parâmetros que identifica como os eventos devem ser gerados. O usuário do simulador programa geradores de eventos que definem o modelo de simulação adotado para a sua simulação.

O gerador de eventos deve ser implementado em um objeto e seus parâmetros são os parâmetros do construtor do objeto. Como o uso de construções de orientação a objetos é possível automatizar várias tarefas comumente necessárias à programação de geradores de eventos, como geração de números aleatórios, geração periódica de eventos e teste periódico de condições, além de incorporar padrões de projeto para simulação (como [85]). O MoBICS define uma forma de programar modelos de simulação simples e flexível, dando ao programador flexibilidade para adicionar a complexidade desejada ao seu modelo. Este modelo está descrito na seção 5.6 .

\subsubsection{Programação de Modelos de Mobilidade}

O modelo de mobilidade define a abstração de movimentação de estações ou usuários móveis em termos de granularidade, padrões e restrições de movimentação. Diversas características do ambiente simulado podem influenciar um modelo de mobilidade, tais como as características físicas do ambiente, tipos de usuários móveis, tipos de aplicações envolvidas e fatores externos ao ambiente simulado. 
A mobilidade pode produzir um impacto em forma e amplitude diferente dependendo do protocolo que se está simulando. Por exemplo, Ho [48] descreve uma modificação no modelo de mobilidade do GloMoSim que permitiu uma melhor avaliação de um protocolo de difusão para redes ad hoc. Os vários modelos de mobilidade já propostos, como $[72,65,69,52,87,59$, 53], foram definidos com o objetivo de se adequar às características específicas de diferentes ambientes de rede, protocolos e aplicações.

Embora as abstrações discutidas na seção 4.5 permitam a definição da geração de eventos de migração, elas não são suficientes para a definir abstrações de localização e de migração. Por isso, a arquitetura de referência propõe três abstrações: a unidade atômica de localização, definida na implementação do simulador, a abstração de localização do usuário, definida pelo programador do modelo de mobilidade e o mapeamento entre abstrações de localização, que define o mapeamento entre as duas abstrações anteriores. A forma como esse mapeamento é implementado nos simuladores, depende da definição da unidade de localização do simulador e pode tão complexa quanto for necessário. No caso do MoBICS, toda localização é mapeada em uma célula. Quando uma migração resulta em uma migração de célula, o evento MoveTo(Location), onde Location é um identificador de célula, é enviado da camada de simulação para a camada de elementos de rede. Neste caso, todo evento MoveTo(Location) deve gerar um hand-off.

\section{Resumo}

Uma arquitetura de referência é uma arquitetura generalizada que define uma infraestrutura e interfaces comuns para sistemas em um mesmo domínio de aplicação. Este capítulo descreveu uma arquitetura de referência para implementação de simuladores de protocolos de alto nível e que permitam a implementação de diferentes modos de simulação.

Para o projeto desta arquitetura foram seguidos vários requisitos com o objetivo de auxiliar o desenvolvimento de protocolos e a modelagem de ambientes de computação móvel. A arquitetura de referência define quatro componentes principais: uma arquitetura de software, um modelo de programação de protocolos, uma abordagem para validação de protocolos e algumas abstrações que permitem ao usuário programar o seu próprio modelo de simulação.

A arquitetura de software proposta é composta de quatro camadas: aplicação, protocolos, elementos de rede e simulação. A arquitetura de software define uma interface entre a camada de simulação e demais camadas que permite a transparência de simulação. Isto significa que diferentes modos de simulação podem ser implementados na camada de simulação, sem que seja necessária qualquer modificação nas demais camadas.

A arquitetura de referência propõe ainda simulações determinísticas como abordagem para teste e avaliação da corretude de protocolos e um modelo de programação de protocolos modular baseado no conceito de micro-protocolos.

O capítulo seguinte apresenta MOBICS, um simulador de protocolos para computação móvel que implementa os conceitos propostos pela arquitetura de referência. Isto significa que a arquitetura de MoBıCS é uma instância da arquitetura de referência proposta. 


\section{Capítulo 5}

\section{O Simulador MobiCS}

MoBICS é um simulador de protocolos distribuídos para computação móvel que implementa a arquitetura de referência descrita no capítulo 4. Este capítulo apresenta o simulador do ponto de vista do usuário, descrevendo como protocolos podem ser implementados (seção 5.3) e incorporados em uma simulação e como funcionam e os seus modos de simulação (seções 5.5 e 5.6 ).

\subsection{Visão Geral do MobiCS}

O MoBiCS (Mobile Computing Simulator) [26, 27] é um simulador distribuído de eventos discretos que permite a prototipagem, teste e avaliação de protocolos distribuídos. Para atingir esse objetivo, MOBICS implementa a arquitetura de referência proposta no capítulo 4 e disponibiliza ao usuário dois modos de simulação: o modo determinístico e o modo estocástico. O modo determinístico (seção 5.5.1) implementa uma simulação determinística, na qual o simulador executa um script que descreve o comportamento dinâmico do ambiente simulado. No modo estocástico (seção 5.5.2), um protocolo é submetido a uma simulação exaustiva conforme o padrão de comportamento dos elementos simulados definido pelo usuário. Esses padrões são programados segundo o modelo de programação descrito na seção 5.6, que implementa as abstrações de modelagem discutidas anteriormente. O objetivo da implementação do simulador foi criar uma ferramenta flexível de simulação e validar a arquitetura de simulação quanto ao seu caráter genérico para permitir a implementação de diferentes modos e/ou algoritmos de simulação.

A home page do MoBICS contém informações completas sobre o simulador, como código fonte e documentação, incluindo API, tutoriais e exemplos, e está localizada na URL http://www.ime.usp.br/ sidam/components/mobics,

Ao longo deste capítulo serão utilizados os termos elemento simulado para denotar qualquer componente de rede simulado no MoBıCS, como por exemplo canais sem fio e estações móveis, e máquina simulada para denotar qualquer elemento de rede simulado que é capaz de incorporar protocolos e processar mensagens, como estações móveis e máquinas fixas. 


\subsection{Uso do MobiCS}

MoBiCS é uma biblioteca Java que implementa todos os objetos necessários para que o usuário programe e simule protocolos. Para criar uma simulação, usuário basicamente implementa classes que definem os protocolos a serem simulados, o ambiente e o modelo de simulação desejado. Estas classes estendem as classes básicas do MoBICS, que implementam a funcionalidade das várias camadas da software do simulador. A figura 5.1 ilustra como o usuário implementa um protocolo e uma simulação a partir das classes básicas implementadas no MoBiCS.
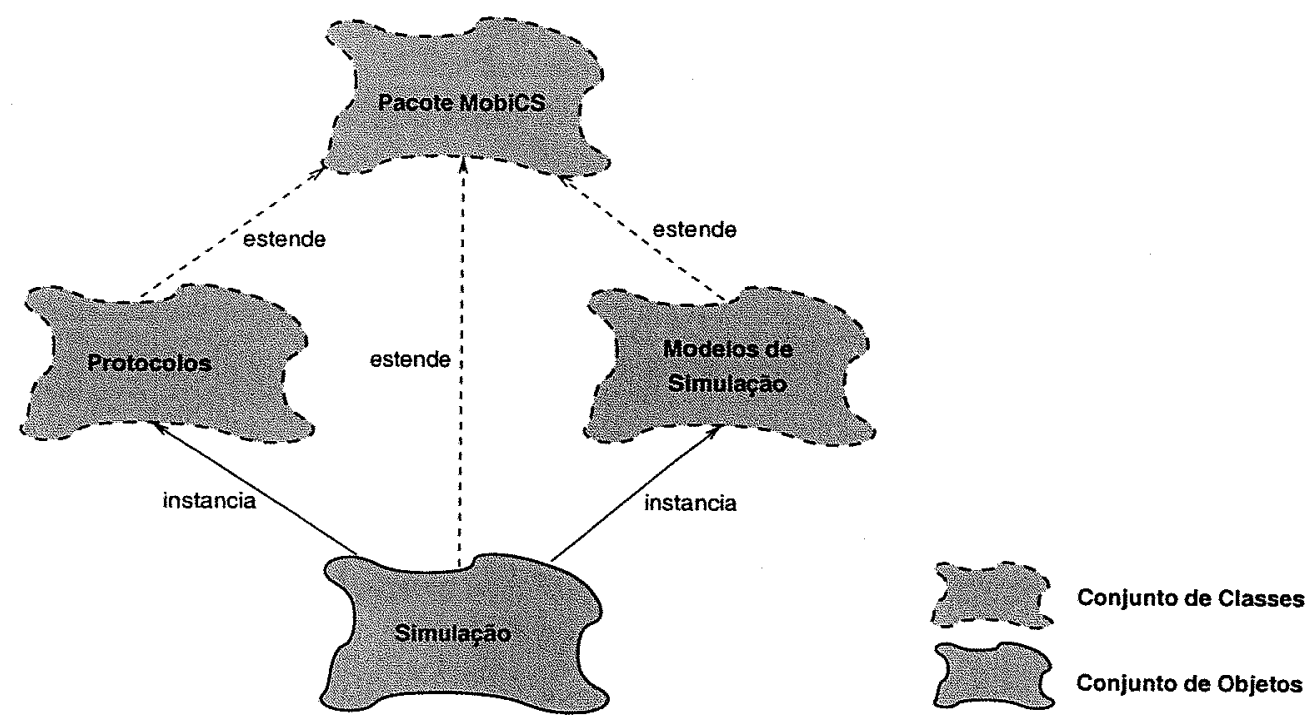

Figura 5.1: Implementação de Protocolos e Simulações a partir do MoBICS

Do ponto de vista do usuário MoBICS, há dois pacotes Java principais que são utilizados para criar uma simulação. Com o pacote ${ }^{1}$ mobics.ppi o usuário programa protocolos que podem ser simulados, fazendo uso de dois subpacotes: mobics.ppi.protocol, que declara as classes necessárias à implementação do protocolo propriamente dito, e mobics.ppi.message, que auxilia a declaração de mensagens utilizadas pelo protocolo. Com o pacote mobics . simulation, o usuário implementa a simulação propriamente dita, em termos de número e tipos de elementos de rede envolvidos na simulação, topologia da rede, tipos de protocolos a serem simulados, modo e modelo de simulação. A organização completa do pacote MoBiCS está descrita no capítulo 7.

A figura 5.2 mostra um diagrama com a seqüência de procedimentos para implementação e simulação um protocolo no MoBICS. Nas etapas indicadas na figura 5.2, o usuário deve realizar as seguintes tarefas:

1. Declarar as interfaces e programar o protocolo a ser simulado, utilizando-se das classes

\footnotetext{
${ }^{1}$ Para efeito de simplificação do texto, o pacote raiz do MoBıCS será referenciado simplesmente por mobics.
} 


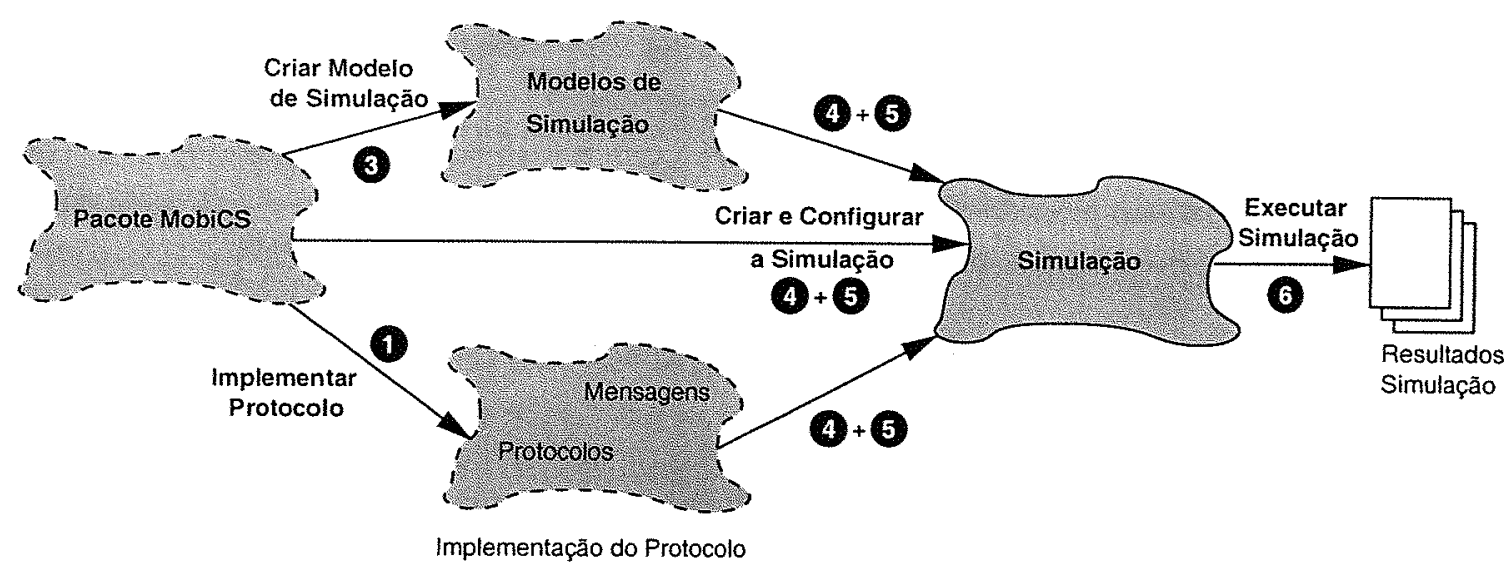

Figura 5.2: Diagrama de Seqüência de Implementação e Simulação de um Protocolo

básicas dos pacotes mobics.ppi.protocol e mobics.ppi.message. Este processo está detalhado na seção 5.3 .

2. Escolher o modo ou tipo de simulação que será aplicado ao ambiente simulado. No MoBICS, o usuário pode escolher entre uma simulação determinística e uma simulação estocástica.

3. Escolher um modelo de simulação apropriado para o protocolo e programá-lo usando o modelo de programação descrito na seção 5.6, no caso de uma simulação estocástica, ou programá-lo na forma de um script determinístico, descrito na seção 5.5.1.

4. Escolher a topologia de rede e os elementos a serem simulados.

5. Criar uma classe simulação, subclasse de mobics. simulation. Simulation, que declara a topologia e os elementos de rede a serem simulados, atribuindo a cada um o modelo e os parâmetros de simulação apropriados. A escolha da subclasse de mobics.simulation. Simulation é determinante para o tipo de simulação a ser executado. Caso o usuário queira executar uma simulação estocástica, ele deve estender a classe mobics.simulation. StochSimulation. No caso de uma simulação deterministica, o usuário deve estender a classe mobics.simulation.DetermSimulation.

6. Implementar um programa Java que cria e inicia um objeto da classe implementada no item 5. Para executar uma simulação, o programa deve chamar o método Simulation. start do seu objeto simulação. A seção 5.5 descreve em detalhes a criação e execução de cada um dos modos de simulação.

\subsection{Programação de Protocolos no MobiCS}

O pacote mobics.ppi declara as classes que compõem a interface de programação de protocolos do MoBiCS. O objetivo dessas classes é implementar os conceitos do modelo de 
programação de protocolos (seção 4.4) no modelo Java e oferecer transparência de detalhes ao programador.

A tabela 5.1 mostra o mapeamento entre os conceitos do modelo de programação de protocolos proposta e o modelo de programação Java.

\begin{tabular}{|l|l|}
\hline \hline Conceito & Modelo de Programação Java \\
\hline \hline Estado & Atributos \\
Micro-protocolo & Conjunto de métodos \\
Mensagem & Objeto de uma subclasse de \\
& mobics.ppi.message.Message \\
Tratadores de Eventos & Métodos \\
Interfaces de micro-protocolos & Interfaces \\
Algoritmo & Corpo de métodos \\
Protocolo & Classe \\
\hline \hline
\end{tabular}

Tabela 5.1: Mapeamento dos Conceitos do Modelo de Programação de Protocolos para o Modelo de Programação Java

Uma instância funcional de um protocolo é implementada em uma classe, cujos atributos descrevem o estado compartilhado entre todos os micro-protocolos. Os métodos do protocolo implementam os tratadores para as mensagens e demais eventos recebidos. Um micro-protocolo é definido pelo conjunto dos métodos da classe que implementam uma funcionalidade desejada, e são declarados em uma interface Java. Portanto, esta interface define a modularização e a divisão do protocolo em micro-protocolos. Por exemplo, para declarar um protocolo $P$ composto de micro-protocolos $\mu P 11, \mu P 12$ e $\mu P 13$ é necessário declarar uma interface para cada um dos micro-protocolos, que chamaremos de $I \mu P 11, I \mu P 12$ e $I \mu P 13$. Cada uma dessas interfaces declara o conjunto de tratadores associados ao respectivo micro-protocolo. O protocolo $P$ é uma classe que implementa as interfaces $I \mu P 11, I \mu P 12$ e $I \mu P 13$, e que consequentemente implementa cada um dos tratadores dos micro-protocolos. A figura 5.3 ilustra este exemplo.

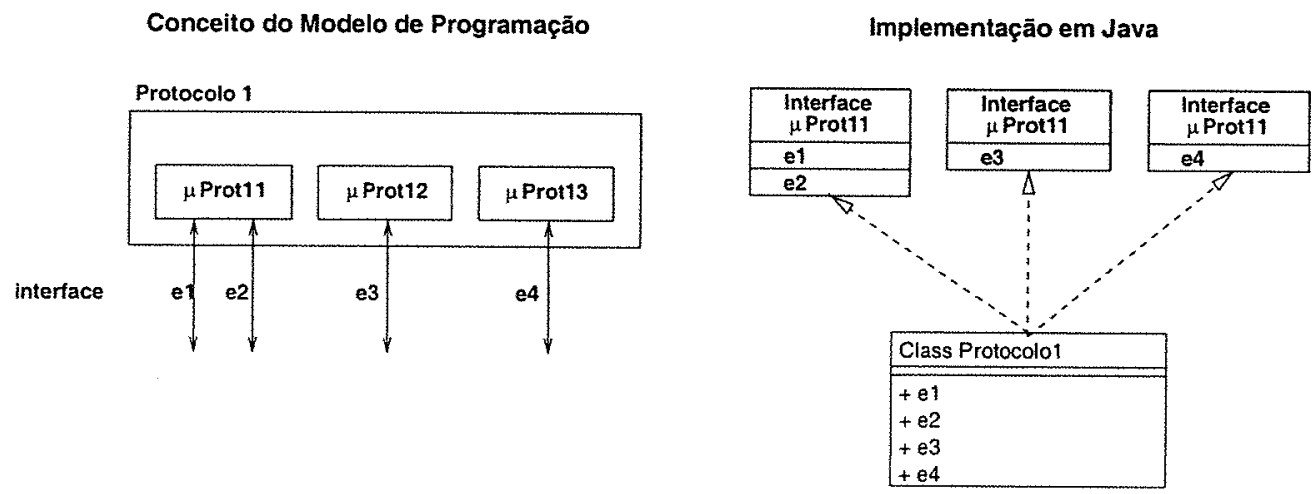

Figura 5.3: Exemplo de Mapeamento de um Protocolo para classes Java

Todas as mensagens trocadas entre máquinas simuladas ou protocolos e tratadas pelos 
métodos do protocolo são objetos de subclasses de mobics.ppi.message.Message. Esses objetos encapsulam as informações de tipagem e o conteúdo que deve ser trocado entre as duas entidades envolvidas na comunicação. As seções 5.3.1 e 5.3.2 descrevem em detalhes a declaração de mensagens e protocolos, respectivamente.

Para construir uma instância funcional de um protocolo é necessário cumprir as seguintes etapas:

1. Definir todas as mensagens trocadas entre os elementos e seus respectivos microprotocolos, atribuindo a elas identificadores únicos e definindo as informações que elas contém.

2. Declarar cada uma das mensagens na forma de uma subclasse de Message, cujos atributos definem o conteúdo da mensagem.

3. Declarar os micro-protocolos em interfaces Java. Cada micro-protocolo deve declarar os métodos tratadores das mensagens associados a ele.

4. Declarar uma subclasse de Protocol que implementa todas as interfaces dos microprotocolos declarados no item 3.

5. Implementar os tratadores de eventos do protocolo, que tratam o recebimento das mensagens ou eventos.

\subsubsection{Pacote mobics.ppi.message e a Declaração de Mensagens}

A mensagem é o evento de interação entre protocolos e máquinas simuladas. Toda mensagem é implementada por um objeto Java, instância de uma subclasse de mobics.ppi.message. Message.

Toda mensagem entre protocolos precisa conter duas informações: o seu tipo e o seu conteúdo. Para o MoBiCS, o tipo de um objeto mensagem é a sua classe e o seu contéudo é definido pelos atributos implementados na sua classe ${ }^{2}$. O conteúdo é a informação que um remetente deseja enviar para o destinatário. A figura 5.4 mostra um diagrama UML com as classes do pacote mobics.ppi.message.

A classe Message determina o conjunto mínimo de informações necessárias para processar uma mensagem. Os atributos sender e receiver armazenam o endereço do remetente e do destinatário da mensagem, respectivamente. $\mathrm{O}$ atributo responsible armazena a classe do protocolo ao qual a mensagem está associada. Quando um elemento simulado recebe uma mensagem, ele verifica se há algum protocolo desse tipo registrado e, em caso positivo, encaminha a mensagem para ser tratada por este. O método Message callHandler (Protocol) determina qual é o método do protocolo que é o tratador daquela mensagem. Este método é chamado pelo destinatário da mensagem e recebe como parâmetro o protocolo responsável por ele. A implementação de Message.callHandler (Protocol) faz uma chamada do método do protocolo com o padrão de assinatura when<tipo da mensagem $>$. Por exemplo, para

\footnotetext{
${ }^{2}$ A sua super classe Message também possui atributos, mas eles não definem o conteúdo da mensagem.
} 


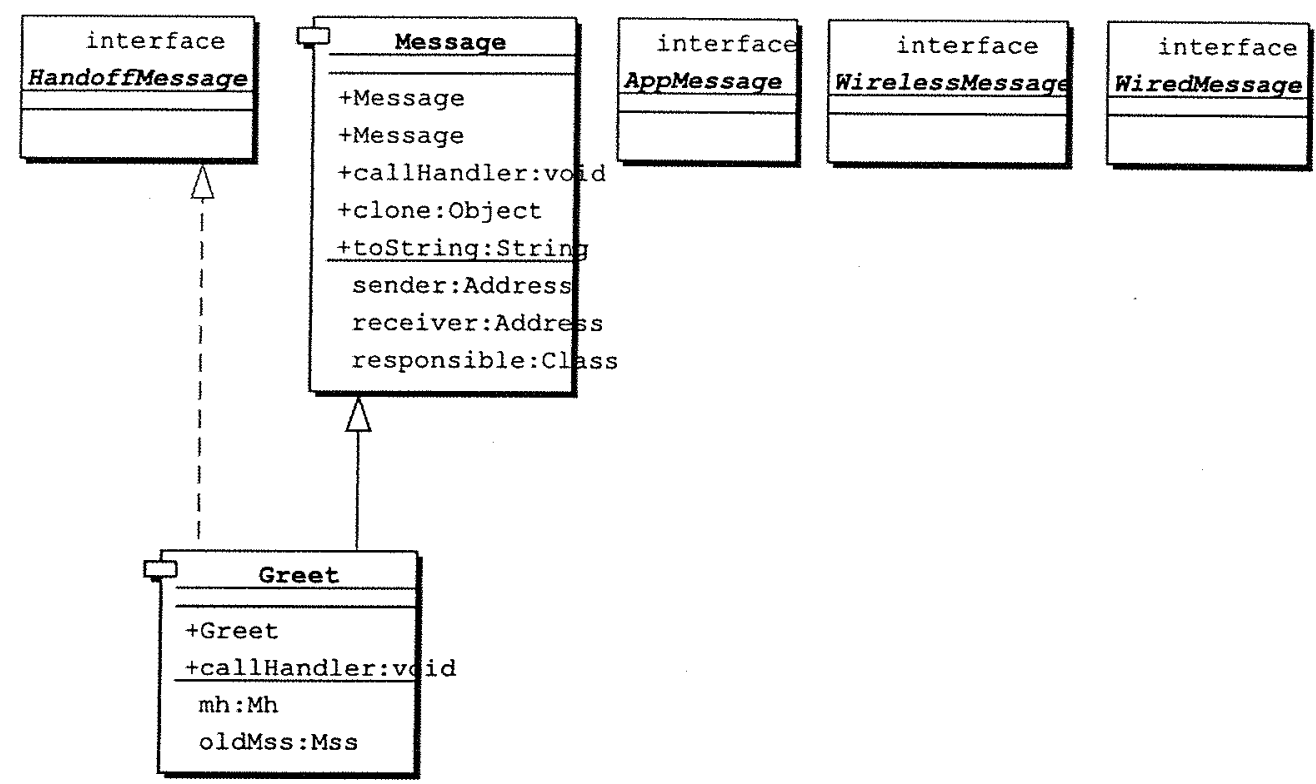

Figura 5.4: Diagrama UML das Classes do Pacote mobics.ppi.message

uma mensagem da classe Ack o tratador invocado deveria ter a assinatura whenAck. Caso ao declarar um novo tipo de mensagem, o programador queira usar outra assinatura para o tratador, ele deve reimplementar o método Message .callHandler (Protocol).

O pacote mobics .ppi.message declara algumas interfaces que são utilizadas para atribuir assinaturas às mensagens. As interfaces HandoffMessage, WiredMessage, WirelessMessage e AppMessage definem assinaturas para mensagens de hand-off, mensagens pelo meio físico, mensagens pelo meio sem fio e mensagens de aplicação, respectivamente. Toda mensagem no MOBICS deve implementar uma dessas interfaces. Essa informação poderá ser utilizada para depuração ou avaliação preliminar de protocolos.

Uma mensagem deve ser um objeto imutável ${ }^{3}$, ou seja, seu estado não pode ser modificado por nenhum de seus métodos públicos, que devem ser apenas métodos de acesso.

O método Message. clone retorna um objeto que é cópia da respectiva mensagem. Para efeito de desempenho, na classe Message o método clone retorna a própria referência para o objeto, sem realizar qualquer cópia. Para cada uma das mensagens criadas, o usuário deve decidir se reimplementa ou não este método, dependendo das estruturas de dados que compõe o conteúdo da mensagem. Caso haja algum atributo que seja um objeto com uma interface que permita a alteração do seu contéudo, é recomendável reimplementar esse método para que seja feita uma cópia do objeto e de seus respectivos atributos. A seção 5.3 .2 discute a necessidade da criação de cópias de mensagens.

No construtor de uma mensagem é possível definir no atributo contentSize um tamanho em bytes para o conteúdo da mensagem. Isso é útil para simular o tamanho de uma mensagem cujo conteúdo é irrelevante para o processamento do protocolo mas cujo tamanho pode ter

\footnotetext{
${ }^{3}$ Padrão de projeto Immutable [42]
} 
influência no atraso no seu envio pelos canais de comunicação. O envio da mensagem pelos canais de comunicação poderá levar em consideração esse tamanho para determinar seu atraso de envio, sem que seja necessário sobrecarregar o tamanho em memória do objeto mensagem.

O pacote mobics .ppi.message declara ainda uma mensagem padrão do MoBICS que é a mensagem Greet, enviada por uma estação móvel para uma estação base para iniciar o hand-off durante uma migração de célula ou após retornar de um estado de inatividade.

\subsubsection{Pacote mobics.ppi.protocol e a Programação de Protocolos}

A figura 5.5 mostra um diagrama UML com as classes e interfaces declaradas no pacote mobics.ppi.protocol e utilizadas para implementar protocolos. Para declarar um microprotocolo é necessário criar uma interface que estende alguma das interfaces WiredModule, WirelessModule ou HandoffModule. Assim como na declaração de mensagens, essas interfaces permitem dar uma assinatura ao micro-protocolo quanto à sua funcionalidade. No corpo do micro-protocolo devem ser declarados todos os tratadores para mensagens e demais eventos que compõem o micro-protocolo. A interface HandoffModule é uma interface que provê uma assinatura para micro-protocolos de hand-off. Essa interface declara um tratador para uma mensagem Greet, enviada por uma estação móvel quando esta migra entre células e que inicia um hand-off. Essa mensagem é declarada no pacote mobics.ppi.message e é automaticamente enviada pela estação móvel durante a migração.
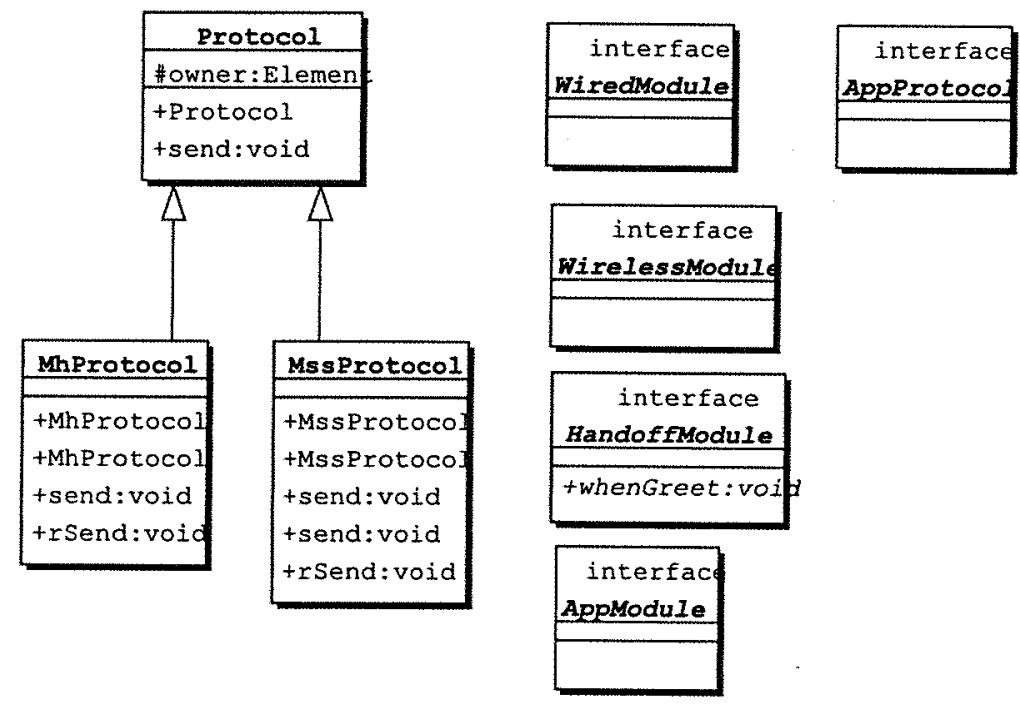

Figura 5.5: Diagrama UML das Classes do Pacote mobics.ppi.protocol

Um tratador de mensagem possui a seguinte sintaxe:

public void when $<$ tipo-da-mensagem $>$ (Message $m$ );

onde <tipo-da-mensagem> é o nome da mensagem a ser tratada, de acordo com o padrão de nome de tratadores definido pelo MoBICS. No corpo do método, implementado pela classe 
Protocol, são definidas as ações que devem ser executadas na entrega de cada mensagem. $\mathrm{O}$ parâmetro recebido pelo tratador é o objeto mensagem recebido pelo protocolo. Por exemplo, para implementar o tratador do protocolo RDP (capítulo 6) para a mensagem Ack, foi declarado o seguinte método:

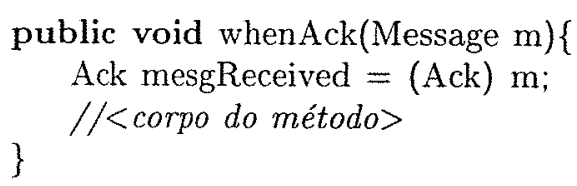

O atributo owner é uma referência à máquina simulada que executa o protocolo, e permite acessar todas as suas interfaces. Isso é particularmente útil para determinar o estado do elemento durante a execução do protocolo. O pacote mobics.ppi.protocol implementa duas subclasses de Protocol: MssProtocol e MhProtocol. Estas classes possuem uma interface específica para a implementação de protocolos em estações base e móvel, respectivamente. Essas classes adicionam atributos owner específicos como mss0wner e mh0wner, que evitam a necessidade de realizar repetidas conversões de classes para se acessar interfaces do elemento simulado.

\section{Envio de Mensagens}

A única forma de interação entre protocolos é através do método Protocol.send(Address, Message), que envia uma mensagem para outra máquina simulada. O envio de mensagens no MовіCS é assíncrono, ou seja, a chamada do método send é liberada antes que o destinatário receba a mensagem.

O método Protocol.send(Address, Message) recebe como parâmetros o endereço do destinatário e a mensagem a ser enviada e pode lançar uma exceção do tipo CommunicationException caso ocorra algum erro durante o envio da mensagem. As classes MssProtocol e MhProtocol implementam várias versões especializadas deste método send. Basicamente há dois tipos: o send que é um envio pelo meio sem fio não confiável e o rSend que é um envio de mensagens confiável pelo meio sem fio. Um envio de mensagens por meio de rSend inclui o recebimento de confirmações por parte dos destinatários. Do ponto de vista do programador de protocolos, essas confirmações são feitas por protocolos de mais baixo nível. A figura 5.6 mostra um exemplo de envio de mensagens pelo comando rSend, que lança a exceção MessageNotAcknowledgedException caso a mensagem não tenha sido recebida pelo destinatário. O envio de mensagens pela rede física sempre é confiável e é feito através do método Protocol.send(Address, Message). As especializações do método de envio de mensagens modificam os parâmetros do método (tipo de endereço de destinatário) e as exceções que podem ser lançadas. Por exemplo, o método MhProtocol. send (WirelessAddress, Message) não lança nenhuma exceção já que o envio da mensagem pela rede fixa é confiável, segundo o modelo de sistema.

O envio de mensagens no MOBICS encaminha o objeto da classe Message passado como parâmetro até o destinatário da mensagem, por sucessivas chamadas de métodos. Para evitar o compartilhamento e acesso concorrente a objetos entre remetente e destinatário, o 


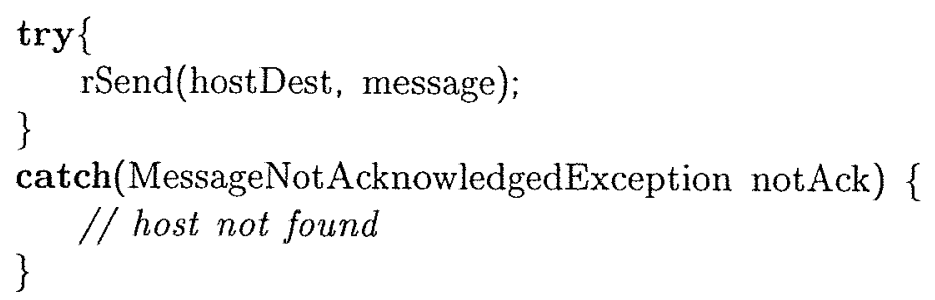

Figura 5.6: Exemplo de Uso de rSend

método de envio de mensagens invoca o método clone da mensagem. Desta forma, é tarefa do programador decidir quando é necessário fazer uma cópia real de uma mensagem entre remetente e destinatário.

\section{Processamento de Mensagens}

A figura 5.7 descreve o diagrama de sequência do envio e processamento de mensagens entre dois protocolos quaisquer. A chamada do método Protocol.send (Address, Message) realiza uma chamada do método send da máquina simulada owner, onde o protocolo está executando. Este send é assíncrono e envia a mensagem pela rede simulada, que inclui interfaces de rede, canais de comunicação e outras máquinas, se necessário. A mensagem chega ao destinatário por uma primitiva receive(Message), com a qual ela é incluída na fila de mensagens da máquina.

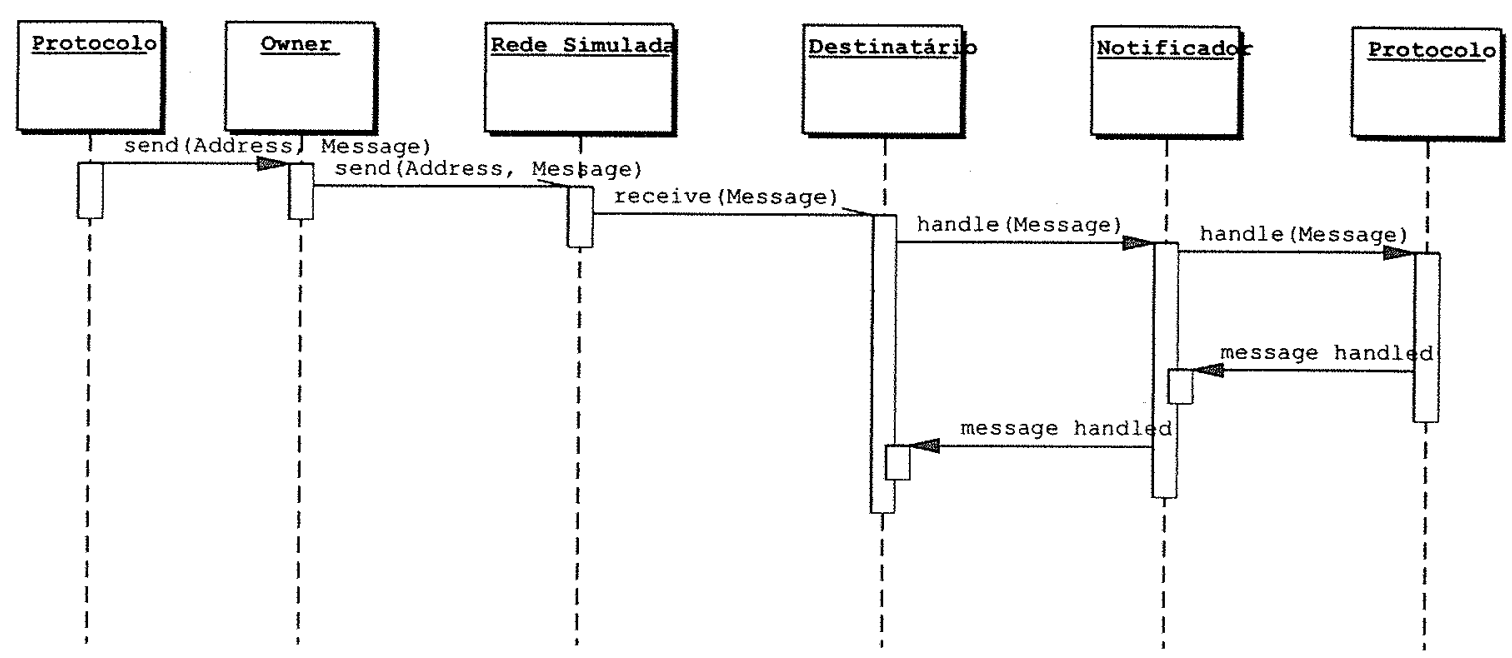

Figura 5.7: Diagrama de Sequência de Envio de Mensagens

Quando a camada de simulação da máquina destinatária decide processar a mensagem, ela é enviada ao notificador de protocolos pela mensagem handle(Message), que requisita o seu tratamento. O notificador entrega a mensagem ao protocolo responsável por ela, executa o método tratador da mensagem e retorna à camada de simulação, indicando que a mensagem 
foi tratada.

\subsubsection{Discussão}

rSend

O comando rSend simula a entrega confiável de mensagens e assim permite programar protocolos que se abstraiam dos detalhes da transmissão confiável, isto é, de confirmação de recebimento de mensagens.

Entretanto, o comando rSend não simula propriamente o recebimento de mensagens de confirmação (acks). Isso ocorre porque o tempo simulado de execução de um tratador de eventos é nulo e o recebimento de acks sempre ocorre após a passagem de um tempo simulado, definida pelo modelo de simulação. Portanto, para simular o envio de mensagens com confirmações o programador deve implementá-las explicitamente.

Apesar disso, o comando rSend é util para que o usuário possa definir o seu protocolo ou modelo de comunicação em um nível mais alto de abstração, pois o seu uso implica na adoção de um modelo confiável de comunicação. O programador deve ter consciência desta semântica do rSend ao implementar os seus protocolos.

\section{Atomicidade de Tratadores de Eventos}

Os tratadores de mensagens são elemento atômicos, ou seja, nenhuma outra mensagem ou evento pode ser processado enquanto um tratador estiver sendo executado. Caso o programador queira simular a ocorrência de eventos durante o tratamento de uma mensagem, ele deverá desmembrar um tratador em dois ou mais tratadores de mensagem.

\section{Restrições à Programação}

Como o modelo de execução de protocolos é sequencial, tratadores de eventos não são thread-safe, ou seja, não é permitida a execução de processos concorrentes que enviem mensagens pela rede simulada. Toda comunicação entre elementos simulados deve ocorrer na execução de um tratador de eventos.

\subsection{Criação do Ambiente Simulado}

O pacote mobics. network declara as classes necessárias para a criação e configuração dos elementos simulados, tais como estações móveis, estações base, máquinas fixas e canais de comunicação.

A classe Element implementa a interface básica e os componentes comuns de uma máquina simulada. Todos as demais máquinas simuladas são subclasses de Element. Uma máquina contém um nome, um endereço e um ou mais protocolos. O nome de um elemento é uma 
cadeia de caracteres que o identifica com um nome significativo para o usuário, determinado por este durante a sua criaçãodo elemento, e que pode ser acessado pelo método Element.getName. $O$ endereço é um identificador único para cada máquina, utilizado para indicar remetentes e destinatários de mensagens. Há dois tipos de endereços: endereços fixos (WiredAddress), que denotam endereços na rede fixa, e endereços sem fio (WirelessAddress), que denotam endereços de máquinas que recebem mensagens por canais sem fio. Estações móveis possuem apenas endereços sem fio, enquanto que estações base possuem os dois tipos de endereço. A classe Element ainda incorpora um conjunto de protocolos que define quais mensagens uma máquina é capaz de tratar e um notificador de protocolos que armazena todos os protocolos registrados na máquina através do método Element.attach (Protocol).

Além das interfaces básicas, todas as classes implementam dois tipos de interfaces com o usuário: interface de usuário de simulação e interface de especialização de tratamento de eventos. A interface de usuário de simulação contém as interface com a qual o usuário ou o simulador requisita a geração de eventos. Estas interfaces contém métodos cuja assinatura é o próprio nome do evento. A interface de especialização de tratamento de eventos declara métodos que podem ser especializados pelo usuário em subclasses e que definem ações adicionais que devem ser realizadas na ocorrência de eventos. A assinatura desses método segue o padrão on<tipo-de-evento>. Por exemplo, o método Mh.moveTo(Cell) implementa a interface de migração da classe Mh, enquanto que o método Mh. onMoveTo pode ser especializado por subclasses de Mh para indicar ações adicionais que devem ser realizadas quanto é iniciada uma migração.

A classe Mh implementa a interface e funcionalidade básicas de uma estação móvel. O método Mh. getMssResp retorna o endereço da estação base responsável pela estação móvel. Os métodos Mh available e Mh . unavailable implementam a mudança do estado de disponibilidade da estação móvel para ativo e inativo, respectivamente. Há três métodos que podem ser especializados em subclasses de Mh: Mh. onMoveTo, Mh. onAvailable e Mh. onUnavailable.

A classe Mss implementa a interface e a funcionalidade básica de uma estação base. A cada Mss necessariamente está associado uma célula, que é um objeto da classe Cell.

A classe WiredLink implementa um canal de comunicação físico entre duas máquinas fixas. A comunicação entre duas máquinas sempre é ponto-a-ponto, e por isso uma máquina fixa só é capaz de se comunicar com outra se for criado um objeto WiredLink que interconecta as duas.

O código da figura 5.8 é um exemplo de criação de elementos simulados. Neste exemplo, todos os elemento simulados foram criados a partir de classes declaradas pelo usuário, como MyMh e MyMss, que são subclasses de Mh e Mss, respectivamente. Observe que o parâmetro sim é uma referência ao simulador utilizado e é parâmetro obrigatório do construtor de cada elemento. No exemplo descrito no capítulo 6 serão vistos mais detalhes sobre a utilização desse parâmetro. 


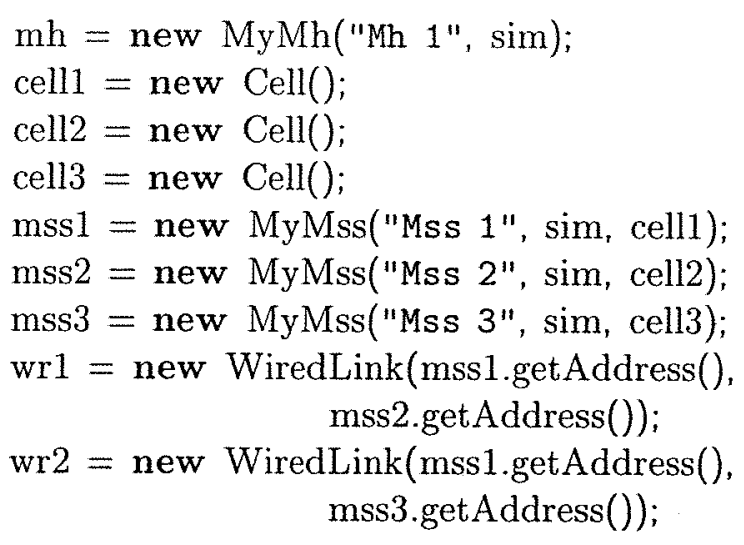

Figura 5.8: Exemplo de Criação de Elementos Simulados

\subsection{Modos de Simulação}

As classes básicas necessárias para criar e iniciar uma simulação estão declaradas no pacote mobics.simulation. MOBICS implementa duas subclasses que definem os dois modos de simulação possiveis: a classe DetermSimulation, que define uma simulação determinística e a classe StochSimulation, que define uma simulação estocástica. Para criar uma simulação, o usuário deve estender uma dessas classes, de acordo com o modo de simulação desejado, e declarar os atributos e métodos necessários para a configuração da simulação.

Os elementos que compõem o ambiente simulado são declarados na forma de atributos da classe simulação estendida. Esta classe deverá implementar o método configure, que cria os objetos que representam os elementos de rede, define seus comportamentos dinâmicos e a topologia da rede desejada.

O usuário define o modo de simulação que irá utilizar no MoBICS definindo qual subclasse de Simulation será estendida. Por exemplo, para criar uma simulação estocástica o usuário deve estender a classe StochSimulation. O programa do usuário deve criar um objeto da classe de simulação implementada e chamar o método Simulation.start que inicia a simulação, conforme mostra o código abaixo.

Simulation simulation $=$ new MySimulation(); simulation.start();

As seções seguintes descrevem como os dois modos de simulação podem ser configurados.

\subsubsection{Modo Determinístico}

MoBICS implementa o modo de simulação determinístico proposto pela arquitetura de referência na seção 4.3. Para criar uma simulação determinística, o usuário deve estender a classe DetermSimulation e implementar o método script que descreve o script deter- 
minístico associado à simulação. A classe DetermSimulation declara uma série de interfaces que podem ser utilizadas para criar o script determinístico. Essas interfaces permitem a criação de pontos de sincronização, o controle das máquinas simuladas e o controle sobre a exibição dos eventos de simulação.

As etapas para criação e execução de um script determinístico são as seguintes:

1. Criar uma subclasse de DetermSimulation

2. Implementar os métodos conf igure e script. No método configure devem ser criados e configurados os objetos que compõem o ambiente simulado. O método script deve conter os comandos relativos ao script determinístico.

3. Criar um objeto da classe implementada e executar a simulação chamando o método start.

O código da figura 5.9 mostra um exemplo de um script determinístico. Um script é composto de chamadas às interfaces de simulação das máquinas, pontos de sincronização, comandos de depuração e comando adicionais criados pelo usuário para facilitar a avaliação da simulação. Uma chamada à interface de simulação de uma máquina simulada escalona o respectivo evento na camada de simulação da máquina, que irá decidir quanto ele será executado. Por exemplo, o método Mh.moveTo (Cell) escalona um evento de migração de uma estação móvel. Todos os eventos escalonados são executados antes do término de um passo de simulação. Como cada elemento simulado é implementado por um processo concorrente, a ordem de execução dos eventos por diferentes elementos simulados em um mesmo passo de simulação é indeterminado. Somente os eventos de um mesmo elemento simulado mantêm a ordem descrita no script.

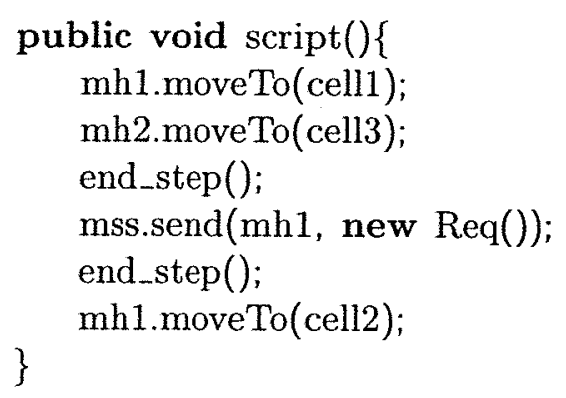

Figura 5.9: Exemplo de Script Determinístico

Os pontos de sincronização são criados com os métodos end_step e accept(Class). O método end_step termina um passo de simulação determinístico e é o único comando que não é executado concorrentemente. O comando accept (Element, Class) cria um ponto de sincronização local para recebimento de mensagens. Este comando recebe como parâmetros uma máquina simulada e a classe da mensagem para a qual o elemento aguardará o recebimento.

$\mathrm{Na}$ execução de um accept, a camada de simulação determinística processa todas as mensagens na fila de mensagens até encontrar e processar a mensagem do tipo desejado. Caso 
tal mensagem não seja encontrada mesmo após a fila ficar vazia, o comando accept fica bloqueado até que o elemento receba uma mensagem daquele tipo. Para evitar deadlocks, o comando é desbloqueado se nenhuma máquina simulada estiver ativa, ou seja, se todos as máquinas terminarem a execução dos comandos do passo corrente ou se estiverem bloqueadas em um accept.

Para garantir que o comportamento dos elementos no script seja determinístico, MoBICS entrega as mensagens em todas as filas de mensagens na ordem total. Caso seja necessário simular uma ordem de recebimento de mensagens diferente, deve-se utilizar o método changeOrderInQueue (Element, Class). Este método processa todas as mensagens na fila de mensagens até que seja encontrada uma mensagem do tipo Class, quando então ela é colocada no fim da fila. Caso a mensagem já seja a última mensagem da fila a ordem de processamentos das mensagens é mantida.

A saída do modo determinístico de simulação é um log dos eventos que ocorreram durante a simulação, com o qual o usuário pode identificar se o protocolo funcionou corretamente ou não. Este log inclui as mensagens internas dos protocolos, verificação do conteúdo de atributos e geração de exceções. Por exemplo, quando um comando accept(Element, Message) é desbloqueado sem que a mensagem seja processada, o MoBICS exibe uma mensagem ao usuário indicando o erro. Entretanto, esta situação não é suficiente concluir que o protocolo está incorreto, uma vez que esta pode ter sido causada por um script mal programado.

Para auxiliar na avaliação do protocolo, o MoBICS provê um comando changeShowMode com o qual o usuário pode habilitar ou desabilitar a exibição de mensagens durante a ocorrência de eventos na simulação, como envio e recebimento de mensagens. Deste modo, o usuário pode requisitar que sejam exibidos no log apenas os eventos relevantes para a simulação.

\subsubsection{Modo Estocástico}

No modo estocástico de simulação, MoBiCS executa uma simulação exaustiva nos protocolos distribuídos, com o objetivo de avaliar o desempenho do protocolo em um cenário aleatório e mais realístico. Com esse modo de simulação é possível também observar o comportamento do protocolo em cenários maiores e exaustivos, cuja descrição é impraticável através de scripts determinísticos. Isso permite avaliar melhor a estabilidade do protocolo.

A diferença básica da simulação determinística para a estocástica é a forma como o cenário de simulação é descrito. Enquanto que na simulação determinística o usuário descreve um cenário bem específico e determinístico, na simulação estocástica o usuário deve descrever os padrões de comportamento dinâmico de todos os elementos de rede: máquinas fixas e móveis e canais de comunicação. Por exemplo, as invés de colocar explicitamente no script comandos mh .moveTo (cell) para realizar uma migração de uma estação móvel, na simulação estocástica o usuário deve indicar com qual freqüência a estação móvel migra de célula. $\mathrm{O}$ usuário programa esses padrões de comportamento utilizando o modelo de programação descrito na seção 5.6. Diferentemente do modo determinístico, o modo estocástico utiliza a noção de tempo simulado e atribui timestamps a todo evento de simulação. 
Após definidos os modelos e parâmetros de simulação dos elementos, devem ser seguidas as seguintes etapas para criação e execução de uma simulação estocástica:

1. Criar uma simulação estocástica através de uma subclasse de StochSimulation.

2. Criar objetos dos modelos de simulação criados, passando-os como parâmetro dos construtores dos canais e elementos simulados. Todos esses objetos devem ser criados na classe StochSimulation.

3. Na código do usuário, invocar o método StochSimulation. start, que inicia a simulação.

\subsection{Programação de Modelos de Simulação}

A programação de modelos de simulação no MoBICS baseia-se em três abstraçães: gerador de eventos, atraso de comunicação e mobilidade. Um gerador de eventos (seção 5.6.2) é uma classe que indica como os eventos são gerados durante a simulação. $\mathrm{O}$ atraso de comunicação (seção 5.6.1) define o comportamento dos canais de comunicação como função do tempo de envio de uma mensagem pelo canal. Essas duas abstrações são incorporadas a um elemento simulado na forma de parâmetros do seu construtor. A figura 5.10 mostra um trecho de código no qual é declarado um objeto mh que implementa uma estação móvel simulada. Neste código, a classe MySimulationModel define um modelo de simulação e p1, p2 e p3 os parâmetros de simulação.

$\mathrm{mh}=$ new MyMh("Mh", sim, new MySimulationModel(p1,p2,p3));

Figura 5.10: Atribuição de um Modelo de Simulação a um Elemento Simulado

A mobilidade (seção 5.6.3) define abstrações sobre a localização e movimentações de estações móveis. A seção 5.6.3 discute a programação dessas abstrações.

\subsubsection{Modelos de Simulação para Canais de Comunicação}

A função de um modelo de simulação para canais de comunicação é definir o atraso associado ao envio de uma mensagem. Este modelo é implementado pela classe LinkSimModel, que declara o método delaySend (NetMessage) responsável pelo cálculo do atraso de envio da mensagem pelo canal de comunicação. Esse valor retornado é utilizado pela camada de simulação para atualizar o valor do timestamp da mensagem quando ela for entregue ao destinatário. Caso a mensagem deva ser perdida, o método deverá retornar um atraso infinito.

Para programar um modelo de simulação para canais, o usuário deve criar uma subclasse de LinkSimModel e implementar o respectivo método delaySend (NetMessage). 
O programador do modelo de simulação define a complexidade do seu modelo, de acordo com as características que deseja simular. Tipicamente, o método delaySend (NetMessage) retorna um valor proporcional ao tamanho da mensagem enviada, que pode ser determinada pelo método Message.getContentSize. Um dos parâmetros típicos de simulação é o throughput do canal.

Para canais de comunicação sem fio, o modelo de comunicação deve ser implementado a partir da classe WirelessLinkSimModel. Esta classe define um método delaySend (Location, Location, NetMessage) e o programador do modelo pode definir o atraso de envio da mensagem baseado também na distância entre o remetente e o destinatário da mensagem, definidos em parâmetros do tipo Location.

\subsubsection{Modelos de Simulação para Elementos}

Em uma simulação estocástica, uma máquina simulada pode se comportar ativamente ou passivamente. Uma máquina ativa produz eventos internos que modificam o seu estado e/ou a forma como ela interage com o restante da rede. Esses comportamentos podem ser o envio de requisições, migrações, etc. Uma máquina passiva não gera nenhum evento durante a simulação e apenas executa ações quando recebe mensagens que podem ser tratadas por seus protocolos.

Para definir uma máquina ativa é necessário implementar um gerador de eventos. No caso de máquinas passivas, o gerador de eventos é nulo (objeto nullEventGenerator).

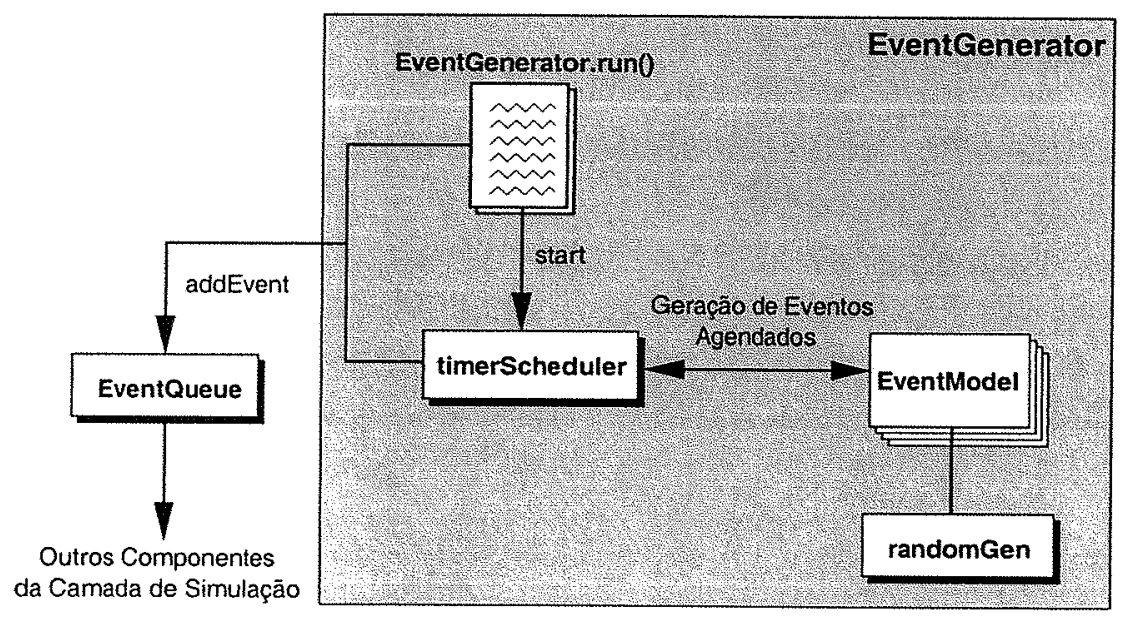

Figura 5.11: Componentes de um Gerador de Eventos

A figura 5.11 mostra o diagrama básico de um gerador de eventos. O modelo de simulação é implementado em uma subclasse de EventGenerator (figura 5.12). Esse gerador de eventos é responsável por criar os eventos de simulação internos da máquina e adicioná-los à fila de eventos EventQueue. Esses eventos são retirados da fila pela camada de simulação e processados de acordo com sua ordem. 


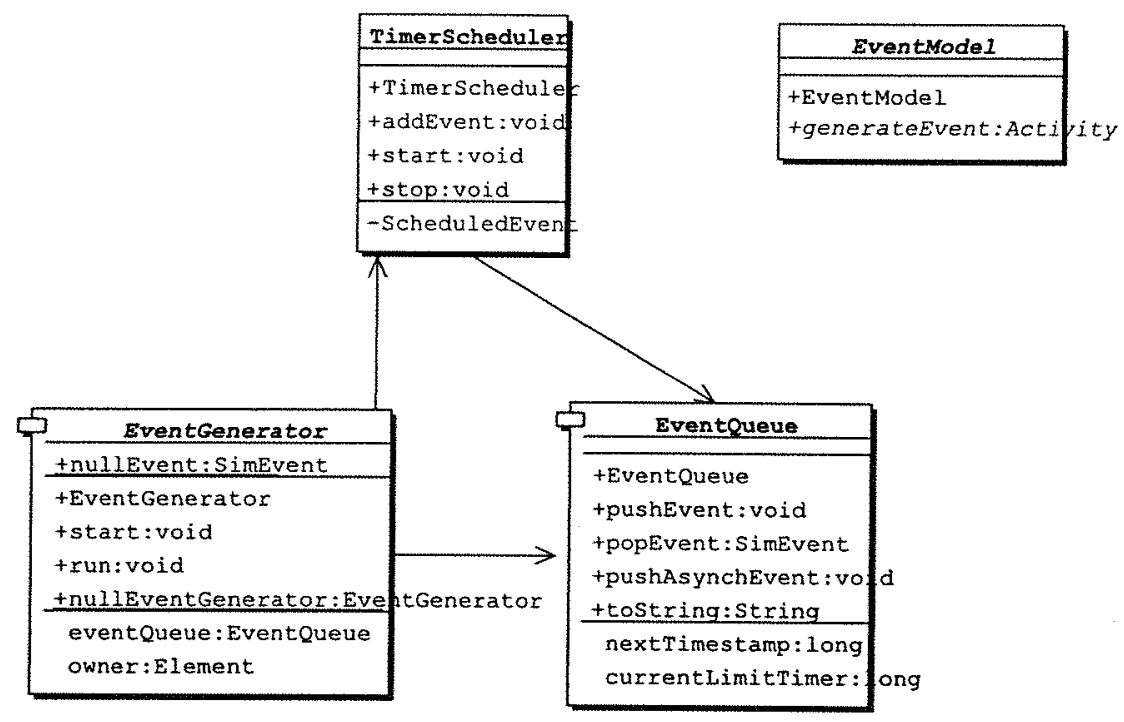

Figura 5.12: Principais Classes do Pacote mobics.simulation.models

Um evento de simulação é um objeto da classe SimEvent e que contém dois atributos: o timestamp e o evento propriamente dito, que é um objeto de uma subclasse de Activity, declarado no pacote mobics.controller. A geração dos eventos é feita no método run do gerador de eventos. Há duas formas de fazê-lo: adicionando os elementos da fila de eventos já ordenados segundo o seu timestamp (método EventQueue . pushEvent (SimEvent)) ou adicionar os eventos fora de ordem (método EventQueue.putAsynchEvent (SimEvent)) e depois indicar o término da geração de eventos ou um timestamp limite, que sinaliza até onde os eventos estão ordenados (método EventQueue.setCurrentLimitTimer(long)).

O timerScheduler auxilia o programador a definir a geração periódica de eventos. O programador do modelo de simulação pode adicionar um modelo de geração de um evento, subclasse de EventModel, ao timerScheduler informando a periodicidade de geração do eventos. Nestes intervalos, o timerScheduler executa o método EventModel.generateEvent(Element) que irá retornar um novo evento de simulação (por exemplo uma nova migração) ou um null, indicando que nenhum evento deve ser gerado naquele timestamp.

Para a implementação do modelo de simulação para um ambiente devem ser seguidos o seguintes passos:

1. Definir todos os parâmetros de simulação e como os eventos serão gerados a partir desses parâmetros.

2. Implementar subclasses de LinkSimModel que define os modelos de simulação dos canais de comunicação e os respectivos métodos delaySend(NetMessage).

3. Implementar subclasses de EventGenerator que definem os modelos de simulação para cada máquina simulada. A programação da geração dos eventos pode ser feita de duas formas: 
(a) Declarar uma subclasse de EventModel para cada tipo de evento a ser gerado periodicamente e implementar seu método EventModel.generateEvent (Element)

(b) Adicionar todos os modelos de eventos criados acima no timerScheduler, no código do construtor do EventGenerator indicando a periodicidade na qual a geração de cada evento deve ser acionada.

\section{$\mathrm{OU}$}

(a) Modificar o método run do gerador de eventos, indicando todos os eventos a serem incluidos na EventQueue e modificar o timestamp limite dos eventos ordenados, quando for necessário.

No capítulo 6 há um exemplo completo de programação de modelos de simulação para o protocolo RDP.

\subsubsection{Modelo de Mobilidade}

A programação de modelos de mobilidade para estações móveis envolve a criação de geradores de eventos MoveTo, a implementação da classe Location e a definição do mapeamento de uma localização para uma célula.

O gerador de eventos MoveTo é o principal componente do modelo de mobilidade. Ele define como serão geradas as migrações a partir dos parâmetros de simulação da estação móvel. Um gerador de eventos de migração é construído utilizando o mesmo modelo de programação discutido na seção 5.6.2, no qual deve-se estender a classe EventModel e programar como os eventos serão gerados.

A classe Location define uma abstração para localização. Todo evento MoveTo deve ser feito para uma localização definida por um objeto da classe Location. A própria classe Cell, que implementa uma célula, é uma subclasse de Location.

O último componente do modelo de mobilidade é o mapeamento de uma localização para célula, ou seja, como um objeto da classe Location é mapeado para uma célula. Para isso, o usuário deve estender a classe MobilityModel e implementar o método MobilityModel.whichCell(Location), que retorna para um objeto Location qualquer a correspondente célula associada àquela localização. A classe MobilityModel e os objetos Location utilizados durante a simulação devem estar sempre consistentes, de maneira que ele sempre seja capaz de identificar corretamente qual a classe concreta que define a localização. Diferentes modelos de mobilidade podem utilizar diferentes e incompatíveis abstrações para localização.

Para definir um modelo de simulação para uma estação móvel, deve-se estender a classe MhEventGenerator, subclasse de EventGenerator, que fornece o modelo de mobilidade (MobilityModel) utilizado ao ser invocado o método MhEventGenerator getMobiModel. Quando um Mh é criado, o seu construtor verifica se existe um gerador de eventos da classe MhEventGenerator definida para o objeto e guarda uma referência para o seu 
modelo de mobilidade. Em toda a migração, quando o simulador executa o método Mh . onMoveTo(Location) ele atualiza a localização da estação móvel e inicia o hand-off caso o método MobilityModel. whichCell (Location) indique que a nova localização da estação móvel corresponde a uma célula diferente da anterior.

Nenhum desses componentes é obrigatório para definir o comportamento de uma estação móvel. É possível definir apenas a geração de eventos de migração, estendendo diretamente a classe EventGenerator. Assim, o programador do modo de simulação pode definir o grau de abstrações adequado à sua simulação.

\subsubsection{Discussão}

\section{Modelos de Canais Sem Fio}

O método delaySend(NetMessage, Location, Location) permite ao programador escolher o nível de complexidade do modelo de comunicação sem fio. Neste modelo podem ser incorporadas quaisquer características dinâmicas que possam ser descritas com função dos parâmetros do método e a partir dos quais possa ser calculado o atraso de envio da mensagem.

Por exemplo, Nguyen [74] apresenta um conjunto de experimentos que avalia a relação entre as várias características dinâmicas de um canal sem fio e apresenta um modelo analítico para essas relações. Uma das relações modeladas foi a influência da taxa de erros na taxa de transmissão efetiva de pacotes. Os modelos analíticos produzidos foram utilizados em [22] para modelar as características dos canais sem fio. Apesar de complexo, esse modelo pode ser reproduzido no MOBICS apenas com o uso do método delaySend(NetMessage, Location, Location).

\section{Modelos de Mobilidade}

Uma vantagem da abordagem de programação de modelos de mobilidade é a divisão da mobilidade em componentes globais e locais. A componente local corresponde à geração de eventos MoveTo, que pode ser definida diferentemente para cada estação móvel simulada. A componente global corresponde ao mapeamento entre localizações e células, que permite modelar aspectos do modelo de mobilidade compartilhados por todo o ambiente, como abstrações de localização, restrições à mobilidade e granularidade de migrações. Outra vantagem dessa abordagem é a possibilidade de definir diferentes modelos de mobilidade para as estações móveis. A maioria dos simuladores e ambientes, quando possibilita a escolha de diferentes modelos de mobilidade não o faz de forma programável como no MoBICS.

\section{Resumo}

MoBiCS é uma biblioteca Java que permite a implementação de protocolos e sua experimentação em um ambiente de computação móvel simulado. Para criar uma simulação, o 
usuário deve estender um conjunto de classes básicas implementadas pelo pacote, configurar sua simulação e compor um conjunto de objetos dessas classes.

O modelo de programação de protocolos proposto pela arquitetura de referência foi implementado no MOBICS baseando-se no modelo de programação Java. Micro-protocolos são declarados em interfaces Java que declaram os métodos que definem seus tratadores de eventos. Um protocolo é uma classe que implementa um conjunto de micro-protocolos. O modelo de execução dos protocolos é sequencial e os tratadores de eventos são executado atomicamente.

Todos os modos de simulação são configurados por meio de extensão de classes, pela qual é possível definir a configuração do ambiente de rede que deve ser simulado. O modelo de simulação de um elemento simulado é um objeto que define como serão gerados os eventos de simulação dinâmicos durante a simulação. $O$ usuário também estende classes básicas do pacote MOBICS para definir tais modelos.

O capítulo seguinte apresenta um exemplo de utilização do MoBICS na implementação e simulação de um protocolo de entrega de respostas a clientes móveis. 


\section{Capítulo 6}

\section{Exemplo de Uso do MobiCS}

Este capítulo descreve um exemplo de programação de um protocolo distribuído e simulação no MoBiCS. O protocolo utilizado no exemplo é um protocolo de entrega de respostas a clientes móveis (RDP), descrito anteriormente na seção 3.3.1. A seção 6.1 descreve como o protocolo foi implementado no modelo de programação de protocolos do MoBICS. As seções 6.2 e 6.3 descrevem a simulação determinística e estocástica do protocolo, respectivamente, e os resultados obtidos. Estas duas seções descrevem a realização das etapas de 2 a 6 para simulação de protocolos, descritas na seção 5.2, para cada um dos modos de simulação. $O$ apêndice $A$ apresenta os principais arquivos Java resultantes da implementação e simulação do protocolo.

\subsection{Implementação do Protocolo RDP}

Para resolver o problema de entrega de respostas de requisições feitas por clientes móveis, o protocolo RDP mantém estruturas de dados nas estações base que armazenam os proxys com as requisições pendentes. Para cada estação móvel que faz uma requisição, o protocolo cria um proxy na sua corrente estação base. Este proxy mantém o registro da atual localização da estação móvel e para o qual a resposta do servidor deve ser reencaminhada.

O protocolo RDP foi implementado no pacote sidam.rdp e suas mensagens foram declaradas no subpacote sidam.rdp.messages. A classe RdpProxysTable implementa a estrutura de dados na estação base que armazena os proxys locais e o endereço de todas as estações base que contêm proxys para suas as estações móveis locais. Cada entrada nessa tabela é um objeto da classe RdpProxys que armazena todas as requisições feitas pela estação móvel.

Cada objeto RdpProxys armazena a identificação da estação móvel associada aos pro$x y s$, a localização corrente da estação móvel (após último hand-off completado), a lista das requisições criadas na estação base pela estação móvel e o endereço das estações base que contêm proxys não locais do cliente móvel.

Quando uma estação móvel entra em uma célula, o processo de hand-off é iniciado e o 
protocolo da estação base adiciona o seu endereco na tabela RdpProxysTable. O protocolo então requisita a lista de proxys da estação móvel à sua antiga estação base e a insere na tabela.

Na tabela 6.1 estão relacionadas todas as possíveis mensagens utilizadas pelo protocolo durante sua execução, com seu correspondente significado.

\begin{tabular}{|c|c|c|}
\hline Mensagens & Participantes & Significado \\
\hline Greet & $\overline{M h \rightarrow M s s}$ & Entrada de um $M h$ na célula. \\
\hline Req & $M h \rightarrow M s s ; M s s \rightarrow$ Server & Requisição para server \\
\hline ForwardRes & $M s s \rightarrow M h ; M s s \rightarrow M s s$ & Resposta da requisição de um $M h$ \\
\hline Ack & $M h \rightarrow M s s ; M s s \rightarrow M s s$ & $\begin{array}{l}\text { Confirmação de recebimento de respos- } \\
\text { ta por um } M h \text {. }\end{array}$ \\
\hline RemPList & $M s s \rightarrow M s s$ & Remoção da lista de proxys em MSSs. \\
\hline UpdateCurrLoc & $M s s \rightarrow M s s$ & $\begin{array}{l}\text { Atualização do endereço da célula cor- } \\
\text { rente de Mh. }\end{array}$ \\
\hline DeReg & $M s s \rightarrow M s s$ & $\begin{array}{l}\text { Desregistro dos proxys de } M h \text { ar- } \\
\text { mazenados em um } M \text { ss. }\end{array}$ \\
\hline PList & $M s s \rightarrow M s s$ & $\begin{array}{l}\text { Envio de lista de proxys de } M s s_{\text {old }} \text { para } \\
\text { o novo } M s s \text { responsável pelo } M h \text {. }\end{array}$ \\
\hline
\end{tabular}

Tabela 6.1: Mensagens utilizadas pelo protocolo RDP.

O protocolo possui duas instâncias funcionais, uma para estações base e outra para estações móveis. A primeira delas é a que implementa a maior parte do algoritmo do protocolo. Para efeito de simulação, foi criada uma terceira instância (servidor) que implementa um protocolo trivial que responde a requisições de estações móveis. A figura 6.1 ilustra os micro-protocolos que implementam o RDP e as mensagens trocadas entre eles.

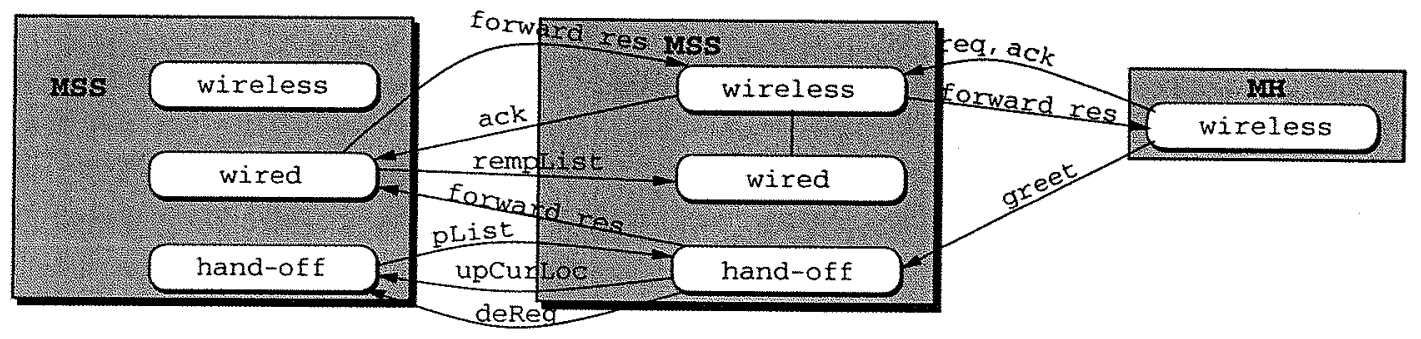

Figura 6.1: Diagrama de Comunicação entre os Módulos do RDP

\subsubsection{Declaração das Mensagens}

O pacote sidam.rdp.messages declara todas as mensagens utilizadas pelo protocolo. A mensagem Ack foi implementada nas classes Ack_Mh e Ack_Mss, que implementam um Ack en- 
viado por uma estação móvel e por uma estação base, respectivamente. A declaração das duas classes é necessária porque são protocolos diferentes que tratam cada uma das mensagens. Isso também ocorre com a mensagem ForwardRes. A figura 6.2 mostra a código que implementa a mensagem Ack_Mh. Estas tarefas correspondem aos passos 1 e 2 de implementação de protocolos enunciados na seção 5.3 .

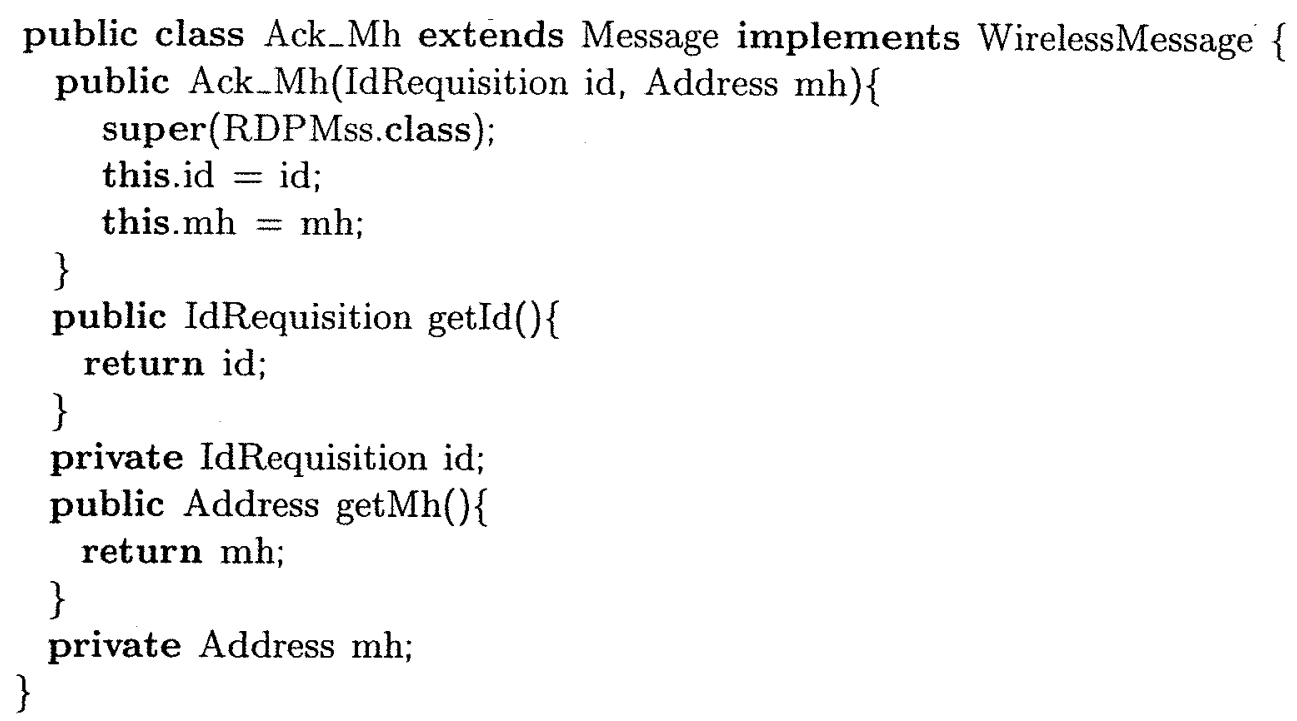

Figura 6.2: Implementação da Mensagem Ack_Mh

As classes Request e Res implementam uma requisição do cliente e uma resposta de requisição, respectivamente. Estas mensagens são encapsuladas em outras mensagens do protocolo RDP durante a execução do protocolo. A seção A.1 apresenta um diagrama completo com todas a mensagens declaradas para o protocolo RDP.

\subsubsection{Implementação dos Micro-Protocolos}

A classe RDPMss implementa a instância funcional do protocolo RDP para estações base, que é composta dos micro-protocolo definidos pelas interfaces Java RDPWireless, RDPWired e RDPHandoff. A declaração dessas interfaces corresponde ao passo 3 de implementação de um protocolo, enunciado na seção 5.3, e a implementação da classe RDPMss corresponde aos passos 4 e 5 para a instância do protocolo para estações base. O código da figura 6.3 mostra a estrutura da classe RDPMss, com os tratadores do micro-protocolo de hand-off. O código completo deste protocolo encontra-se na seção A.3.

A figura 6.4 mostra o código do tratador da mensagem Ack_Mh, implementado no método RDPMss . whenAck_Mh (Message). O método verifica na tabela de proxys se o proxy da requisição está armazenado na estação base. Neste caso, a mensagem Ack_Mss é enviada para o servidor e uma mensagem RemPList é difundida para todos as demais estações base. Caso o proxy não seja local, o método envia a mensagem Ack_Mss para a estação base que o armazena. 


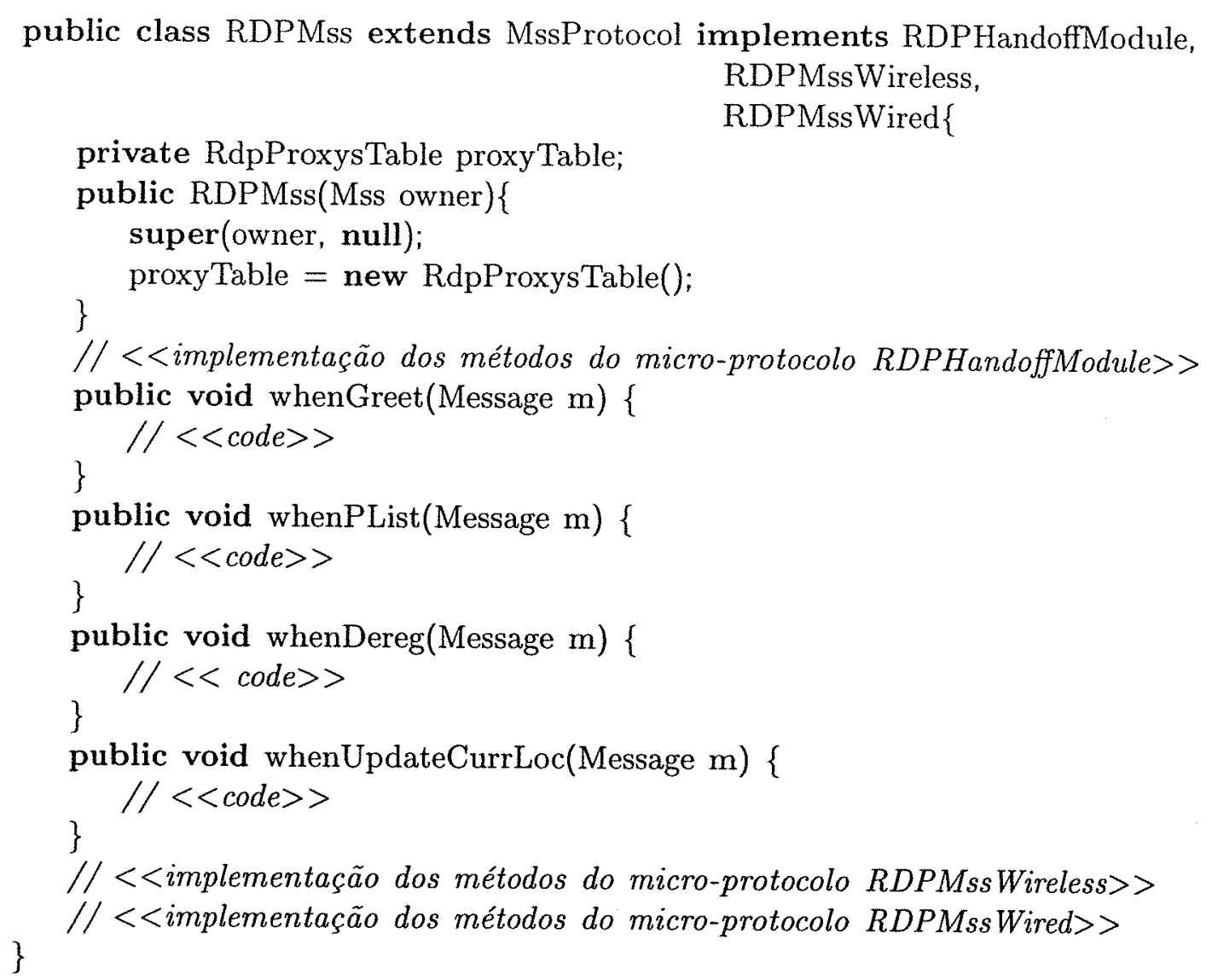

Figura 6.3: Estrutura da Classe RDPMss

A instância funcional do RDP para estações móveis implementa apenas o micro-protocolo RDPMhWireless, responsável pelo envio de mensagens pelo meio sem fio, que essencialmente consiste de um tratador para a mensagem ForwardRes.

\subsection{Simulação Determinística do RDP}

Como um exemplo de simulação determinística do RDP foi escolhido um cenário que testa a consistência do protocolo quanto a duas propriedades: a entrega da resposta à unidade móvel requisitante independementemente de sua localização e a capacidade de atualizar corretamente as estruturas de dados do protocolo independentemente da duração de um hand-off. A implementação e execução desta simulação segue os passos de 1 a 3, descritos na seção 5.5.1. Esta seção descreve basicamente o passo 3, no qual a simulação é implementada.

Para testar a primeira situação, foi reproduzido o cenário da figura 6.5. O cenário é composto de cinco elementos: Mh que é o cliente móvel, server, um servidor capaz de responder a requisições de clientes, e as estações base MSSp, MSSo e MSSn. O script determinístico foi elaborado para reproduzir a situação na qual Mh migra para a célula de MSSn após MSSp enviar 


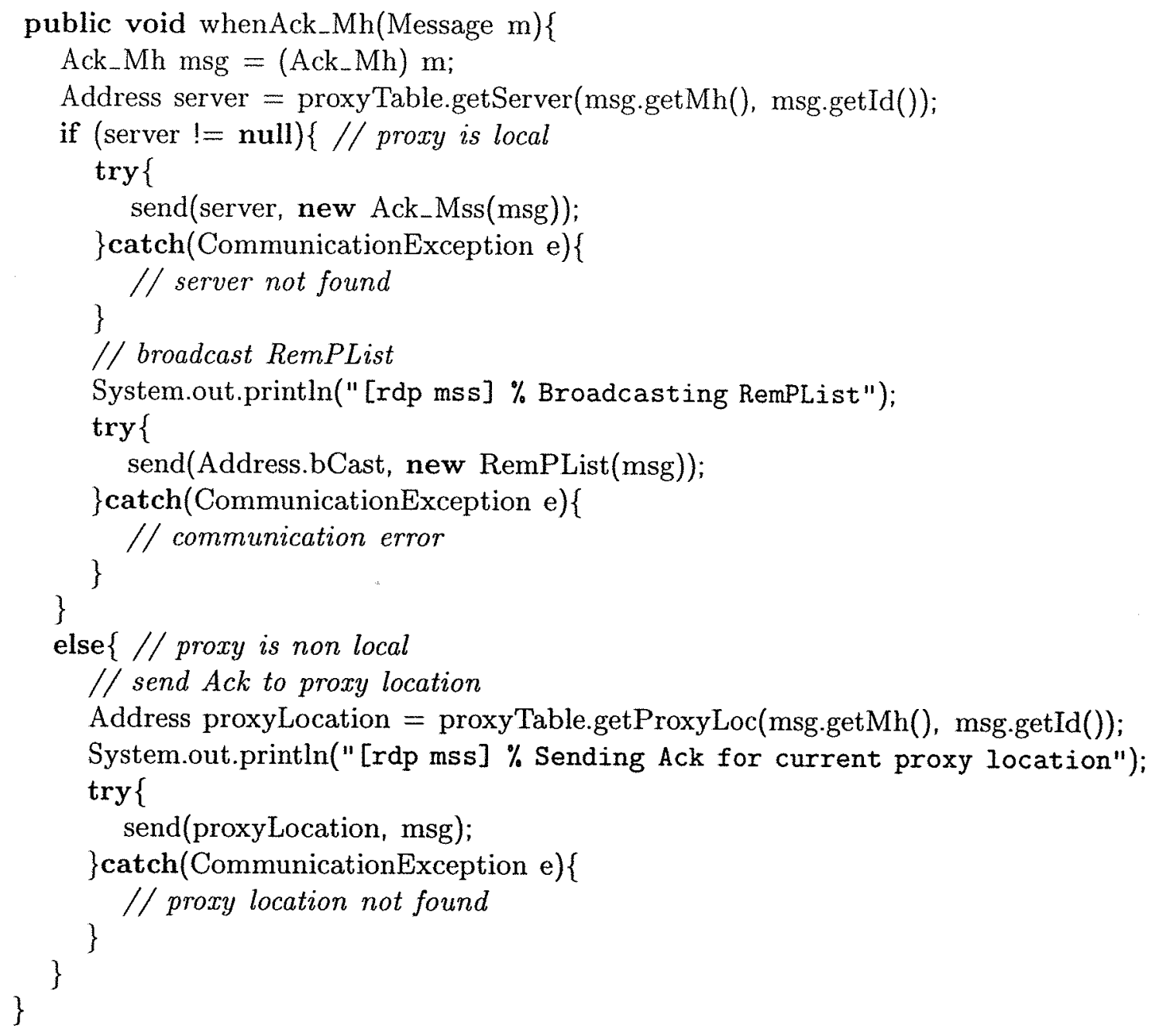

Figura 6.4: Implementação do Tratador da Mensagem Ack

a mensagem ForwardRes para MSSo e antes de começar o hand-off do Mh.

A figura 6.6 mostra o código do script, que implementa o cenário determinístico desejado. O script corresponde à implementação do método MySimulation.script, onde MySimulation é a classe que implementa a simulação determinística. Para reproduzir a situação na qual Mh migra da célula de MSSo para a do MSSn antes de receber a mensagem ForwardResult, o script utiliza o recebimento da requisição pelo servidor como instante para sincronizar os eventos. No script da figura 6.6, o modo de aceitação de mensagens de server permanece desligado (comando acceptTurnon (server, false) até que o fim do passo de simulação no qual ocorre a migração de Mh do MSSo para MSSn. Para evitar que neste passo ocorra o hand-off de Mh, o modo de aceitação de mensagens de MSSn também é desligado. No passo de simulação seguinte, server é habilitado a processar a mensagem request, fazendo com que MSSo receba a mensagem ForwardRes e tente enviá-la (sem sucesso) para Mh. No último passo de simulação, MSSn é habilitado a processar a mensagem Greet de Mh e ocorre 


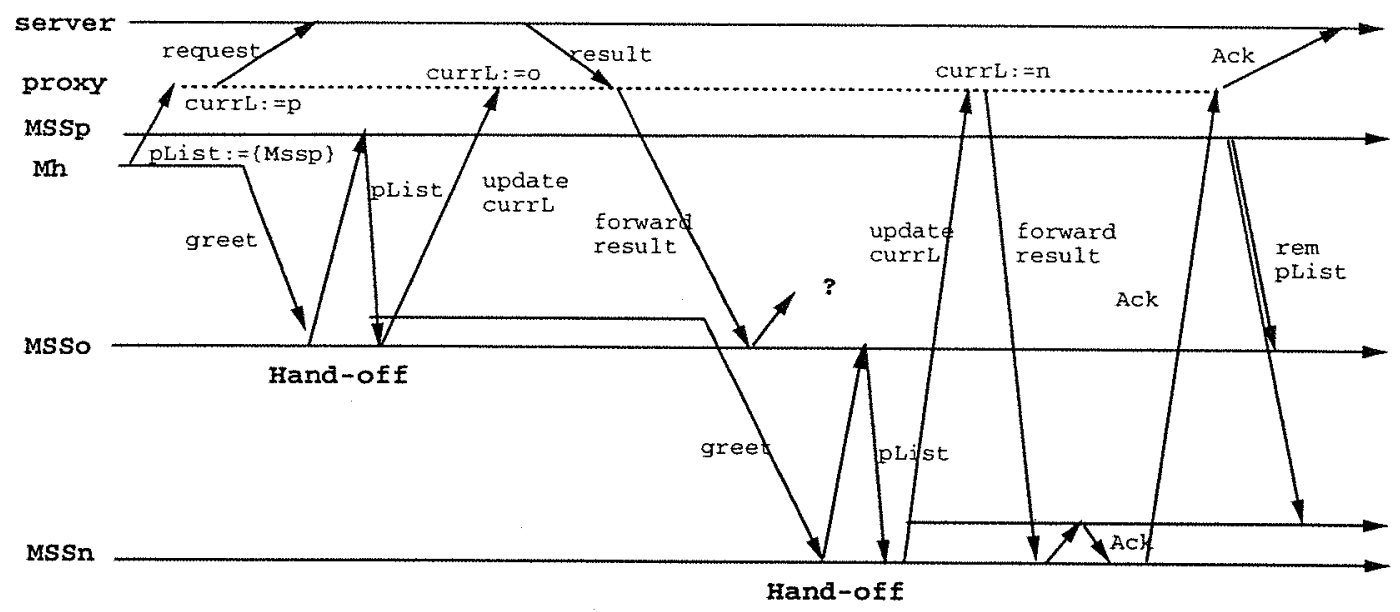

Figura 6.5: Cenário de Teste Determinístico do Protocolo RDP

o hand-off da estação móvel.

A saída da execução desse script é o log de eventos gerados pelo código do protocolo e pelo simulador. A figura 6.7 mostra esse log para o script utilizado, que exibe comentários internos ao código do protocolo, indicando as ações realizadas, e a indicação de cada migração do Mh feita pelo próprio simulador. O usuário define o tipo e a quantidade de eventos desejadas no $\log$ da simulação.

Com comandos no script, o usuário pode requisitar a exibição ou ocultamento de mensagens que indicam ocorrências dos eventos de recebimento, envio e processamento de mensagens, migração e início de um novo passo de simulação. Para efeito de simplificação, no exemplo da figura 6.6 poucas mensagens são mostradas.

Essas mensagens são úteis para identificar se a execução do protocolo foi correta, ou seja, se o protocolo teve o comportamento esperado para o cenário do script. Outras informações bastante úteis ao usuário são as exceções geradas na simulação. No exemplo anterior, nenhuma exceção nenhuma exceção ocorreu porque o protocolo executou corretamente e o script foi programado de acordo com o funcionamento correto do protocolo. As exceções geradas durante a simulação podem indicar comandos accepts que não puderam ser concluídos. $O$ próprio código dos protocolos pode gerar exceções que indiquem violações às suas assertivas, além das exceções em tempo de execução de Java.

\subsection{Simulação Estocástica do RDP}

A simulação estocástica permite avaliar o desempenho de protocolos a partir de experimentos em cenários aleatórios, e determinar deficiências e propriedades do protocolos do ponto de vista do seu desempenho. Na simulação estocástica, o desempenho do protocolo RDP pode ser avaliado em função de duas informações: 


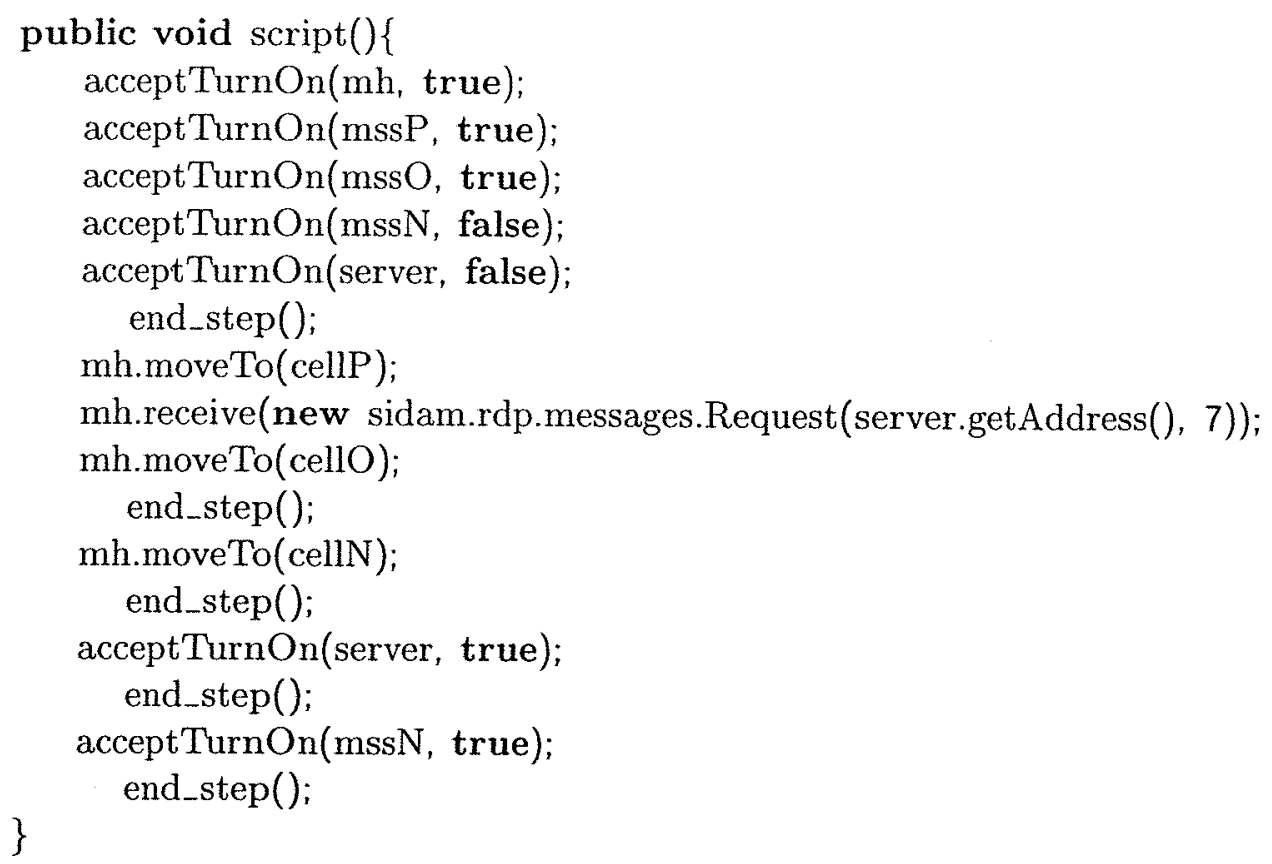

Figura 6.6: Implementação do Script Determinístico do Cenário do RDP

- Número total de mensagens ForwardRes reenviadas para estações móveis até o recebimento da confirmação Ack_Mh. O número de reenvios de ForwardRes indica a sobrecarga provocada na rede pela migração das estações móveis.

- Tamanho médio da estrutura de dados PList, que mantém a lista de proxys de uma estação móvel. Essa informação indica a sobrecarga de mensagens na rede de acordo com o número de requisições e migrações das estações móveis.

Esta seção mostra um exemplo de simulação estocástica do protocolos RDP, no qual foi analisada a influência da mobilidade no número de mensagens ForwardRes enviadas pelo protocolo.

\subsubsection{Modelo de Simulação}

O modelo de simulação estocástico definido para o protocolo RDP contém cinco componentes [27]: atraçâa, mobilidade, vizinhança entre células, qualidade da comunicação sem fio e padrẫo de requisições. Essas componentes possuem o seguinte significado:

Atração Cada célula possui um parâmetro chamado atração que indica a probabilidade de cada estação móvel estar localizada na sua região. A atração indica para quais células as estações móveis migram com maior e menor frequência.

Mobilidade $\mathrm{O}$ coeficiente de mobilidade especifica a probabilidade de migração de uma estação móvel para uma célula qualquer. 


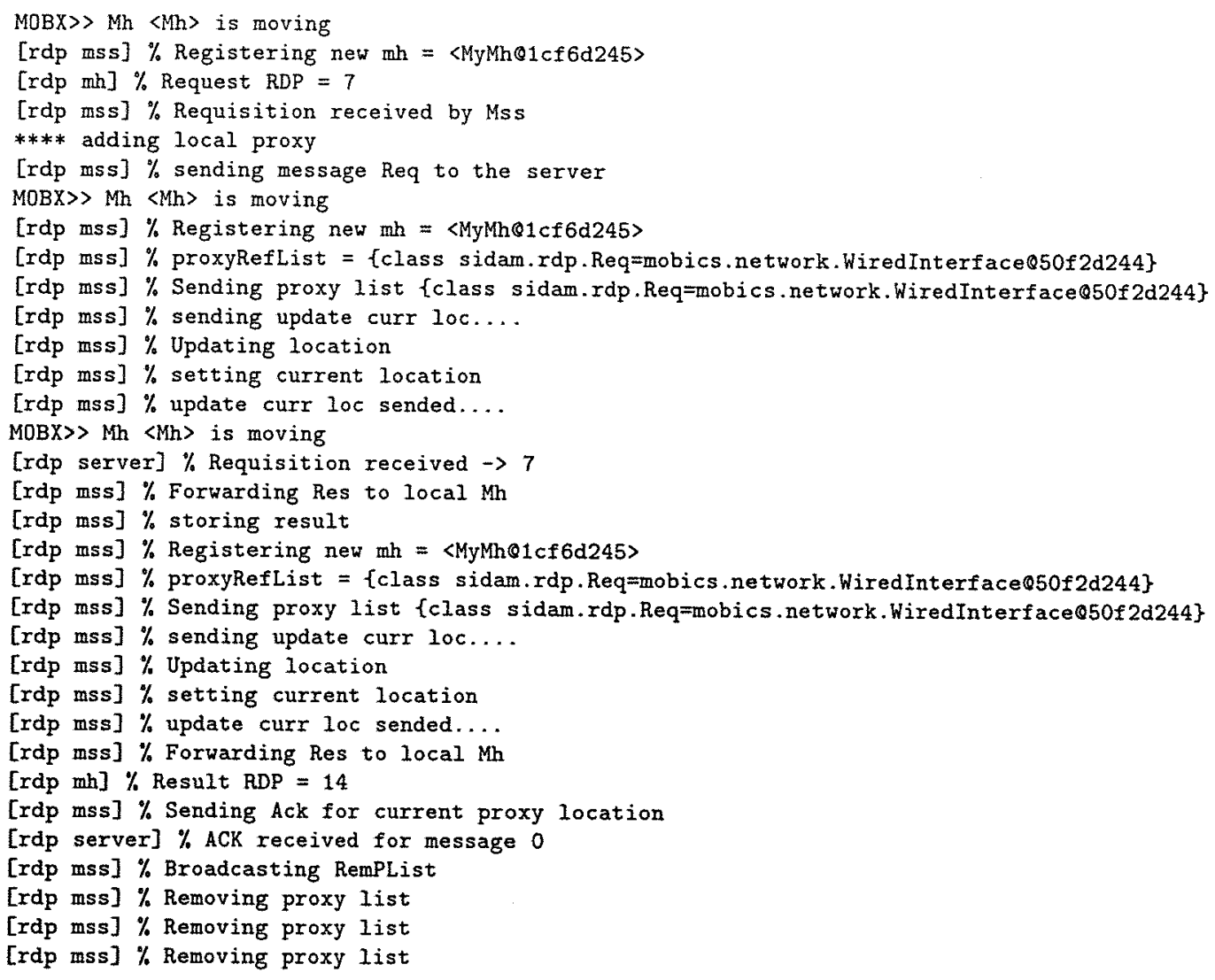

\section{Figura 6.7: Saída Parcial da Simulação Determinística}

Vizinhança entre Células Um grafo que indica a relação de vizinhança entre as células. A atração e a vizinhança entre as células definem a próxima célula visitada por uma estação móvel.

Qualidade da Comunicação sem Fio A qualidade da comunicação sem fio exprime a taxa efetiva de envio de dados pelo canal sem fio, em função do tamanho da mensagem enviada.

Padrão de Requisições Exprime a taxa com que a camada de aplicação faz requisições ao protocolo RDP.

A atração e o coeficiente de mobilidade definem o tempo médio de permanência das estações móveis nas células.

\subsubsection{Implementação da Simulação}

Para implementar a simulação determinística do RDP foram implementadas uma subclasse de StochSimulation, que implementa a simulação em si, e subclasses de EventGenerator, que implementam os modelos de simulação para os elementos simulados. 
A classe EventGenerator define um modelo de simulação para elementos simulados. Para cada elemento simulado deve ser criado um objeto dessa classe que gerará os eventos de simulação internos, tais como migrações (classe MigrationEventModel) e requisições (classe RequestModel).

De acordo com o modelo de simulação apenas estações móveis geram eventos. A classe MhEventModel, (subclasse de EventGenerator) implementa o modelo de simulação para as estações móveis, em função dos parâmetros mobilidade e do padrão de requisiçôes, mencionados anteriormente.

A geração de cada tipo de evento foi implementada em subclasses de EventModel. A classe MigrationEventModel implementa o modelo de migração das estações móveis, ou seja, como são gerados eventos de migração durante a simulação. Conforme o modelo de simulação definido, um evento de migração é gerado de acordo com o coeficiente de migração associado à estação móvel. O objeto EventGenerator de uma estação móvel cria um objeto da classe MigrationEventModel, e com o auxílio da classe TimerScheduler agenda o teste periódico de geração desse evento para um período de tempo simulado específico.

Durante a simulação, o objeto MigrationEventModel verifica se uma migração deve ocorrer tendo como parâmetro o coeficiente de mobilidade da estação móvel. Em caso afirmativo, o objeto obtém a lista das células vizinhas da célula corrente da estação móvel e determina, a partir da atração de cada célula, a probabilidade relativa de migração para cada uma delas, incluindo a célula corrente. A partir dessas probabilidade, o objeto da classe MigrationEventModel define para qual célula a estação móvel deve migrar. Caso a célula escolhida para migração tenha sido a célula corrente, o evento de migração não é gerado.

A classe RequisitionModel implementa o modelo de geração de requisições de uma estação móvel ao protocolo RDP, a partir da probabilidade de requisições definida para a simulação. A classe WILinkSimModel implementa o modelo de qualidade de comunicação sem fio, que retorna o atraso de envio da mensagem.

Para definir o número de células e a vizinhança entre elas, o usuário informa a dimensão $m \times n$ da matriz de células escolhida para a simulação. No modelo adotado, as células possuem um formato hexagonal e sua disposição na matriz define a vizinhança entre células. A figura 6.8 ilustra a matriz de vizinhança construída para uma simulação. No exemplo da figura, a célula $A$ é vizinha de $B, D$ e $E$, e a célula $B$ é vizinha de $A, C, E$ e $F$. A vizinhança de cada célula pode ser determinada a partir da sua posição na matriz de vizinhança $m \times n$.

O último passo para implementação da simulação é a criação da classe MyStochSimulation (subclasse de StochSimulation) que declara e inicializa os elementos simulados.

Para determinar número de mensagens ForwardRes reenviadas, a classe MyMss reimplementa os métodos Mss.onReceive(NetMessage) e Mss.onSend(NetMessage). Estes métodos atualizam variáveis globais durante o envio e recebimento das mensagem, que guardam as informações desejadas.

A seção A.5 apresenta a implementação completa da simulação estocástica do protocolo RDP. 


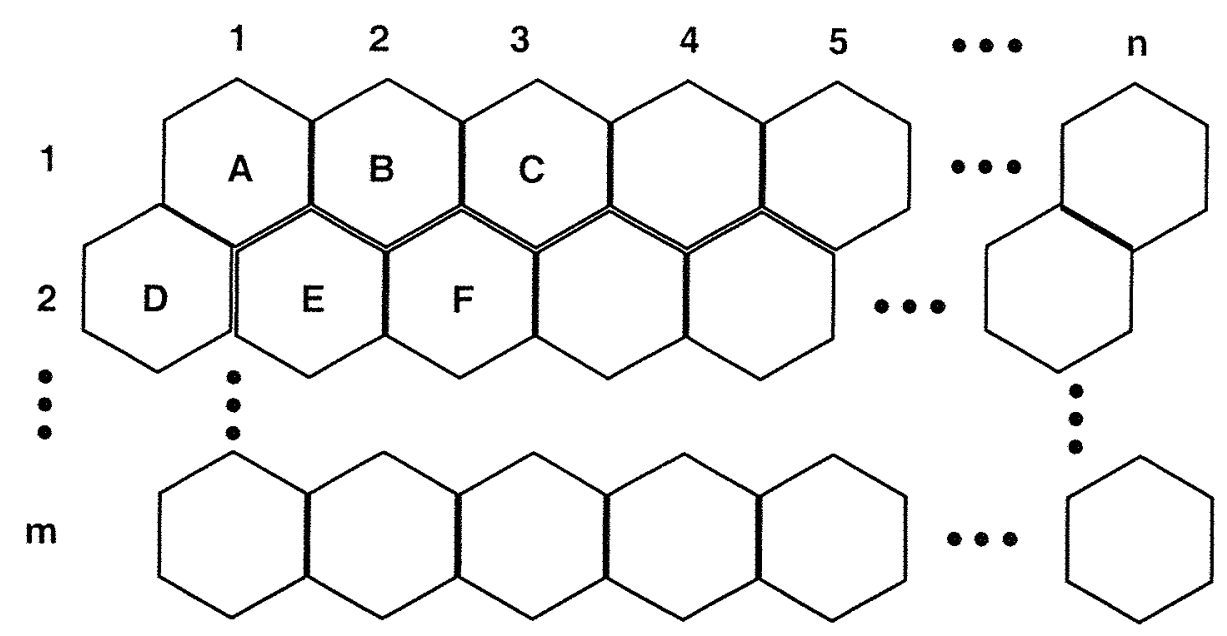

Figura 6.8: Matriz de Vizinhança entre Células

\subsubsection{Resultados da Simulação}

Como o objetivo da simulação estocástica foi analisar o comportamento relativo do protocolo em relação à taxa de migração, as grandezas de simulação foram escolhidas em função de uma unidade de tempo simulada UT. A tabela abaixo descreve o valor dos parâmetros de simulação utilizados na simulação. Esses valores foram escolhidos de maneira a limitar a migração das estações para que a atomicidade do hand-off não fosse violada, ou seja, para que um hand-off de uma estação móvel só fosse iniciado após o término do seu hand-off anterior.

\begin{tabular}{rr}
\hline Intervalo mínimo entre migrações & $15 \mathrm{UT}$ \\
Intervalo entre requisições & $2 \mathrm{UT}$ \\
Atraso pelo meio sem fio & $40 \mathrm{UT}$ \\
Atraso pela rede fixa & $2 \mathrm{UT}$ \\
Critério de parada & 1.000 Req \\
\hline
\end{tabular}

A periodicidade efetiva de migrações é dependente da probabilidade de migração usada na simulação, que variou entre 0 e $100 \%$ nas simulações realizadas. Uma probabilidade de migração de $100 \%$ indica que será gerada uma nova migração para a estação móvel a cada 15 UT. O critério de parada da simulação foi a geração de 1000 requisições pelas estações móveis ao servidor. O gráfico da figura 6.9 representa o resultado obtido nesta simulação, onde foi coletada a razão entre o número de mensagens ForwardRes geradas pelo protocolo e o número de requisições realizadas solicitadas pelos clientes móveis. Como ilustra a figura, o número de mensagens ForwardRes enviadas é sempre menor do que o dobro das requisições feitas, quando o hand-off é mantido atômico.

Para avaliação da relação entre o tamanho médio da mensagem PList e a mobilidade, foram utilizadas as mesmas grandezas da primeira simulação. Neste caso porém, a migração foi mantida constante e a probabilidade de requisições foi variada de maneira que fossem geradas de zero a duas requisições por migração. O critério de garantia da atomicidade do hand-off foi mantido também para esta simulação. 


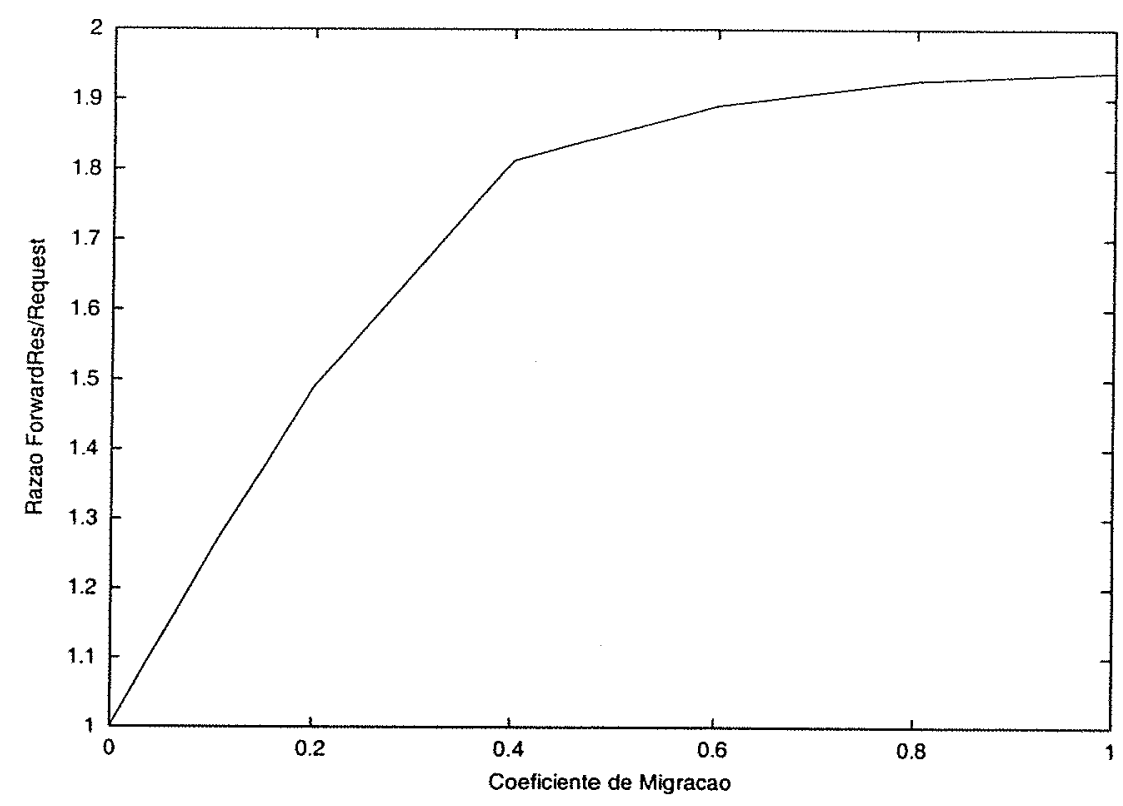

Figura 6.9: Número relativo de mensagens ForwardRes em função da probabilidade de migração

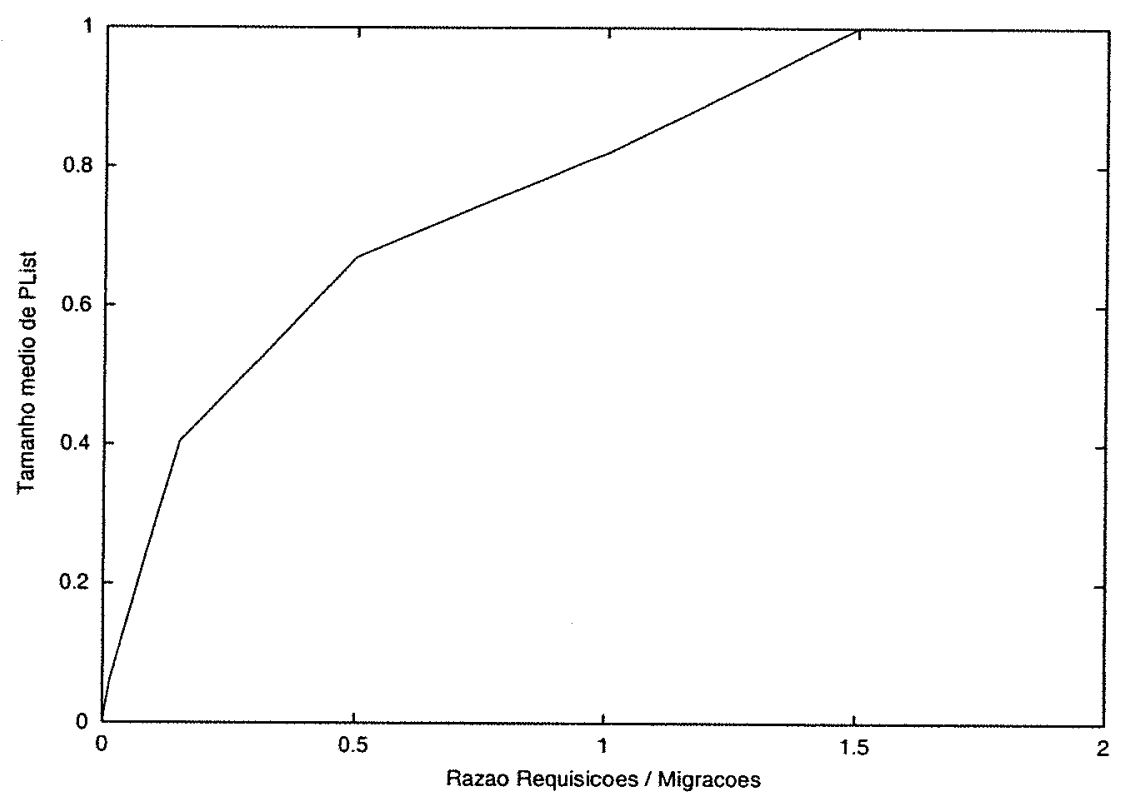

Figura 6.10: Tamanho médio de PList em função do número de requisições por migração

O gráfico da figura 6.10 ilustra a influência do número de requisições por migração no tamanho da estrutura PList. Para uma razão maior ou igual a 1.5, o tamanho da estrutura PList chega ao seu máximo e não aumenta mais. Tendo em vista que esse valor foi limitado a um proxy por mensagem PList devido ao critério de atomicidade, pode-se considerar que o valor do gráfico está normalizado. Para limites maiores o gráfico deverá se comportar da 
mesma maneira.

\section{Resumo}

Este capítulo apresentou um exemplo de utilização do MoBICS, que descreve a implementação e simulação de um protocolo de entrega de respostas a clientes móveis. Este protocolo apresentou vários aspectos que sugerem uma validação pelo modo determinístico. $\mathrm{Na}$ seção 6.2 foi apresentada uma simulação determinística que compreende o teste de apenas um desses aspectos. O protocolo foi submetido a uma simulação estocástica com o objetivo de avaliar o seu desempenho, indicado pelo aumento da retransmissões de respostas a clientes móveis e o aumento no tamanho das mensagens de hand-off, em função da migração das estações. A partir desta simulação foram obtidos gráficos que permitiram uma análise mais detalhada do comportamento do protocolo. 


\section{Capítulo 7}

\section{Implementação do MobiCS}

Este capítulo descreve a abordagem e os detalhes de implementação do MoBICS. A seção 7.1 enuncia as características gerais da implementação e discute a abordagem de implementação, em função dos requisitos e decisões de projeto indiretamente relacionados com a arquitetura de referência. Umas das decisões de projeto do MoBICS foi permitir que novos modos de simulação pudessem ser programados e incorporados no simulador. Para isso, MOBICS define um arcabouço para implementação de modos de simulação, discutido na seção 7.3. As seções 7.2 e 7.4 descrevem a implementação dos elementos de rede e da camada de simulação, respectivamente.

\subsection{Visão Geral}

MoBiCS é uma biblioteca Java que permite implementar os modelos e máquinas de simulação descritas no capítulo 5 . Um usuário MOBICS estende as classes básicas da biblioteca para definir protocolos e a configuração da simulação, incorporando-os no seu próprio programa. A biblioteca é composta de cerca de 120 classes, totalizando quase 10.000 linhas código.

Vários simuladores para computação móvel já foram implementados em Java, como $[63,86,23]$. Uma discussão aprofundada sobre as vantagens da utilização desta linguagem em aplicações de simulação pode ser encontrada em [64, 39, 80]. No caso do MoBICS, a linguagem Java foi escolhida por quatro razões principais:

- Java é uma linguagem de alto nível e por isso adequada a prototipagem de protocolos.

- Java incorpora em seu próprio mecanismo a programação de aplicações concorrentes baseadas em threads. Essa é uma característica frequentemente útil em qualquer software de simulação [36] e que foi amplamente utilizada na implementação do MoBıCS.

- As bibliotecas para invocação remota de métodos (RMI) e a possibilidade de execução de código Java em diferentes sistemas operacionais permitem a distribuição da simu- 
lação em diferentes máquinas. Essa característica deverá ser implementada futuramente no MOBICS.

- A escolha de Java também foi motivada pelo fato de que outros componentes da arquitetura SIDAM também estão sendo implementados nesta linguagem. Assim, espera-se que o uso de Java permita integrá-los mais facilmente e produzir um protótipo do SIDAM tendo o MoBiCS como elemento central. Juggler [30] e um protótipo do serviço de localização [28] são exemplos de componentes implementados em Java.

A tabela 7.1 mostra a organização da biblioteca MoBıCS.

\begin{tabular}{|l|l|}
\hline \hline Pacote & Função \\
\hline \hline mobics . simulation & $\begin{array}{l}\text { Declara as classes básicas para que o usuário crie uma simu- } \\
\text { lação. }\end{array}$ \\
\hline mobics.network & Implementa os elementos de rede simulados. \\
\hline mobics.ppi & $\begin{array}{l}\text { Implementa a interface de programação de protocolos, definin- } \\
\text { do as classes básicas para que o usuário crie o seu próprio } \\
\text { protocolo. O subpacote mobics.ppi.protocol implementa } \\
\text { a abstração de protocolo e o subpacote mobics .ppi.message } \\
\text { implementa a abstração de mensagem. }\end{array}$ \\
\hline mobics.exception & $\begin{array}{l}\text { Define exceções utilizadas pelo simulador e pelo programador } \\
\text { de protocolos. }\end{array}$ \\
\hline mobics .controller & $\begin{array}{l}\text { Implementa as máquinas de simulação. O subpa- } \\
\text { cote mobics. controller.deterministic implementa a a } \\
\text { máquina de simulação determinística e o subpacote } \\
\text { mobics. controller.stochastic implementa a máquina de } \\
\text { simulação estocástica. }\end{array}$ \\
\hline mobics.util & Declara classes adicionais úteis à simulação. \\
\hline \hline
\end{tabular}

Tabela 7.1: Organização da Biblioteca MoBICS

A abordagem de implementação do MOBICS baseou-se em três características: extensibilidade, uso intensivo de objetos e flexibilidade de incorporação de outros modos de simulação.

\section{Extensibilidade}

MoBICS foi implementado para ser um núcleo de simulação, ou seja, ele implementa apenas a funcionalidade fundamental para que protocolos possam sem prototipados e simulados. MOBICS não implementa um ambiente de simulação propriamente dito, mas a biblioteca pode ser facilmente incorporada em outros programas para compor um ambiente de simulação. Um usuário pode estender o simulador e adicionar novas interfaces com usuário e abstraçôes, sem que seja necessária a modificação no código do simulador. Por exemplo, um desenvolvedor pode implementar um ambiente integrado de desenvolvimento de protocolos que inclua, por exemplo, automatização na construção de protocolos, interface de configuração do ambiente simulado e depuração. 


\section{Uso Intensivo de Objetos}

No projeto da arquitetura de classes do MoBICS toda abstração é implementada na forma de um objeto. Essa decisão de projeto tem como objetivo promover extensibilidade, modularidade e uniformidade da implementação.

\section{Incorporação de Outros Modos de Simulação}

Embora o MoBiCS implemente apenas os modos de simulação estocástico e determinístico, sua arquitetura de classes permite que possam ser programados e incorporados outros modos de simulação, sem que seja necessária nenhuma modificação na biblioteca. Essa característica é parcialmente possibilitada pela arquitetura de referência proposta, que padroniza as interfaces de comunicação entre as camadas de software do simulador. Entretanto, para que isso fosse possivel é necessário ainda permitir que as interfaces do modo de simulação com o usuário fossem flexíveis. Esses dois requisitos foram incorporados no MовіCS fazendo com que a biblioteca definisse um arcabouço para implementação de modos de simulação. A seção 7.3 discute em detalhes como MOBICS implementa esse arcabouço.

\subsection{Implementação dos Elementos de Rede}

A seção 5.4 descreveu como um usuário utiliza as classes declaradas no pacote mobics.network para criar um ambiente de rede simulado. Esta seção discute os detalhes de implementação dessas classes.

Cada elemento simulado é implementado em uma classe do pacote mobics . network. Há duas classes de elementos que implementam as camadas da arquitetura de software, discutidas na seção 4.2: máquinas de rede e canais de comunicação.

\subsubsection{Máquinas de Rede}

As máquinas de rede são subclasses da classe Element que implementam todo elemento simulado capaz de processar e gerar eventos de simulação. MOBICS declara as classes Mh, Mss e Fh, subclasses de Element, que implementam o comportamento de estações móveis, estações base e máquinas fixas, respectivamente. Todo objeto que implementa uma máquina de rede simulada é composta por quatro componentes: interfaces de rede, fila de mensagens, notificador de protocolos e camada de simulação. Esses componentes são objetos com a seguinte função:

Interfaces de Rede Implementam o envio e recebimento de mensagens pela rede. Uma mensagem é entregue à máquina destino através de sua interface de rede que se encarrega de adicioná-la à fila de mensagens da máquina. Toda interface de rede implementa ainda uma primitiva para envio de mensagens. Um endereço de rede é uma abstração sobre a interface de rede de uma máquina. De acordo com o canal de comunicação pela 
qual a interface envia mensagens, o endereço de rede define uma localização na rede fixa ou na rede sem fio.

Fila de Mensagens Fila que armazena as mensagens recebidas pela rede, ordenadas segundo seus timestamps. A camada de simulação decide quando uma mensagem é retirada da fila, de acordo com o algoritmo da máquina de simulação.

Notificador de Protocolos Armazena todos os protocolos incorporados a uma máquina de rede. Quando a camada de simulação decide processar uma mensagem, ela invoca o método ProtocolNotifier.handleMessage(Message), passando como parâmetro a mensagem que deve ser processada. O notificador então verifica se há um protocolo registrado para tratar a mensagem e, em caso afirmativo, executa o tratador da mensagem. Cada máquina de rede possui a sua própria instância de um protocolo.

$\mathrm{Na}$ atual implementação, MoBICS permite apenas uma camada de protocolos. Consequentemente a única composição possível de protocolos é horizontal.

Camada de Simulação Implementa a máquina de simulação distribuída do MoBICS. Cada máquina de rede possui a sua própria instância de objeto que implementa a camada de simulação. A camada de simulação é encapsulada por um objeto que implementa a interface AbstractSimulatedElement, conforme descrito na seção 7.3.1.

A seção 5.4 classificou as interfaces das classes que implementam máquinas de rede em interfaces de usuário de simulação e interface de especialização de eventos. Do ponto de vista da implementação do MOBICS, essas interfaces possuem um significado particular. As interfaces de usuário de simulação, compostas pelos métodos com assinatura igual a $<$ evento>, como Mh.moveTo(Cell) e Mh.available, indicam o envio de <evento> para a camada de simulação. A implementação dessas interfaces cria um correspondente objeto com interface Activity que implementa o evento e o encaminha para a camada de simulação.

As interfaces de especialização de eventos, compostas pelos métodos com assinatura on $<$ evento $>$, definem as ações que devem ser executadas pela camada de elementos de rede quando ela recebe o evento < evento> da camada de simulação. Esses métodos são invocados apenas pela camada de simulação. Em outras palavras, do ponto de vista da implementação do MoBICS, um método com assinatura <evento> é uma interface de envio do evento $<$ evento $>$, enquanto que um método com assinatura on<evento $>$ é a interface usada pela camada de simulação para enviar o evento <evento > para a camada de elementos de rede.

\subsubsection{Canais de Comunicação}

Os canais de comunicação possuem apenas duas camadas arquiteturais: a camada de elementos de rede e a camada de simulação. A camada de simulação é implementada por um objeto que implementa a interface AbstractLinkSimLayer. Esta interface declara o método scheduleSend (NetMessage) que implementa o recebimento do evento MsgArrived enviado pela camada de elementos de rede. As camadas de simulação determinística e estocástica implementam diferentemente o método scheduleSend(NetMessage) nas suas classes DetermLinkLayer e StochLinkLayer. Na simulação determinística, o envio de uma 
mensagem é um evento síncrono, ou seja, o envio da mensagem pela interface de rede da máquina remetente necessariamente incorpora o recebimento da mensagem pelo destinatário. $\mathrm{Na}$ simulação estocástica, esse evento é assíncrono. O envio do evento MsgArrived requisita o escalonamento do evento na camada de simulação, que decide se o evento será enviado para a camada de elementos de rede e qual será o timestamp associado ao evento. A interface Link.onSend (NetMessage) declara o envio de MsgArrived da camada de simulação para a camada de elementos de rede.

A camada de elementos de rede dos canais de comunicação implementa a entrega de mensagens entre remetente e destinatário. A camada de simulação de um canal de comunicação define o modelo de atraso de mensagens.

\subsection{Arcabouço de Implementação de Modos de Simu- lação}

O projeto da arquitetura de classes de MовICS possibilita a implementação e incorporação de outros modos de simulação, além dos modos determinístico e estocástico. Para isso, MoBıCS define um arcabouço para implementação de modos de simulação, descrito nesta seção.

A implementação de um novo modo de simulação no MoBICS usualmente implica na incorporação da implementação de nova máquina de simulação e na disponibilização para o usuário de novas interfaces para uso do modo. No projeto das classes do MoBICS foi implementado um mecanismo que define de maneira uniforme como a camada de simulação é criada na execução do MoBıCS e como o usuário utiliza as interfaces do modo de simulação. Este mecanismo é baseado nas classes AbstractSimulatedElement, declarada no pacote mobics controller, Simulator e Simulation, declaradas no pacote mobics.simulation. Para implementar um modo de simulação, um programador deve estender cada uma dessas classes e definir os aspectos específicos do modo.

A figura 7.1 mostra um diagrama com as interdependências e colaborações entre as classes que implementam o mecanismo. No diagrama, as classes contendo o prefixo Concrete, constituem classes declaradas para implementar um modo de simulação específico. Todas as classes que não possuem o prefixo Concrete são pertencentes ao MoBiCS. Os modos de simulação determinístico e estocástico definem suas respectivas classes Concrete da figura.

\subsubsection{Classe AbstractSimulatedElement}

A classe abstrata AbstractSimulatedElement declara a interface básica entre as camadas de elementos de rede e de simulação. Cada modo de simulação deve definir, no mínimo, uma classe concreta que implementa a interface AbstractSimulatedElement e declara as interfaces específicas do modo de simulação. A implementação desta classe, assim como a classe ConcreteSimulatedElement do diagrama da figura 7.1, deve criar a camada de simulação do elemento (objeto da classe SimLayer) que intermedia a comunicação com a 


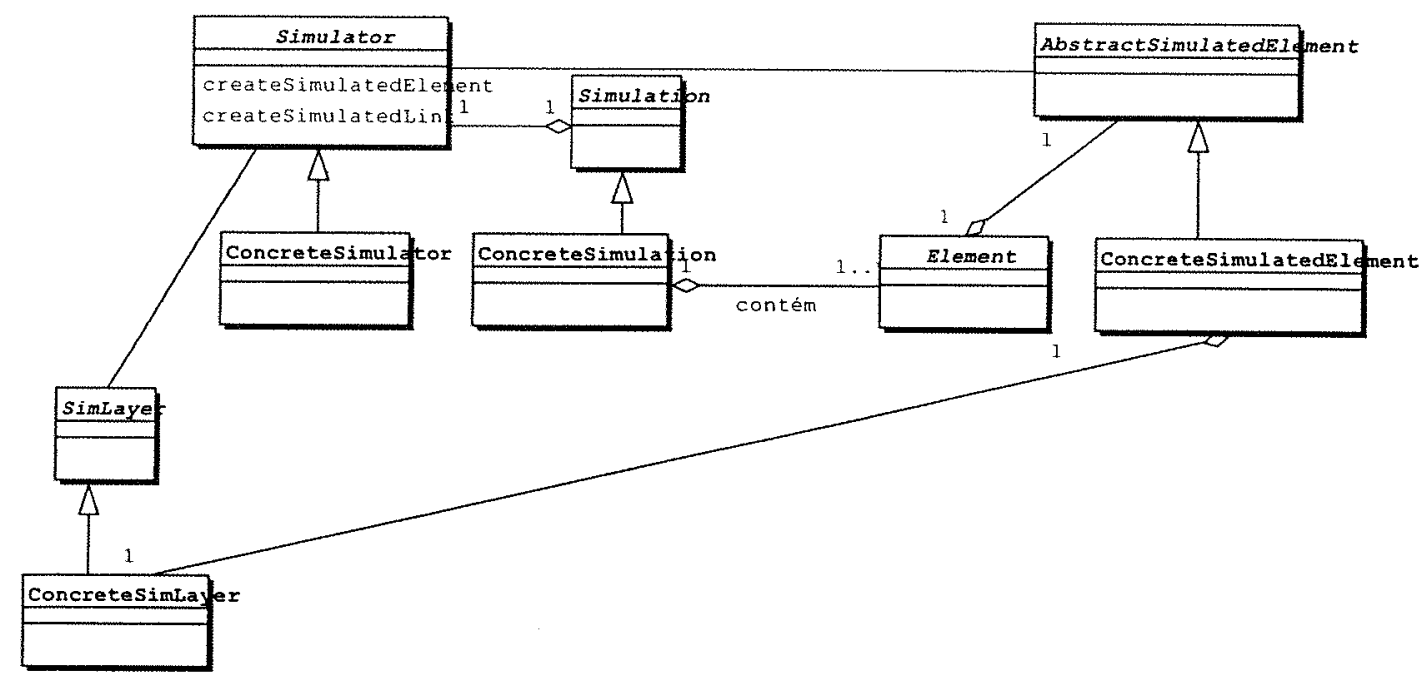

Figura 7.1: Diagrama de Classes do Arcabouço

camada de elementos de rede.

A classe AbstractSimulatedElement declara o método addBehavior(Activity) que reencaminha um evento da camada de elementos de rede para a camada de simulação. Além disso, esta interface declara os métodos onMsgArrived, onReceive e onSend que em sua implementações devem indicar as ações específicas do modo de simulação que devem ser executadas quando ocorrer algum desses eventos. Por exemplo, a implementação do método DetermElement.onMsgArrived do modo determinístico, exibe no log de eventos as informações sobre a mensagem recebida pelo elemento simulado.

Além dessa interface, o modo de simulação deve definir classes que implementem a interface AbstractSimulatedLink. Essa interface é o equivalente da interface AbstractSimulatedElement para canais de comunicação simulados. Diferentemente da outra interface, AbstractSimulatedLink declara apenas o método scheduleSend(NetMessage), que escalona na camada de simulação o envio de uma mensagem pelo canal de comunicação.

O objetivo das interfaces AbstractSimulatedElement e AbstractSimulatedLink é apenas declarar as novas interfaces com o usuário da camada de simulação. Toda funcionalidade da camada de simulação é implementada exclusivamente pela respectiva subclasse de SimLayer.

\subsubsection{Classe Simulator}

A classe abstrata Simulator declara as interfaces de inicialização de uma simulação e define quais os objetos específicos de modo de simulação serão criados para cada elemento simulado.

A classe Simulator declara dois métodos abstratos: createSimulatedElement (...) 
e createSimulatedLink(...), que retornam respectivamente objetos da classe ConcreteSimulatedElement e da classe ConcreteSimulatedLink. Uma classe ConcreteSimulator, específica do modo de simulação, implementa esses dois métodos que definem, para um elemento ou canal de comunicação simulado, qual é o objeto específico do modo de simulação que deve ser criado. Os parâmetros desses métodos contém informações independentes de modo de simulação e que definem o tipo de elemento simulado (ou canal de comunicação) que deve ser criado e alguns de seus componentes internos.

No caso do modo de simulação determinístico do MoBiCS, a implementação do método DetermSimulator.createSimulatedElement (...) é a seguinte:

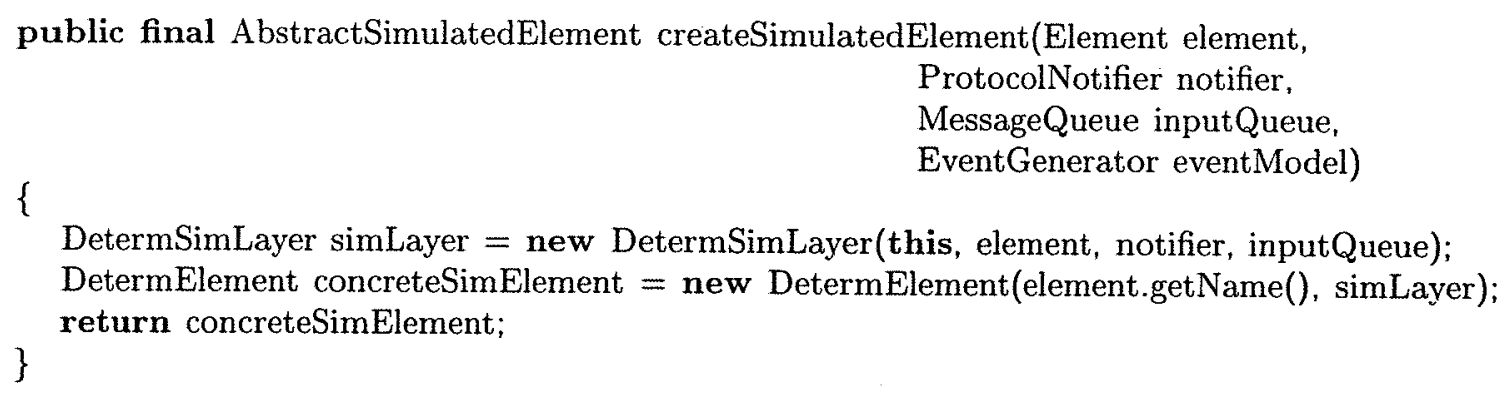

DetermSimLayer simLayer $=$ new DetermSimLayer(this, element, notifier, inputQueue);

DetermElement concreteSimElement $=$ new DetermElement(element.getName(), simLayer); \}

return concreteSimElement;

Observe que o código cria a camada de simulação do novo elemento, objeto da classe DetermSimLayer (subclasse de SimLayer), e o utiliza como argumento da criação do elemento simulado concreteSimulatedElement.

\subsubsection{Classe Simulation}

A classe abstrata Simulation define a interface do modo de simulação com o usuário, convertendo chamadas a seus métodos para as respectivas chamadas da classe ConcreteSimulator e das subclasses de ConcreteSimulatedElement.

Dois tipos de interfaces podem ser definidas: globais, cuja implementação interfere no estado de todo ambiente simulado, e locais, cuja implementação corresponde a uma chamada da interface de ConcreteSimulatedElement de um elemento simulado. No caso da simulação determinística, a única interface global é o método DetermSimulation.next. Os demais métodos, como por exemplo DetermSimulation.accept(Element, Class), correspondem à interface local de simulação determinística. O modo estocástico não declara nenhuma interface adicional à simulação.

\subsubsection{Criação dos Objetos}

A figura 7.2 mostra o diagrama de seqüência de criação de objetos. O construtor da classe ConcreteSimulation cria a classe ConcreteSimulator. No momento da criação de um elemento simulado através do método ConcreteSimulation. configure, ConcreteSimulation passa uma referência para ConcreteSimulator, com a qual o elemento simulado Element solicita a criação do seu objeto da classe ConcreteSimulatedElement. Este objeto, por 
usa vez, cria a camada de simulação do elemento simulado. Com a referência ao objeto ConcreteSimulatedElement, Element termina a sua inicialização e retorna o controle para ConcreteSimulation, que então pode criar outro elemento ou realizar outro processamento.

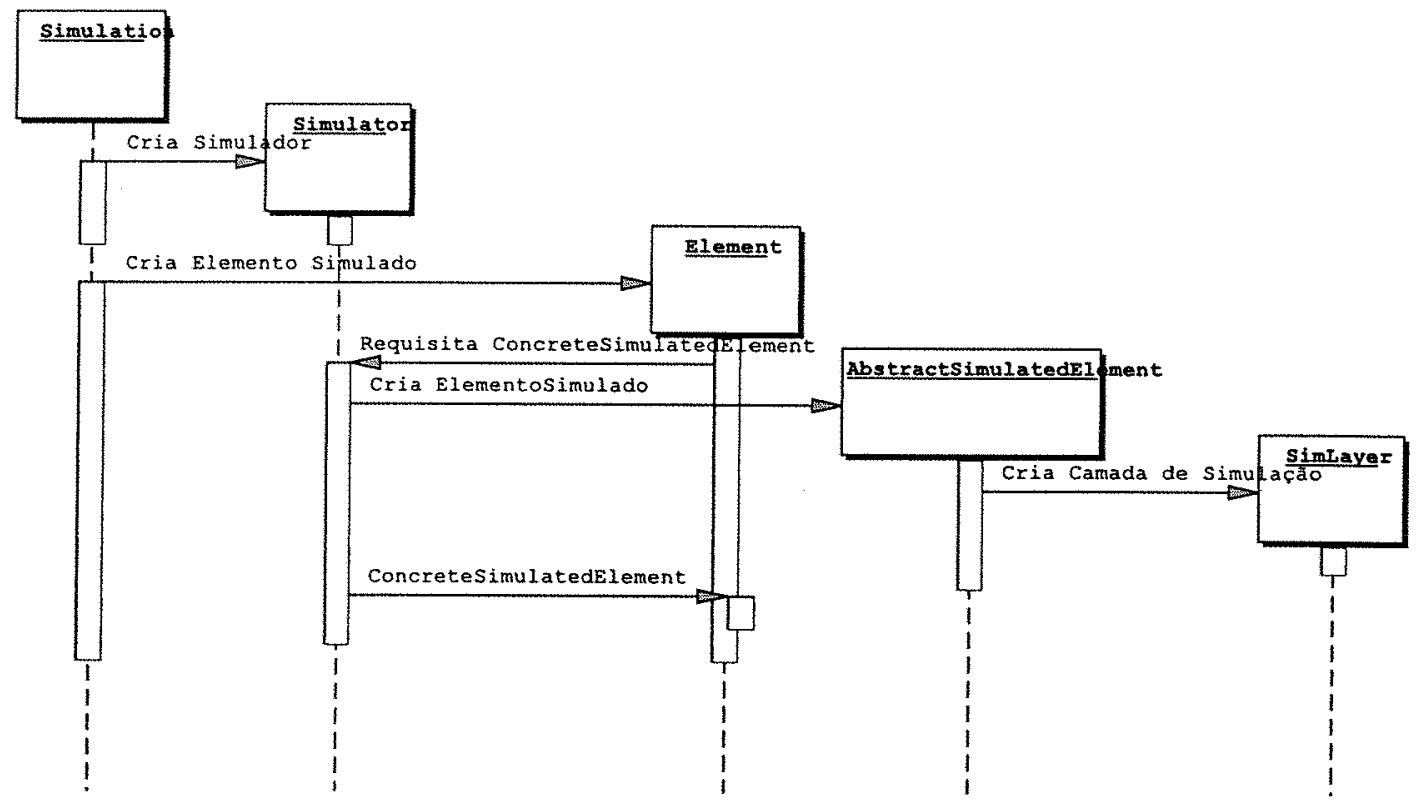

Figura 7.2: Diagrama de Seqüência de Criação de Objetos

\subsubsection{Discussão}

A biblioteca MoBiCS implementa uma série de mecanismos ou padrões de projeto de classes que the conferem flexibilidade e extensibilidade. Esta seção descreveu como o MoBICS implementa um mecanismo que permite a implementação e incorporação de novos modos de simulação. Este é um mecanismo fundamental do MoBICS porque confere programabilidade de modos de simulação ao MOBICS, fazendo com que a biblioteca seja também um arcabouço de implementação de modos de simulação de protocolos.

A arquitetura de classes descrita implementa três padrões de projeto: Factory, Adapter e Strategy [41]. Consequentemente, a abstração dessa arquitetura define um padrão de projeto que integra esses três padrões.

\subsection{Camada de Simulação}

Os pacotes mobics . controller deterministic e mobics. controller. stochastic implementam as camadas de simulação determinística e estocástica, respectivamente. Esta seção descreve os detalhes de implementação desses dois modos de simulação do MoBICS. 


\subsubsection{Arquitetura Geral}

As camadas de simulação determinística e estocástica do MoBICS foram implementadas baseando-se em uma arquitetura comum, mostrada na figura 7.3.

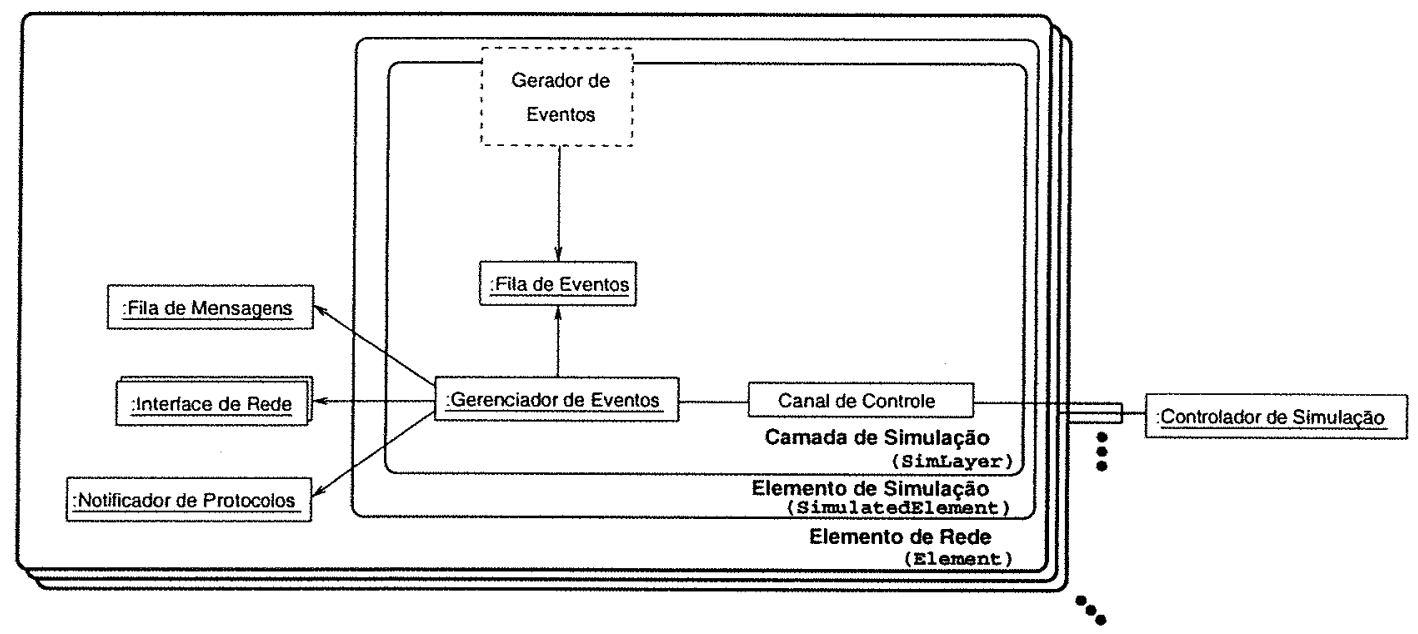

Figura 7.3: Arquitetura Geral da Camada de Simulação

A função de cada um dos componentes do diagrama é a seguinte:

Fila de Eventos : armazena os eventos de simulação que devem ser processados pela camada, ordenados segundo o seu timestamp.

Gerador de Eventos : gera os eventos de simulação e os adiciona à fila de eventos. Dependendo do modo de simulação, esse componente pode ser um objeto agregado à camada de simulação ou apenas uma interface através da qual eventos podem ser adicionados externamente.

Gerenciador de Eventos : É uma thread que continuamente retira os eventos da fila de eventos e os processa, de acordo com o algoritmo de simulação implementado. No processamento de um evento, o gerenciador pode retirar mensagens da fila de eventos, enviar mensagens pelas interfaces de rede ou requisitar ao notificador de protocolos o tratamento de uma mensagem.

Controlador de Simulação : elemento central no simulador que estabelece uma sincronização entre as camadas de simulação de todos os elementos simulados, com o objetivo de garantir que o processamento de todos os eventos respeite a ordem causal.

Canal de Controle : canal de comunicação entre uma camada de simulação e o controlador de simulação, pelo qual os dois componentes trocam informações de controle de simulação.

A interface Activity declara a interface dos eventos de simulação, que devem implementar o método Activity.runAction. Esse método é invocado pelo gerenciador de eventos no 
momento do processamento de um evento. O pacote mobics.controller declara vários eventos de simulação, como por exemplo MoveTo e Send, correspondentes a uma migração e um envio de mensagem, respectivamente. O método SimLayer.addBehavior (Activity) adiciona os eventos na fila de eventos da camada de simulação.

Apenas a camada de simulação de máquinas de rede implementa esses componentes do diagrama. No caso de canais de comunicação, a camada de simulação compreende apenas o algoritmo que implementa o método LinkLayer.scheduleSend(NetMessage). Cada um dos dois modos de simulação implementa diferentemente cada um desses componentes e a interação entre eles.

\subsubsection{Modo Determinístico}

No modo de simulação determinístico, todos os eventos de simulação são gerados pelo script, com a exceção dos eventos resultantes do processamento de algum evento. Por este motivo, na camada de simulação determinística o componente gerador de eventos é substituído pela interface de incorporação de eventos, pela qual o objeto da classe DetermElement adiciona os eventos que devem ser processados. A classe ActivityScheduler implementa a fila de eventos, adicionando algumas interfaces específicas à fila e utilizadas apenas neste modo de simulação.

O controlador de simulação interage com as camadas de simulação para garantir que os elementos só comecem a executar os eventos de um passo de simulação quando todos os elementos terminaram a execução dos eventos do passo anterior. Para isso, a máquina de simulação determinística implementa o diagrama de estados da figura 7.4, que define um conjunto de estados e transições para cada um dos elementos simulados.

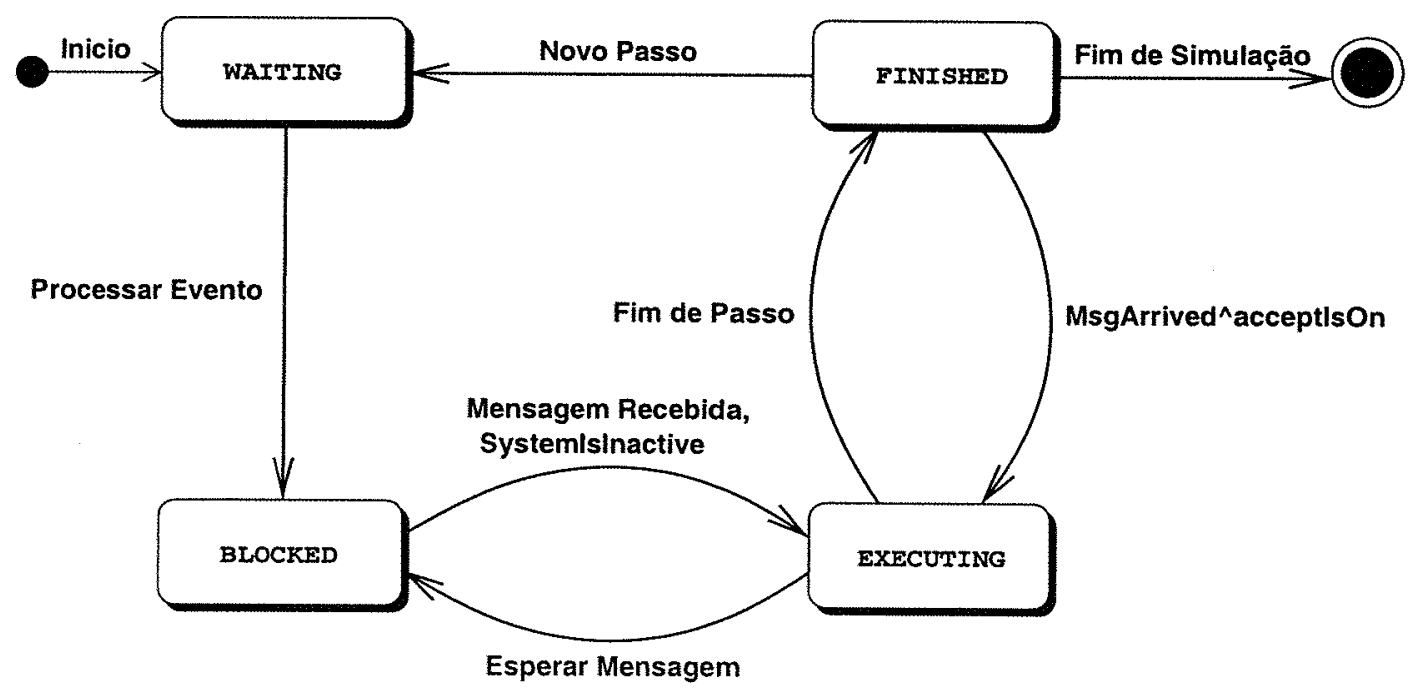

Figura 7.4: Diagrama de Estados dos Elementos Simulados no Modo Determinístico

Conforme mostra o diagrama, durante uma simulação determinística um elemento simulado pode ficar em quatro estados distintos: WAITING, EXECUTING, BLOCKED ou FINISHED. 
Para mudar de um estado para outro, o gerenciador de eventos envia uma mensagem changeState para o controlador de simulação. Os estados possuem o seguinte significado:

WAITING : O gerenciador de eventos está esperando pela inserção de um evento na fila de eventos, para realizar o processamento.

EXECUTING : O gerenciador de eventos está processando um evento.

BLOCKED : O gerenciados de eventos está bloqueado em um evento Accept para uma mensagem de uma classe não encontrada na fila de mensagens. Neste estado, o gerenciador de eventos espera até que uma das seguintes condições seja atendida:

1. O gerenciador recebe uma mensagem SystemisInactive do controlador, indicando que todos os demais elementos simulados estão inativos naquele instante, ou seja, eles estão ou no estado BLOCKED ou no estado FINISHED.

2. Uma nova mensagem é adicionada na fila de mensagens.

FINISHED : O gerenciador de eventos executou todos os eventos do corrente passo de simulação.

Um elemento no estado FINISHED pode voltar ao estado EXECUTING caso o modo de aceitação de mensagens esteja ligado e caso seja adicionada uma nova mensagem na fila de mensagens. Neste estado de aceitação de mensagens, a fila de mensagens deve necessariamente estar vazia quando o elemento terminar um passo de simulação. No fim de um passo, o gerenciador de eventos verifica as mesmas duas condições testadas quando um elemento está no estado BLOCKED. A transição de estados neste caso é mais complexa do que mostrado na figura 7.4, e o estado FINISHED é implementado por um conjunto de estados. Para efeito de simplificação, esses estados adicionais não foram mostrados no diagrama da figura 7.4 porque correspondem a uma situação especial do sistema simulado. Caso todos os elementos estejam no estado FINISHED ou BLOCKED, o controlador envia a mensagem SystemlsInactive para os elemento, mas os elementos em FINISHED só podem migrar para o estado final do diagrama quando, no máximo, um elemento estiver no estado BLOCKED.

\subsubsection{Modo Estocástico}

$\mathrm{Na}$ atual implementação, o algoritmo da máquina de simulação estocástica do MoBıCS é sequencial. Entretanto, isso não significa que somente um elemento por vez possa processar eventos. Como os elementos simulados são implementados em processos concorrentes eles podem processar em paralelo os eventos de mesmo timestamp.

Neste modo de simulação, a camada de simulação possui um gerador de eventos, que é defindo pelo usuário para descrever o modelo de simulação do elemento. A comunicação entre as camadas de simulação e o controlador é feita pelas mensagens nextTimestamp, com a qual o controlador requisita do gerenciador de eventos o timestamp do próximo evento, e runEvent, através do qual o controlador autoriza o processamento do evento. 


\section{Entrega de Mensagens por Canais sem Fio}

Caso o modelo de comunicação de um canal sem fio defina que a qualidade da comunicação varia com a migração intracelular de uma estação móvel, o algoritmo de entrega de mensagens por esse canal torna-se mais complexo. Isso ocorre porque neste caso o tempo de envio de uma mensagem não será mais o resultado do método LinkSimModel.delaySend (NetMessage, Location, Location) mas a somatória dos atrasos de partes da mensagem enviadas durante uma sequência de migrações. Para calcular o atraso final da mensagem, a camada de simulação estocástica implementa o algoritmo descrito na função recursiva da figura 7.5.

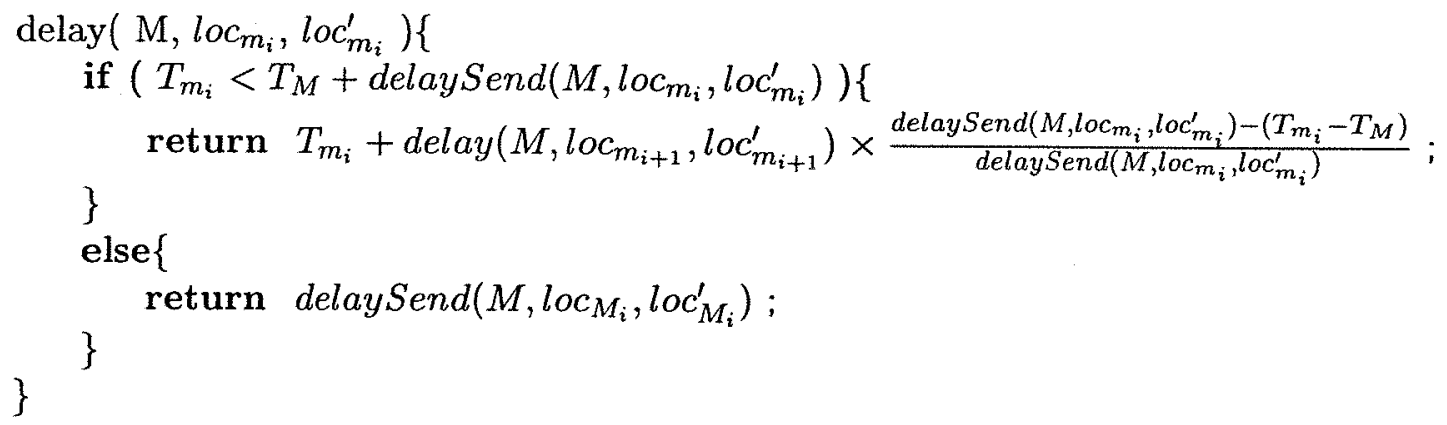

Figura 7.5: Algoritmo de Cálculo do Atraso de Envio de Mensagem por Canal sem Fio

No algoritmo, delay $\left(M, l o c_{m_{i}}, l o c_{m_{i}}^{\prime}\right)$ é uma função que retorna o atraso do envio da mensagem $M$, quando a localização do remetente e destinatário da mensagem são respectivamente $l o c_{m_{i}}$ e $l o c_{m_{i}}^{\prime}$, onde $i$ é o índice da $i$-ésima migração do elemento após o timestamp $T_{M}$ de envio da mensagem $M$. Desta forma, $l o c_{m_{0}}$ e $l o c_{m_{0}}^{\prime}$ são as localizações do remetente e do destinatário no momento do envio da mensagem e $T_{m_{i}}$ é o timestamp em que ocorre a migração $m_{i}$.

Quando alguma migração $m_{i}$ é inter ou extracelular, o algoritmo deve retornar um valor infinito, para indicar que a mensagem foi perdida. Esse detalhe não está indicado no algoritmo da figura 7.5 .

Para implementar o algoritmo, as camadas de simulação de um canal sem fio e dos elementos destinatário e remetente da mensagem devem se comunicar sem intermediação do controlador, para que o algoritmo receba as informações de cada $m_{i}$. Isso é feito por um método das interfaces de rede dos elemento, que permite o acesso à sua camada de simulação, sem a perda do encapsulamento ${ }^{1}$.

Esse algoritmo permite que o cálculos dos atrasos de mensagens possam ser programados nos modelos de comunicação sem fio, sem que seja necessário o conhecimento da mobilidade das estações móveis.

\footnotetext{
${ }^{1}$ Utilizando o padrão de projeto Memento [41]
} 


\section{Resumo}

O pacote MoBICS foi totalmente implementado em Java, com o objetivo de ser um núcleo de simulação. Isto significa que ele implementa apenas a funcionalidade mínima de um ambiente de simulação e permite a simulação das características básicas de um ambiente de computação móvel. Novas características podem ser incorporadas à ferramenta e ao ambiente simulado por extensão das classes básicas. Como parte dessa abordagem de implementação, foi desenvolvido um arcabouço para implementação de modos de simulação com o qual é possivel implementar e incorporar novos modos de simulação ao MOBICS.

Os modos de simulação determinístico e estocástico foram implementados a partir de uma arquitetura comum, baseada em um controlador de simulação centralizado. $\mathrm{O}$ algoritmo de simulação da máquina estocástica é sequencial. 


\section{Capítulo 8}

\section{Avaliação}

Este capítulo apresenta uma avaliação da utilidade e aplicabilidade do MoBıCS para a simulação de protocolos para computação móvel, baseada na experiência obtida com seu uso. A seção 8.1 discute as vantagens e limitações do MoBICS observadas a partir do seu uso. A seção 8.2 compara MOBICS com os trabalhos apresentados no capítulo 2 e resume as principais contribuições do simulador.

\subsection{Experiência de Uso do MobiCS}

Além da simulação do protocolo RDP, o MoBICS foi utilizado por cerca de 15 alunos em uma disciplina de pós-graduação do IME-USP para implementar e simular um protocolo de multicast para computação móvel (MCAST) [2]. Durante este uso, várias melhorias foram sugeridas e implementadas com o objetivo de superar algumas limitações e dificuldades relatadas pelos usuários. Há ainda um aluno de mestrado utilizando o simulador para implementar um protocolo de multicast atômico para estações móveis [32]. As seções seguintes apresentam algumas conclusões obtidas a partir da experiência de uso do modelo de programação de protocolos e dos modos de simulação determinístico e estocástico.

\subsubsection{Modelo de Programação de Protocolos}

A experiência com uso do MOBICS demonstrou que seu modelo de programação de protocolos do MOBICS não acrescentou complexidade de programação para usuários com uma experiência mínima na linguagem Java. Os programadores puderam se concentrar nos detalhes do protocolo, que foi implementado diretamente a partir de sua especificação. No caso do protocolo MCAST, a escolha dos micro-protocolos foi direta pois a sua especificação modularizava o protocolo em componentes wired, wireless e hand-off.

O uso de Java facilitou a programação dos protocolos, pois aproveitou a experiência dos usuários nesta linguagem e permitiu a utilização de estruturas de dados como vetores dinâmicos e tabelas de hashing, implementadas no pacote java. util do JDK. Essa facilidade 
de uso também se deve ao fato de que o MoBıCS não exigiu nenhuma alteração na sintaxe ou semântica da linguagem para implementar o seu modelo de programação de protocolos.

Entretanto, o poder de programação de Java também permitiu que o usuário utilizasse no protocolo estruturas ilegais ao modelo de programação de MoBICS, sobretudo threads. Como o modelo de execução dos protocolos é sequencial, o uso de threads causa um comportamento não-determinístico aos protocolos.

Outro problema de programação observado foi o compartilhamento de estruturas de dados entre diferentes elementos simulados devido ao envio de objetos em mensagens. A modificação concorrente dessas estruturas foi a causa de boa parte dos erros de programação encontrados. O método Message.clone (seção 5.3.2) foi um recurso implementado para minimizar este problema.

Embora o conceito de micro-protocolos fosse utilizado para promover a modularização, na prática isso mostrou-se limitado porque todos os tratadores de mensagens declarados pelos micro-protocolos deveriam ser implementados em uma mesma classe. Isto impediu que os micro-protocolos ficassem explícitos.

Outra dificuldade encontrada pelos usuários foi a falta de atomicidade no processo de hand-off, isto é, a possibilidade que outras mensagens ou eventos interferissem no processo de hand-off. Isso acarretou muitos erros durante a simulação estocástica do protocolo MCAST pois o protocolo não era capaz de tratar novas migrações de estações móveis sem que seus hand-offs anteriores fossem completados. Esse problema não era previsto na especificação do protocolo e gerou inconsistências nas estruturas de dados implementadas. Embora o problema pudesse ser contornado explicitamente na implementação dos protocolos, a falta de uma semântica de atomicidade para hand-off dificultou a realização de simulações estocásticas.

\subsubsection{Simulação Determinística}

O mecanismo de exceções de Java foi bastante útil para a depuração dos protocolos, tanto no modo determinístico como no modo estocástico. As exceções associadas aos scripts determinísticos possibilitaram a investigação mais eficaz das situações geradoras de erros nos protocolos. Essa característica poderia ser mais explorada se o MoBICS definisse um padrão para a declaração de assertivas nos protocolos, que gerassem exceções caso alguma propriedade fosse violada.

Mesmo no modo de simulação determinístico, em alguns casos foi detectada a ocorrência de erros não-determinísticos nos protocolos. Isso aconteceu em passos de simulação que contiam vários comandos que executavam concorrentemente. Esta situação foi bastante útil para a depuração dos protocolos pois tais erros são mais fáceis de serem identificados e corrigidos na simulação determinística, uma vez que o cenário global de simulação é bem conhecido. 


\subsubsection{Simulação Estocástica}

A experiência com o MoBICS demonstrou que a programação de modelos de simulação é simples, embora não tenham sido testados padrões mais complexos de mobilidade e qualidade de comunicação sem fio. A maior dificuldade encontrada pelos usuários foi compreender que o instante em que os eventos de simulação são gerados é diferente do instante em que eles são processados pelos elementos simulados. A metodologia correta é programar os modelos de simulação para guardar internamente o estado do elemento simulado e atualizá-lo sempre que eventos forem gerados. Por exemplo, para gerar eventos de migração nos quais a célula destino é decidida a partir da célula atual, não deve ser utilizado o método Mh getMss() getCell() porque a célula obtida corresponde à localização da estação móvel no instante da geração do evento e não no instante da execução daquele evento. $O$ correto seria guardar uma referência para a célula da estação móvel no inicio da simulação e atualizá-la a cada geração de evento de migração.

A saída da simulação estocástica permitiu interpretar o comportamento do ambiente simulado e avaliar a adequação do modelo de simulação programado ao protocolo. A simulação estocástica colaborou também para a identificação de problemas nos protocolos não levados em consideração em suas especificações ou não detectados com simulações determinísticas. Esses problemas seriam muito difíceis de serem detectados por outros meios senão por simulação. No caso do MCAST foram encontradas várias situações de erro não previstas pelo protocolo.

Uma dificuldade verificada na simulação determinística e estocástica foi identificar quais informações geradas eram relevantes ao usuário. Isso ocorreu na avaliação das exceções geradas, que incluiam referência ao código interno do MoBICS na pilha de execução, e porque as mensagens de traços de simulação eram muitas e dificultavam a identificação do elemento gerador e a sua identificação no cenário simulado.

\subsection{Comparação com outros Simuladores}

Os simuladores e ambientes para desenvolvimento de protocolos descritos no capítulo 2 podem ser comparados com o MOBICS sob diferentes aspectos. Em geral, as características dos simuladores são determinadas pelo compromisso entre a disponibilização de abstrações para programação de protocolos e o requisito de desempenho de simulação. A tabela 8.1 resume as principais diferenças entre o MoBICS e alguns simuladores, incluindo ns e GloMoSim, sob diferentes aspectos como objetivo do simulador, extensibilidade e modelo de programação de protocolos. A tabela inclui também alguns simuladores de rede, com o objetivo de acentuar as diferenças entre as classes de simuladores de rede e de protocolos.

O GloMoSim é um simulador de protocolos que favorece um melhor desempenho de simulação, em detrimento das abstrações de programação, que são limitadas ao modelo de programação de Parsec. O ns adotou um modelo de programação dividido com o objetivo de balancear desempenho e abstrações de programação. O MoBICS, por sua vez, fornece ao programador o maior número de abstrações possíveis, seja para a programação de protocolos, 


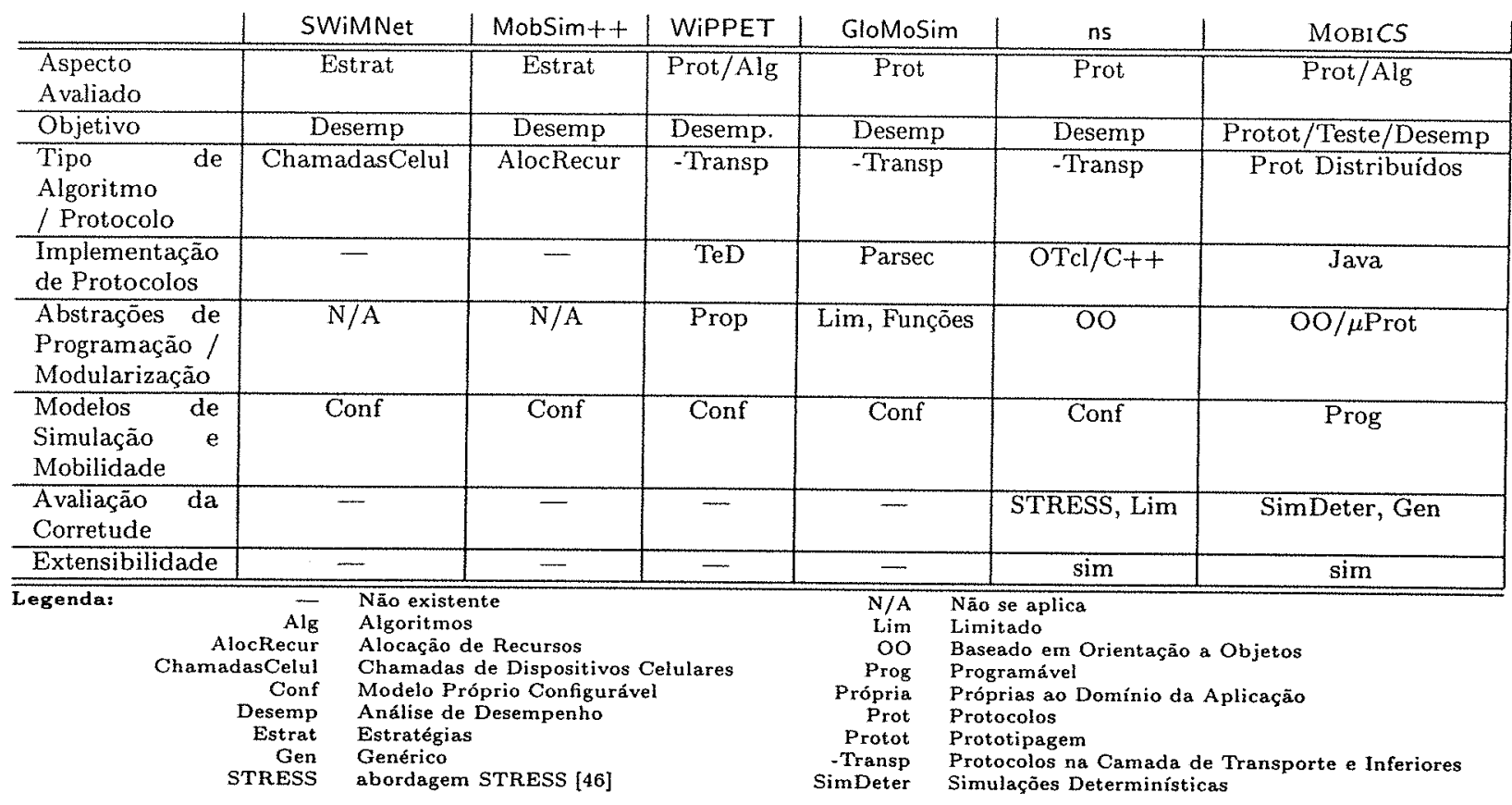

Tabela 8.1: Tabela Comparativa entre Diferentes Simuladores

seja para a programação de simulações. Devido a essa abordagem, o modelo de programação de MOBICS permite a construção de protocolos de uma maneira mais simples e adequada à prototipagem de protocolos. Apesar disso, ns e MoBICS compartilham o mesmo caráter extensível, que permite ao usuário adicionar ou modificar a funcionalidade do ambiente simulado. Diferentemente de GloMoSim, ns e dos demais simuladores, MoBICS foi projetado com o objetivo de permitir também a prototipagem e teste de protocolos.

GloMoSim e ns foram desenvolvidos para permitir a simulação de protocolos de diferentes camadas, e têm sido utilizados sobretudo para a simulação de protocolos nas camadas de transporte e de rede. MoBICS não permite uma simulação eficiente dessa classe de protocolos uma vez que provê abstrações que encapsulam os detalhes básicos de comunicação entre máquinas e utiliza intensivamente objetos para modelar uma comunicação pela rede.

MOBICS foi desenvolvido para a simulação de protocolos de alto nível como algoritmos distribuídos e aplicações, enquanto que os demais simuladores foram desenvolvidos ou para a simulação de protocolos de camadas inferiores ou para a simulação de estratégias/algoritmos bem específicos, conforme destaca a tabela 8.1. No ns, tais algoritmos devem ser simulados como aplicações (como Telnet e FTP) e com um grau de detalhamento muito maior do que o necessário. Em alguns casos, é mais prático desenvolver um novo simulador para reproduzir e avaliar o comportamento do protocolo, do que utilizar o ns ou GloMoSim. Tais algoritmos podem ser implementados e simulados com maior facilidade no MoBICS, desde que não seja necessária uma simulação em larga escala. O simulador é adequado também à experimentação de estratégias para ambientes de computação móvel, não necessariamente associadas a um protocolo de rede, como as estratégias simuladas por SWiMNet e MobSim ++ .

Entre os simuladores caracterizados na tabela 8.1, MoBICS é o único que permite a 
programação de modelos de simulação, incluindo a mobilidade. Em geral, os simuladores definem um modelo bem específico que pode ser configurado pelo usuário e que na maioria das vezes se restringe ao modelo de mobilidade. Esta característica complementa o caráter genérico do MoBICS, pois permite que sejam programados ou escolhidos os modelos de simulação mais adequados à análise do protocolo ou das características da aplicação alvo.

Conforme mostra a tabela 8.1, apenas o ns e MoBICS possuem uma abordagem para validação de protocolos. A validação do ns é baseada em simulações exaustivas segundo a abordagem STRESS [46] mas que não é genérica o suficiente para ser aplicada a qualquer protocolo. MOBICS por sua vez adota uma abordagem genérica baseada em simulações determinísticas, que permite a avaliação da corretude de qualquer protocolo distribuído e constitui uma ferramenta útil para a realização de testes. Outro aspecto único do MoBICS é a disponibilização de diferentes modos de simulação em uma mesma ferramenta. Do ponto de vista do tratamento do tempo simulado, os simuladores em geral implementam o modo de simulação estocástico, com diferentes algoritmos de simulação e interface com as demais camadas arquiteturais do simulador.

Os modelo de programação de protocolos dos simuladores da tabela 8.1 acrescentam abstrações e modularidade quanto mais a coluna do simulador está à direita. O ns utiliza um modelo de programação orientado a objetos, baseado na linguagem OTcl. MoBICS adiciona outro nível de abstração ao modelo de programação de ns, incorporando o conceito de microprotocolos do ambiente Coyote. O objetivo do modelo de programação de Coyote é permitir que protocolos possam ser desenvolvidos em componentes configuráveis e facilitar o teste de diferentes componentes que implementem uma mesma funcionalidade. Apesar da implementação da modularização ser limitada, conforme discutido na seção 8.1, a programação de protocolos no MoBICS implementa micro-protocolos, eventos e tratadores de eventos de uma forma mais adequada que o próprio Coyote. Isso acontece porque Coyote não especifica uma linguagem de programação de protocolos. Os tratadores de eventos são funções $\mathrm{C}$ que devem ser explicitamente registradas para tratar as respectivas mensagens. Esta solução faz com que a aplicação dos conceitos definidos no Coyote seja limitada, conforme destaca [15].

MoBICS separa a funcionalidade da rede, implementada na camada de elementos de rede, da máquina de simulação da mesma forma como o arcabouço TeD/C++ de WIPPET. A diferença fundamental é que TeD é uma linguagem própria para implementação de redes de telecomunicações e por isso define estruturas de linguagem próprias para este domínio de aplicação.

\section{Resumo}

Este capítulo discutiu a avaliação do MOBICS quanto à sua usabilidade e às suas contribuiçōes. O simulador foi utilizado por cerca de 15 alunos de uma disciplina no IME-USP para a simulação de um protocolo de multicast e demonstrou ser bastante útil. A principal dificuldade encontrada nas simulações, tanto estocástica como determinística, foi identificar os eventos relevantes no $\log$ de eventos gerado.

MoBICS apresenta várias características não encontradas em outros simuladores. 
MoвICS é único simulador que possibilita de maneira flexível e genérica a análise de desempenho e a validação de protocolos. Além disso, MoBICS incorpora dois modos de simulação distintos e permite a implementação e incorporação de novos modos.

Tento em vista essas características, MOBICS é o simulador mais adequado para a simulação de algoritmos distribuídos ou experimentação de estratégias de alto nível, não diretamente associadas a um protocolo de rede. 


\section{Capítulo 9}

\section{Conclusões e Trabalhos Futuros}

Protocolos para computação móvel são geralmente mais complexos do que os protocolos convencionais para redes fixas, devido às características dinâmicas das redes móveis, como a mobilidade e variação na qualidade da comunicação nos canais sem fio. Estas variáveis adicionais dificultam a avaliação dos protocolos devido à complexidade de reprodução de cenários dinâmicos reais.

Esta dissertação apresentou MoBiCS, uma ferramenta integrada para teste e avaliação do desempenho de protocolos distribuídos para computação móvel. MOBICS foi projetado para permitir o desenvolvimento de protótipos de protocolos e facilitar a descrição de simulações. Para isso, MoBıCS provê ao usuário um modelo de programação baseado em micro-protocolos, com o qual é possível descrever protocolos altamente modularizados e organizados em componentes funcionais. O modelo de programação sugere que um protocolo seja organizado, no mínimo, em componentes wired, wireless e hand-off.

No MoBICS ainda é possível programar diferentes modelos de simulação a serem aplicados na simulação do protocolo. Essa característica facilita a escolha de modelos de simulação e a criação de cenários que sejam adequados para a avaliação do protocolo. O modelo de mobilidade é o principal componente do modelo de simulação que pode ser programado no MOBICS.

O simulador utiliza simulações determinísticas como abordagem para teste e avaliação da corretude de protocolos. Neste tipo de simulação é possível reproduzir um cenário crítico de execução e verificar o comportamento do protocolo. Esta abordagem é útil para a depuração e a avaliação da corretude de protocolos em cenários simples. Para simulações determinísticas nas quais o número de elementos simulados é grande e/ou o cenário descrito é complexo, é necessário o uso de geradores de cenários. As vantagens da simulação determinística são que ela é uma abordagem genérica, aplicável a qualquer protocolo, e que não exige nenhuma especificação formal para avaliação da corretude do protocolo.

A arquitetura do MoBICS possibilita total transparência de simulação ao programador de protocolos. Diferentes modos de simulação podem ser utilizados sem que seja necessária nenhuma modificação nos protocolos sob teste. Além disso, o usuário pode estender protocolos ou elementos simulados com o objetivo de incorporar novos elementos ou comportamentos 
ao ambiente simulado. MoBiCS utiliza Java como linguagem única para implementação do ambiente simulado e das máquinas de simulação.

Essas características fazem de MoBiCS um simulador flexível e extensível. Em contrapartida, a implementação dessas características no simulador limitaram o seu desempenho de simulação.

MobiCS mostrou-se útil para a simulação de protocolos de alto nível, assim como de algoritmos e/ou estratégias para ambientes de computação móvel com um pequeno número de elementos simulados. O desempenho de simulação também é deteriorado caso o protocolo envolva um número alto de interação entre os elementos simulados. Isso ocorre especialmente quando se trata de protocolos que manipulam pacotes, como os protocolos da arquitetura TCP/IP ou de camadas inferiores. Neste caso, o desempenho de simulação é limitado porque toda mensagem é modelada como um objeto Java, de acordo com a abordagem de implementação descrita na seção 7.1 .

As principais contribuições desta dissertação foram:

- Proposta de uma arquitetura de referência que define elementos arquiteturais, conceitos e abstrações úteis para a implementação de simuladores de protocolos para computação móvel que implementem diferentes modos de simulação, com total transparência para o programador de protocolos. A arquitetura propõe simulações determinísticas como abordagem para validação de protocolos. A arquitetura de referência é uma generalização da arquitetura do MoBıCS, que orienta a implementação de diferentes simuladores mesmo que façam uso de diferentes abordagens de implementação.

- A ferramenta de simulação MoBiCS, que mostrou-se útil para simulação de protocolos distribuídos para ambientes de computação. MoBiCS pode ser utilizado para a avaliação preliminar de protocolos, implementação de protótipos ou em disciplinas onde seja necessário apresentar os aspectos de ambientes de computação móvel, sobretudo quanto ao desenvolvimento de protocolos.

- Desenvolvimento de um arcabouço para a implementação de modos de simulação, com o qual novos modos de simulação podem ser desenvolvidos e incorporados ao MOBICS.

MOBICS não pretende ser um ferramenta completa de simulação, mas somente um núcleo de simulação, no qual novas características podem ser acrescentadas de maneira a prover um ambiente tão completo quanto necessário. Neste sentido, MoBICS define apenas as abstrações mínimas, a flexibilidade e a extensibilidade necessárias para a implementação de um ambiente completo. Consequentemente, é possível enumerar uma extensa relação de modificações que podem ser incorporadas ao simulador. Algumas dessas modificações deverão ser futuramente incorporadas ao simulador tendo em vista o seu uso no projeto SIDAM, tais como:

- Implementação de um modo de emulação de rede, com o qual será possível integrar elementos de uma rede real com elementos simulados pelo MOBICS. Essa característica é necessária para permitir a integração dos demais componentes de software do SIDAM em um protótipo de sua arquitetura, que terá o MoBICS como elemento central. 
- Implementação de uma biblioteca mínima com vários modelos de mobilidade e modelos de canais sem fio mencionados na literatura.

- Implementação de algoritmos paralelos de simulação na máquina estocástica do MoBICS, com o objetivo de melhorar o desempenho de simulação e validar a arquitetura do MOBICS no que se refere à sua generalidade, isto é, capacidade de incorporar diferentes algoritmos de simulação. Em [27] foi apresentado um algoritmo conservador de simulação paralela, que deverá ser incorporado aо MoвıCS.

- Implementação da distribuição do simulador em várias máquinas, com o objetivo de melhorar o desempenho do MOBICS e permitir uma melhor integração de componentes da arquitetura SIDAM executando em diferentes máquinas.

- Para melhorar a usabilidade do MOBICS, poderá ser implementada uma interface com o usuário mais amigável, que permita a visualização do comportamento do ambiente simulado, uma melhor implementação das exceções geradas durante a simulação e a implementação de ferramentas que automatizem a construção de protocolos.

Outro trabalho futuro que deverá ser realizado é a simulação de diferentes abordagens para implementação do protocolo RDP. Além da implementação mostrada nesta dissertação, deverá ser implementada uma versão estendida descrita em [31] e outra versão que utiliza coleta de lixo para eliminar os proxys sem uso. A simulação dessas três alternativas eventualmente mostrará novas necessidades do simulador na avaliação do desempenho de protocolos. 


\section{Apêndice A}

\section{Implementação do Protocolo RDP}

\section{A.1 Declaração das Mensagens}

RDP.

A figura A.1 mostra o diagrama de classes de declaração das mensagens do protocolo

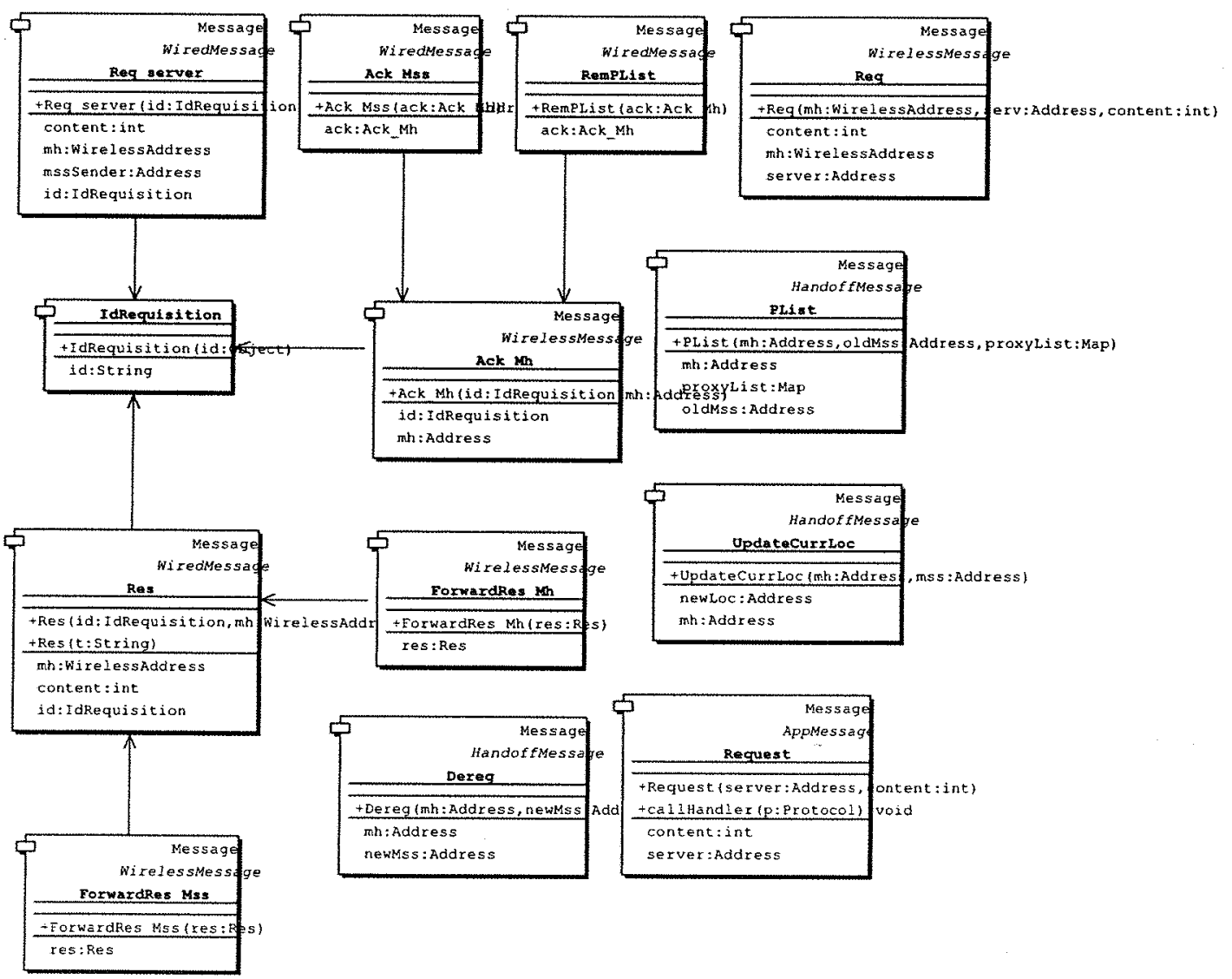

Figura A.1: Diagrama de Classes das Mensagens do Protocolo RDP 


\section{A.2 Declaração dos Protocolos e Micro-Protocolos}

A figura A.2 mostra o diagrama de classes de declaração dos micro-protocolos e das instâncias funcionais do protocolo RDP (classes RDPMss, RDPMh e RDPMss).

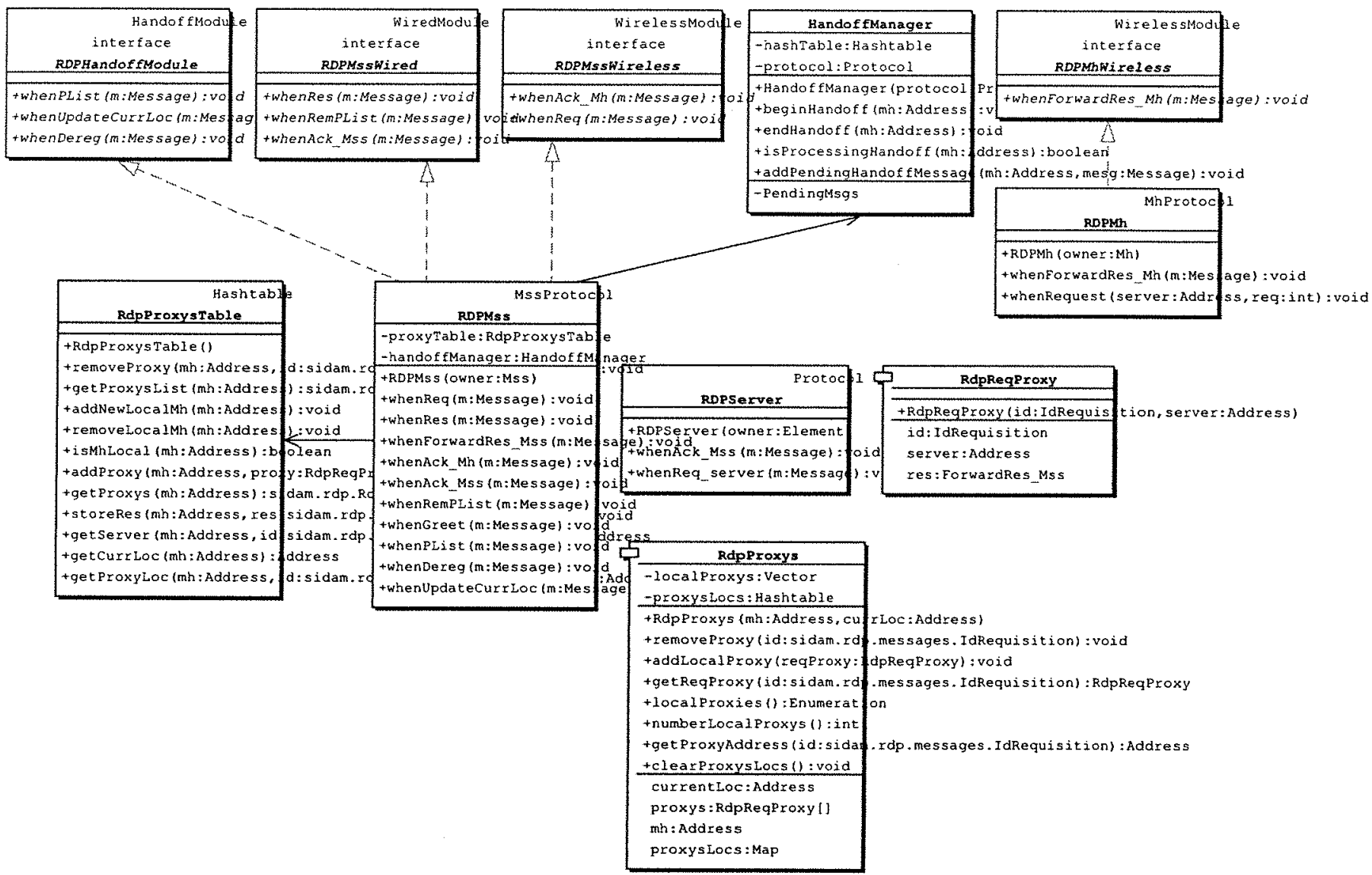

Figura A.2: Diagrama de Classes de Declaração dos Micro-Protocolos e Instâncias do Protocolo RDP 


\section{A.3 Implementação do Protocolo RDPMss}

O código abaixo é a implementação da classe RDPMss, instância funcional do protocolo RDP para estações base.

public class RDPMss extends MssProtocol implements RDPHandoffModule,

RDPMssWireless,

private RdpProxysTable proxyTable;

RDPMssWired \{

public RDPMss(Mss owner) \{

super(owner, null);

\}

proxyTable = new RdpProxysTable();

public void whenReq(Message $\mathrm{m})\{$

Req $\mathrm{msg}=(\operatorname{Req}) \mathrm{m}$;

System.out.println("[rdp " + owner.getName() + "] \% Requisition received by Mss");

// create proxy to new requisition

IdRequisition idNewReq = new IdRequisition(msg); // create unique id to

// requisition

RdpReqProxy px = new RdpReqProxy(idNewReq, msg.getServer());

$/ /$ insert proxy into proxy table

proxyTable.addProxy (msg.getMh(), px);

// send requisition to the server

System.out.println("[rdp " + owner.getName() + "] \% sending message Req to the server");

try \{

send(msg.getServer(), new Req_server(idNewReq, msg,

\} owner.getAddress()));

catch(CommunicationException e) \{

\}

// server not found

Group dest $=$ new Group();

dest.add(msg.getMh());

\}

send(dest, new ForwardRes_Mh(new Res("t")));

public void whenRes(Message $\mathrm{m})\{$

Res $\mathrm{msg}=($ Res $) \mathrm{m}$;

if (proxyTable.isMhLocal(msg.getMh ()$))\{$

$/ / \mathrm{mh}$ is local $\rightarrow$ deliver message and wait ack

send(msg.getMh(), new ForwardRes_Mh(msg));

numberOfForwardRes++;

// store Res into proxy (as ForwardRes message)

ForwardRes_Mss forwRes = new ForwardRes_Mss(msg);

\} proxyTable.storeRes(msg.getMh(), forwRes);

else \{

// deliver Res to current location of Mh

Address currLoc $=$ proxyTable.getCurrLoc(msg.getMh());

if (currLoc $!=$ null)

ForwardRes_Mss forwRes = new ForwardRes_Mss(msg);

$/ /<<$ MODIFIED $>>$ 


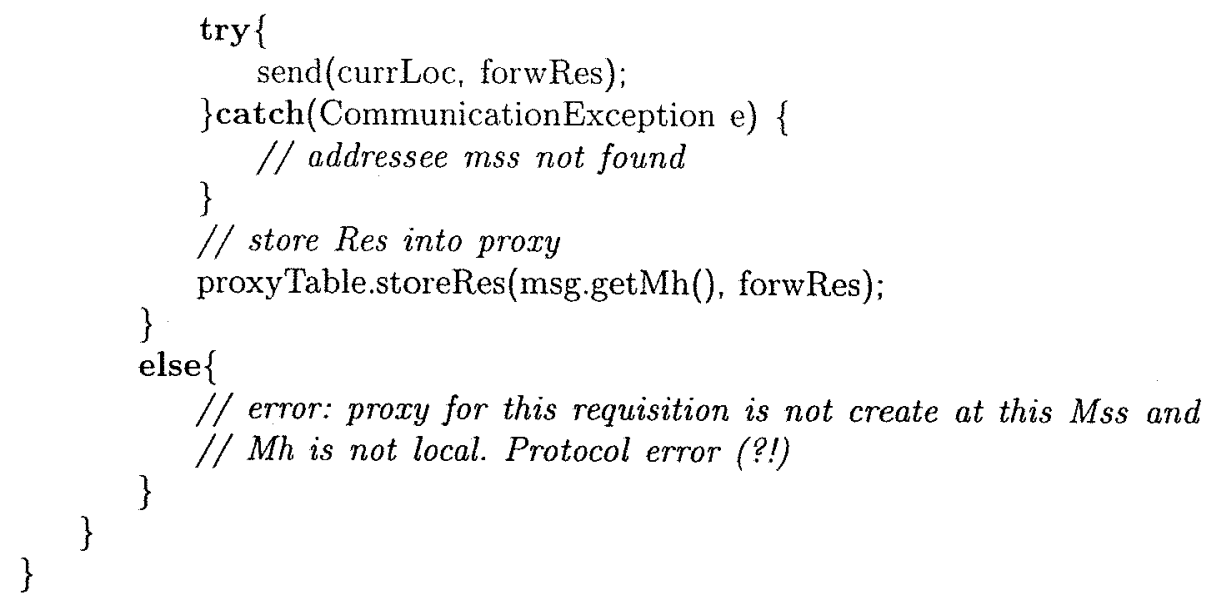




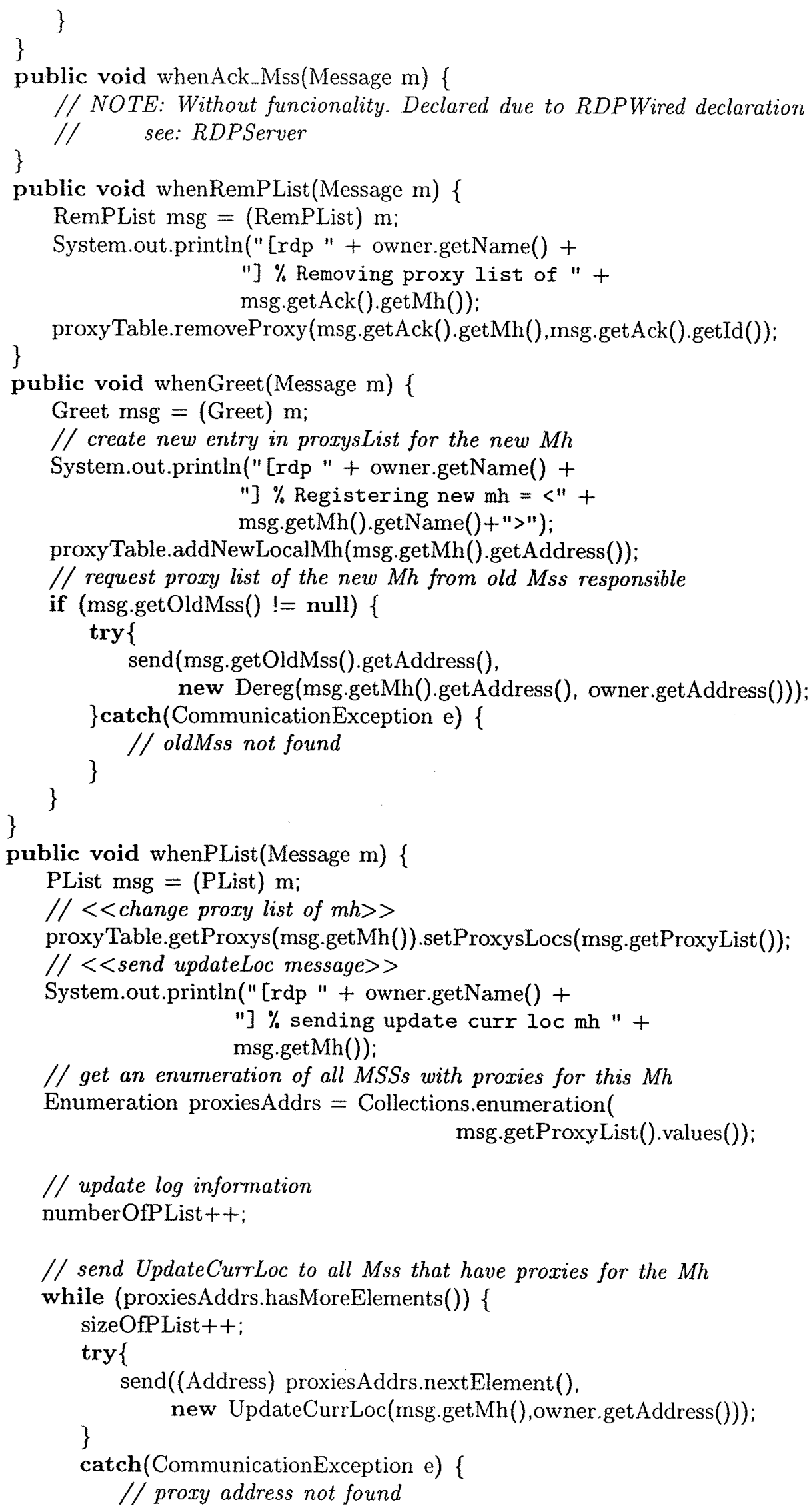




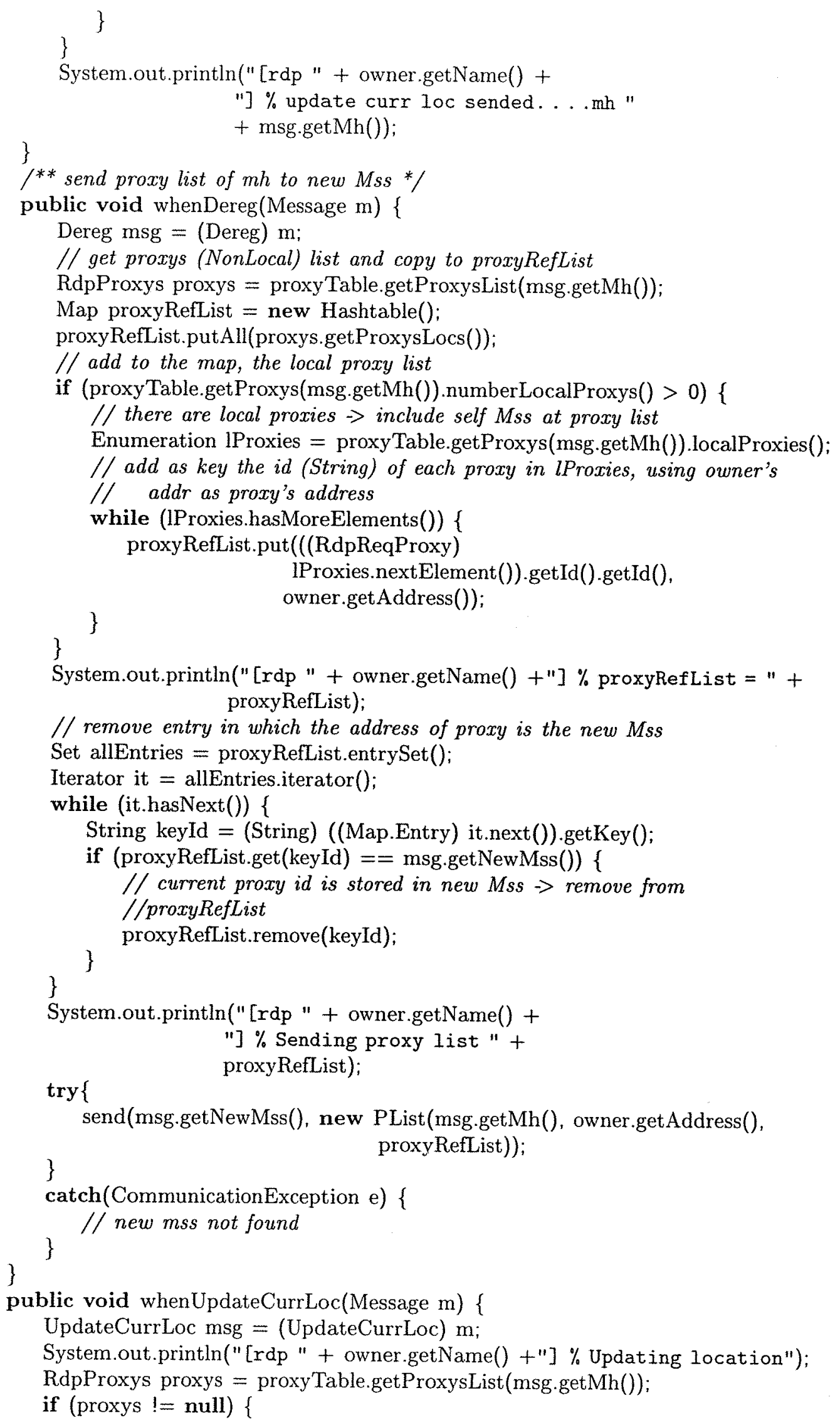




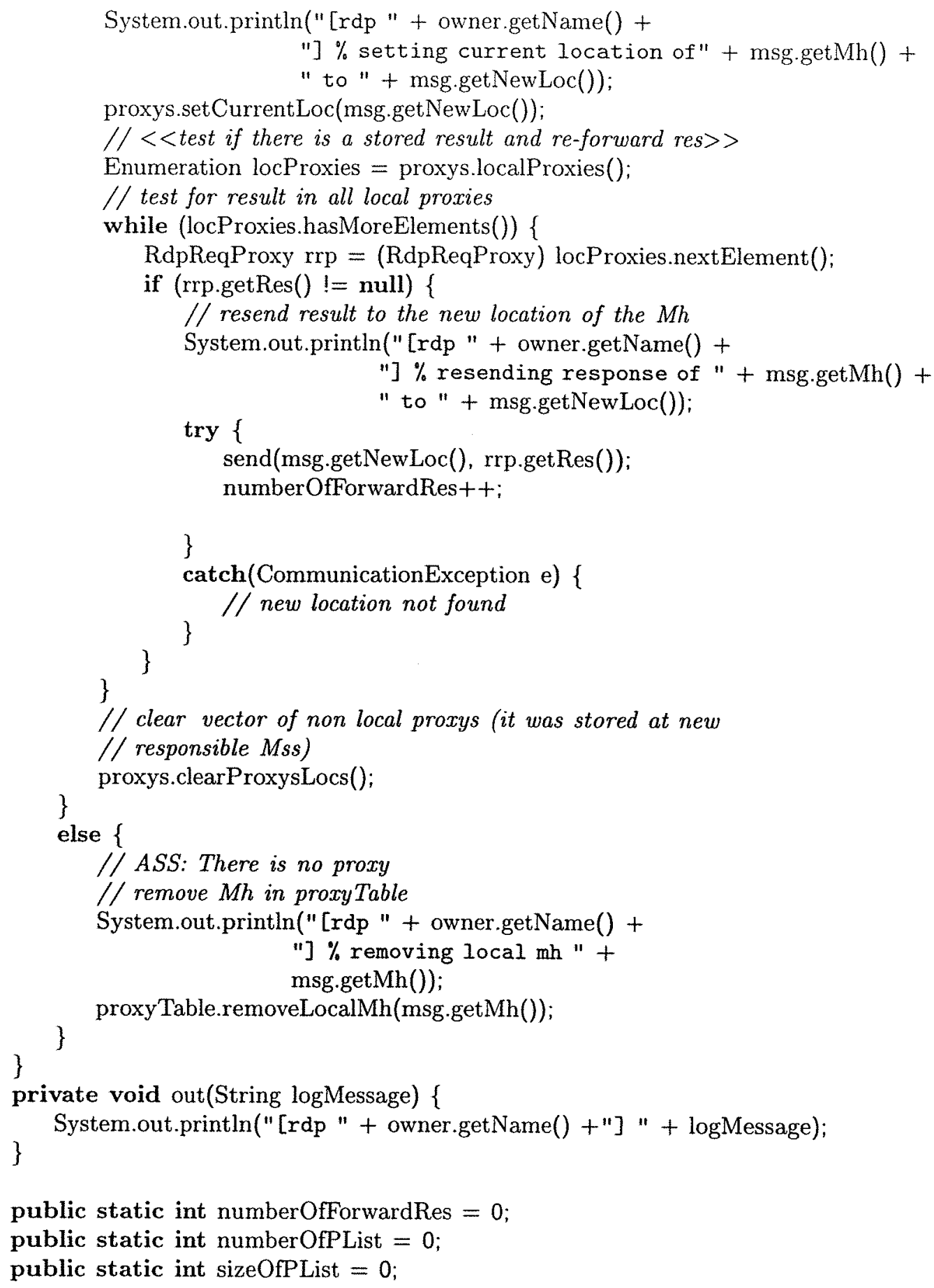

public static int numberOfForwardRes $=0$; public static int numberOfPList $=0$; public static int sizeOfPList $=0$; \}

\section{A.4 Simulação Determinística}

O código abaixo é a implementação da classe MySimulation, que cria uma simulação determinística para o protocolo RDP. 
public class MySimulation extends DetermSimulation \{

Mh mh, mh2, mh3, mh4;

Cell cellP, cellO, cellN, emptyCell;

Mss mssP, mssO, mssN, server;

Wiredlink wr, wr2, wr3, wr4, wr5, wr6;

public MySimulation()\{

super();

((DetermSimulator) sim) setDebug(SHOW, 0);

\}

((DetermSimulator) sim) setDebug(SHOW, 1);

public void configure()\{

$\mathrm{mh}=$ new $\mathrm{MyMh}(" \mathrm{Mh} ", \mathrm{sim}) ;$

$\mathrm{mh} 2=$ new MyMh("Mh2", $\operatorname{sim}) ;$

$\mathrm{mh} 3=$ new MyMh("Mh3",sim);

$\mathrm{mh} 4=$ new MyMh("Mh4",sim);

cellP = new Cell();

cellO $=$ new Cell ()$;$

cellN = new Cell();

emptyCell = new Cell();

mssP = new MyMss("MSSp",sim,cellP);

$\mathrm{mssO}=$ new MyMss("MSSo",sim,cellO);

mssN = new MyMss("MSSn",sim,cellN);

server = new MyMss("server",sim,emptyCell);

$\mathrm{wr}=$ new WiredLink(mssO.getAddress(),mssP.getAddress());

wr2 $=$ new WiredLink $(m s s P$.getAddress () ,mssN.getAddress());

wr3 = new WiredLink(server.getAddress(),mssP.getAddress());

wr4 $=$ new WiredLink(server.getAddress(),mssN.getAddress());

wr5 = new WiredLink(mssO.getAddress(),mssN.getAddress());

\}

wr6 $=$ new WiredLink(server.getAddress(),mssO.getAddress());

public void script ()\{

acceptTurnOn(mh, true); acceptTurnOn(mh2, true); acceptTurnOn(mh3, true);

acceptTurnOn(mh4, true);

acceptTurnOn(mssP, true);

acceptTurnOn(mssO, true);

acceptTurnOn(mssN, false);

acceptTurnOn(server, false);

changeShowMode(mssP, SHOW, DetermElement.EVENT_MESSAGE_RECEIVING); changeShowMode(mssO, SHOW, DetermElement.EVENT_MESSAGE_RECEIVING); changeShowMode(mssN, SHOW, DetermElement.EVENT_MESSAGE_RECEIVING); next(SHOW, 0);

mh.moveTo(cellP);

mh.receive(new sidam.rdp.messages.Request(server.getAddress(), 7));

mh.moveTo(cellO);

next();

mh.move To(cellN);

next();

acceptTurnOn(server, true);

next();

acceptTurnOn(mssN, true);

\}

next (); 


\section{A.5 Simulação Estocástica}

As seções seguintes mostram algumas classes que compõem a simulação estocástica do protocolo RDP. Esta seção apresenta três classes: MyStochSimulation, MigrationEventModel e MyMh.

\section{A.5.1 Classe MyStochSimulation}

O código abaixo implementa a classe MyStochSimulation, que cria a simulação estocástica do protocolo RDP apresentada anteriormente nao capítulo 6 .

public class MyStochSimulation extends StochSimulation \{

public static int REQLIMIT $=1000$;

public static Cell defaultCell;

public static int numberOfForwardRes;

public static int numberOfRequisitions;

public static int numberOfResponses;

public static Mss server;

private Cell emptyCell $=$ new $\operatorname{MyCell}(0)$;

private MyMh[] mhArray;

private MyCell[][] cellSet;

private MyMss[] mssArray;

public MyStochSimulation( $)\{$

\}

super();

public class linksModel extends LinkSimModel \{

public long throughput;

public linksModel(long throughput) \{

\}

this.throughput = throughput;

public long delaySend(NetMessage $m)\{$

\}

return this.throughput;

\}

public void configure ()\{

numberOfForwardRes $=0$;

numberOfRequisitions $=0$;

numberOfResponses $=0$;

int $1=2$;

int $c=2$;

int $\mathrm{mhNum}=5$;

cellSet $=$ createCellMatrix $(1, c)$;

mssArray = new MyMss $[1 *$ c];

int indMssArray $=0$;

for (int $\mathrm{i}=0 ; \mathrm{i}<1 ; \mathrm{i}++$ ) \{

for (int $\mathrm{i} 2=0 ; \mathrm{i} 2<\mathrm{c} ; \mathrm{i} 2++$, indMssArray ++ ) \{ 


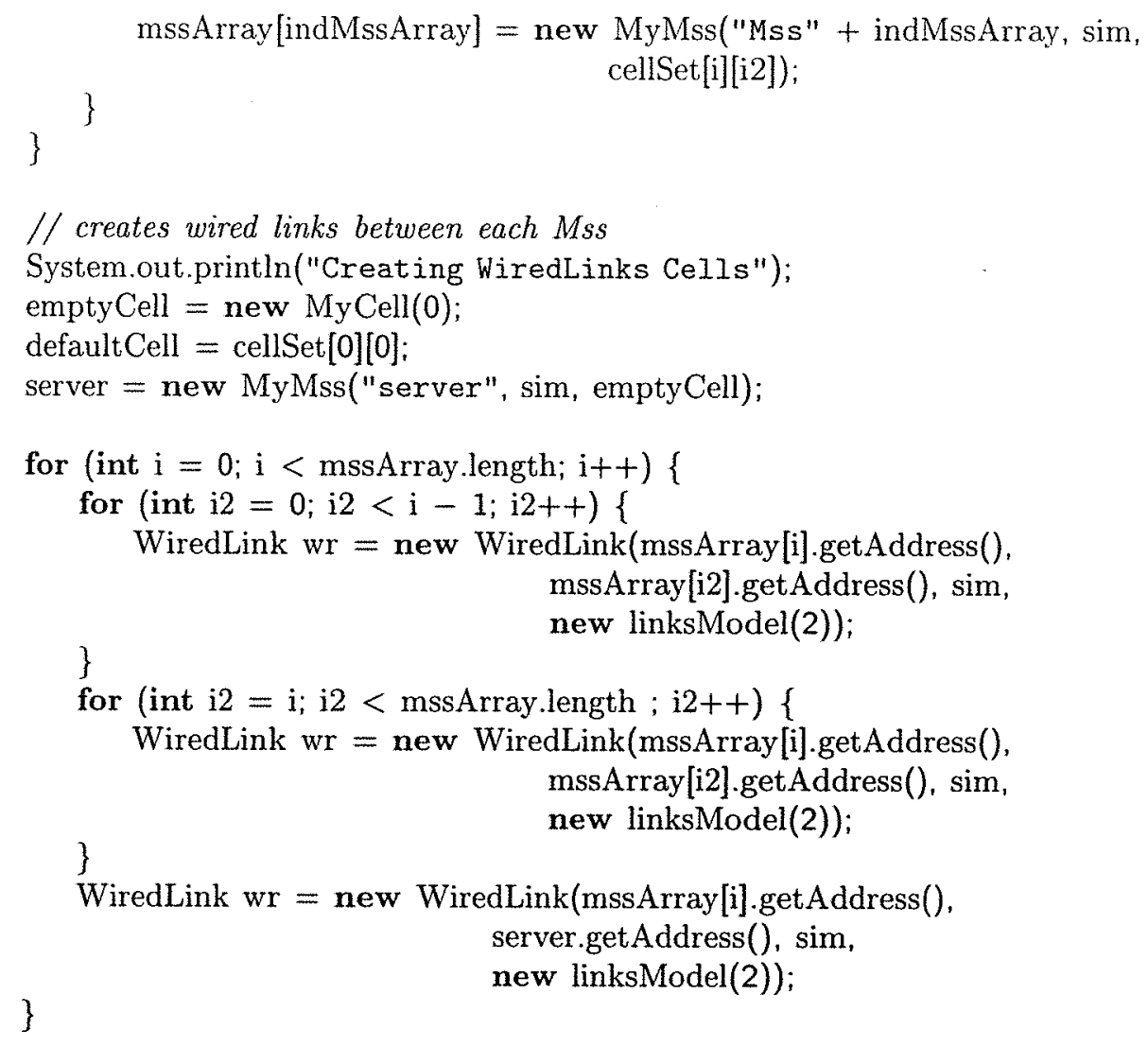

// populates cells with mhs System.out.println("Creating Mhs"); mhArray $=$ new MyMh[mhNum];

for (int $i=0 ; i<$ mhArray.length; $i++$ ) \{

\}

mhArray[i] $=$ new MyMh $(" M h "+i, \operatorname{sim})$; \}

System.out.println("!@! elements created");

public Cell[] createNeighArray(MyCell[][] cellMatrix, int line, int column) \{

int dimLine = cellMatrix.length;

int $\operatorname{dimColumn}=$ cellMatrix $[0]$.length;

Vector neigh = new Vector();

int begin AddCol $=-1$;

int limitCol $=1$;

try \{

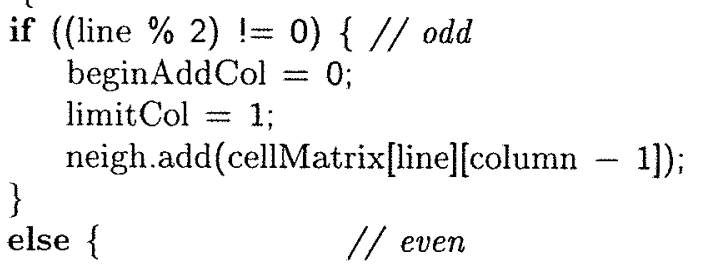




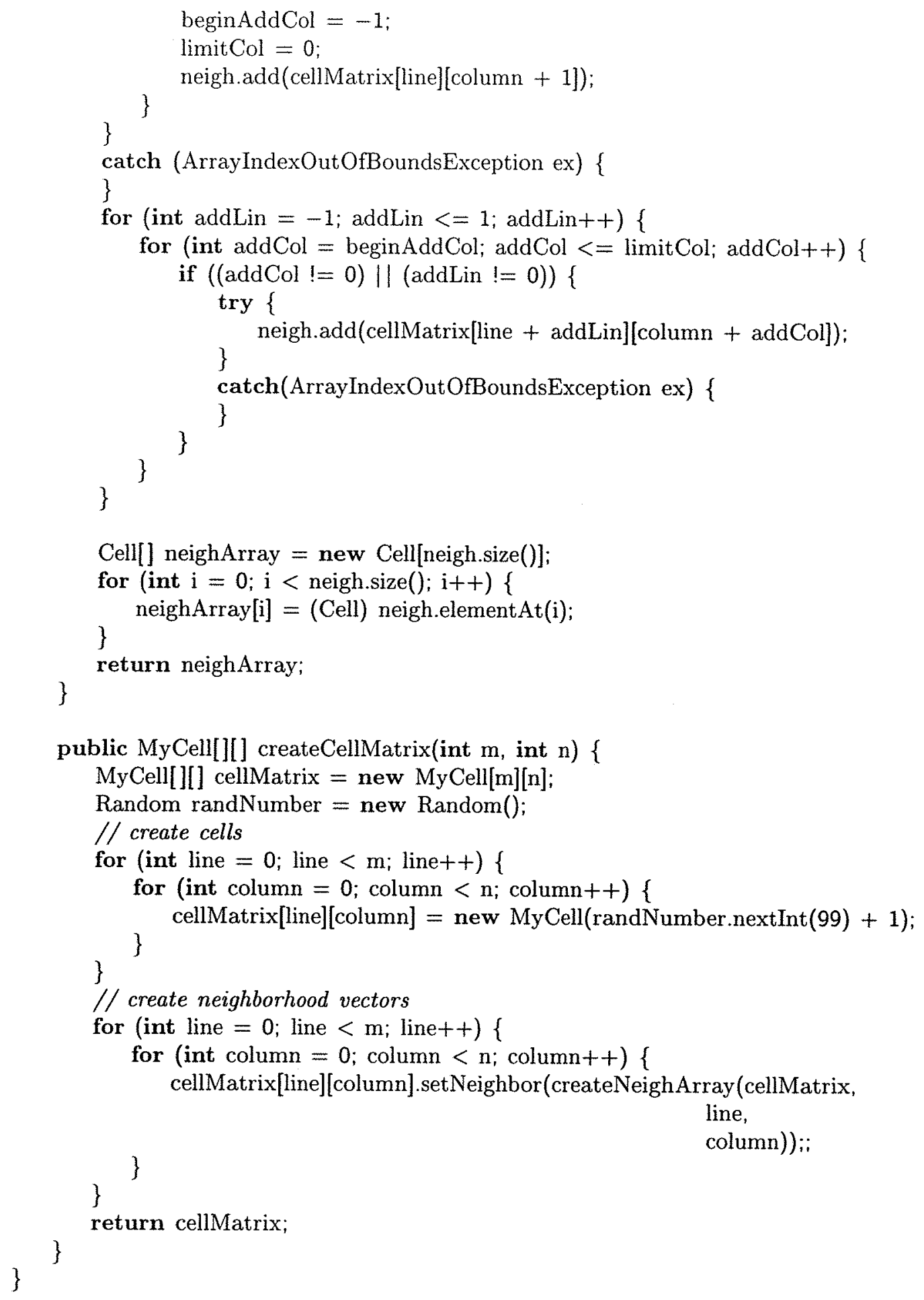

\section{A.5.2 Classe MigrationEventModel}

A classe MigrationEventModel implementa o modelo de mobilidade utilizado na simulação estocástica do protocolo RDP. 
public class MigrationEventModel extends EventModel \{

private MyCell currentCell;

private double migrationCoef;

public MigrationEventModel(MyCell cellInit, double migrationCoef)\{

this.currentCell = cellInit;

\}

this.migrationCoef = migrationCoef;

public Activity generateEvent(Element owner) \{

if (randomGenerator.nextBoolean(migrationCoef) \{

int random Number $=$ randomGenerator.nextInt(100);

Cell[] neighbor = currentCell.getNeighbor();

int [] attractionList $=$ new int [neighbor.length +1$]$;

int attractionSum $=0$;

for (int $\mathrm{i}=0$; $\mathrm{i}<$ neighbor.length; $\mathrm{i}++$ ) \{

\} attractionSum $+=(($ MyCell $)$ neighbor[i] $) \cdot \operatorname{get}$ Attraction () ;

attractionSum $+=$ currentCell.getAttraction();

int indCell $=-1$;

int normAttrac $=0$;

while (normAttrac < randomNumber) \{

indCell ++ ;

if (indCell $==$ neighbor.length) \{

break;

\}

else \{

normAttrac $+=100 *(($ MyCell $)$ neighbor[indCell]).getAttraction()

\}

\}

/ attractionSum;

$/ /$ index " $i$ " $\rightarrow$ next cell to move

if ((indCell $==$ neighbor.length) $\|$ (indCell $==-1)$ )

$/ /$ migration for the same cell

\}

return null;

else \{

currentCell $=($ MyCell $)$ neighbor[indCell];

\}

\}

return new MoveTo((Mh) owner, neighbor[indCell]);

\}

\}

return null;

\section{A.5.3 Classe MyMh}

A classe MyMh implementa as estações móveis utilizadas na simulação estocástica do protocolo RDP. 
public class MyMh extends Mh\{

public static class RequestModel extends EventModel \{

public Activity generateEvent(Element owner) \{

if (MyStochSimulation.numberOfRequisitions < MyStochSimulation.REQLIMIT) \{

MyStochSimulation numberOfRequisitions++;

return new Receive((Mh) owner,

\}

new Request(MyStochSimulation.server.getAddress(), 5));

else \{

\}

\}

return null;

\}

public static class StopCriteria extends EventModel \{

public StopCriteria(TimerScheduler timerScheduler) \{

\}

this.timerScheduler $=$ timerScheduler;

public Activity generateEvent(Element owner) \{

if (MyStochSimulation.numberOfRequisitions $>=$

MyStochSimulation.REQLIMIT) \{

\}

return new StopEventGeneration(timerScheduler);

else \{

\}

return null;

\}

private TimerScheduler timerScheduler;

public static class MhSim extends EventGenerator \{

public $\operatorname{MhSim}()\{$

super();

// a cada 15 UT's faz uma chamada de MigrationEventModel.generateEvent

timerScheduler.addEvent(15, new MigrationEventModel((MyCell)

MyStochSimulation.defaultCell,

1));

timerScheduler.addEvent(1000, new RequestModel());

\}

timerScheduler.addEvent(10, new StopCriteria(timerScheduler));

public void run() \{

eventQueue.pushEvent(new SimEvent(0,

new MoveTo((Mh) owner,

super.run(); MyStochSimulation.defaultCell)));

\}

\}

public MyMh(String name, Simulator simulator) \{

super(name, simulator, new MhSim());

rdp = new RDPMh(this);

// registers $R D P$ protocol at protocol notifier

\}

protocolNotifier.attach(this.rdp); 
public RDPMh rdp; \} 


\section{Referências Bibliográficas}

[1] Mark B. Abbott and Larry L. Peterson. A language-based approach to protocol implementation. In Proceedings of the Conference on Communications Architectures and Protocols, volume 22(4) of SIGCOMM, pages 27-39, New York, NY, USA, August 1992. ACM Press.

[2] Arup Acharya and B. R. Badrinath. Delivering multicast messages in networks with mobile hosts. In 13th International Conference on Distributed Computing Systems, pages 292-299, Pittsburgh, US, May 1993.

[3] Arup Acharya and B. R. Badrinath. Checkpointing distributed applications on mobile computers. In Third International Conference on Parallel and Distributed Information Systems, Austin, TX, October 1994.

[4] Divyakant Agrawal and Amr El Abbadi. An efficient and fault-tolerant solution for distributed mutual exclusion. ACM Transactions on Computer Systems, 9(1):1-20, February 1991.

[5] Sridhar Alagar and S. Venkatesan. Causally ordered message delivery in mobile systems. In IEEE Workshop on Mobile Computing Systems and Applications, Santa Cruz, CA, US, December 1994.

[6] M. W. Atkinson. Network simulation using Simscript. Globecom '84. IEEE Global Telecommunications Conference, Atlanta, Georgia, November 26-29. Paper 24.4.1-4, 1984.

[7] B. R. Badrinath, Arup Acharya, and Tomasz Imielinski. Impact of mobility on distributed computations. ACM Operating System Review, 27(2):15-20, April 1993.

[8] B. R. Badrinath, Arup Acharya, and Tomasz Imielinski. Designing distributed algorithms for mobile computing networks. Computers and Communications, 1994.

[9] B. R. Badrinath, A. Bakre, Tomasz Imielinski, and R. Marantz. Handling mobile clients: A case for indirect intercation. In Fourth Workshop on Workstation Operating System, pages 91-97, Napa, US, October 1993.

[10] Rajive Bagrodia, Richard Meyer, Mineo Takai, Yu-an Chen, Xiang Zeng, Jay Martin, and Ha Yoon Song News. Parsec: A parallel simulation environment for complex systems. IEEE Computer, 31(10):77-85, October 1998. 
[11] Ajay V. Bakre. Design and Implementation of Indirect Protocols for Mobile Wireless Environments. PhD thesis, Rutgers University, October 1996.

[12] A. Belinfante. Lotos integrated tool environment. Web Page, 1994. http://wwtios.cs.utwente.nl/Docs/toplevelentries/lotos/lite/glossy/glossy.html.

[13] Nina T. Bhatti, Matti A. Hiltunen, Richard D. Schlichting, and Wanda Chiu. Coyote: a system for constructing fine-grain configurable communication services. $A C M$ Transactions on Computer Systems, 16(4):321-366, November 1998.

[14] Nina T. Bhatti and Richard D. Schlichting. Configurable communication protocols for mobile computing. In Proceedings of the 4th International Symposium on Autonomous Decentralized Systems, pages 220-227, Tokyo, March 1999.

[15] Nina Trappe Bhatti. A System for Constructing Configurable High-Level Protocols. PhD thesis, University of Arizona, December 1996.

[16] R. Binder, N. Abramson, F. Kuo, A. Okinaka, and D. Wax. ALOHA packet broadcasting - a retrospective. AFIPS, 44(4):203-215, 1975.

[17] Grady Booch. Object-Oriented Analysis and Design With Applications. Addison-Wesley Pub Co, 2nd edition, 1994.

[18] Azzedine Boukerche, Sajal K. Das, Alessandro Fabbri, and Oktay Yildiz. Exploiting model independence for parallel PCS network simulation. In Proceedings of the 13th Workshop on Parallel and Distributed Simulation (PADS '99), pages 166-173, Atlanta, GA USA, May 1999.

[19] Donald F. Box, Douglas C. Schmidt, and Tatsuya Suda. ADAPTIVE: a dynamically assembled protocol transformation, integration and evaluation environment. Concurrency: Practice and Experience, 5(4):269-286, June 1993.

[20] L. Brakmo and L. Peterson. Experiences with network simulation. In SIGMETRICS '96, June 1996.

[21] Lee Breslau, Deborah Estrin, Kevin Fall, Sally Floyd, John Heidemann, Ahmed Helmy, Polly Huang, Steven McCanne, Kannan Varadhan, Ya Xu, and Haobo Yu. Advances in network simulation. IEEE Computer, 33(5):59-67, May 2000.

[22] Josh Broch, David A. Maltz, David B. Johnson, Yih-Chun Hu, and Jorjeta Jetcheva. A performance comparison of multi-hop wireless ad hoc network routing protocols. In Proceedings of the 4th Annual ACM/IEEE International Conference on Mobile Computing and Networking (MOBICOM-98), pages 85-97, New York, October 25-30 1998. ACM Press.

[23] Tracy Camp, John Lusth, and Jeff Matocha. Reduced cell switching in a mobile computing environment. In Proceedings of the 6th Annual International Conference on Mobile Computing and Networking - MobiCom'2000, pages 143-154, Boston, MA USA, August 2000. ACM SIGMOBILE. 
[24] C. Carothers, R. Fujimoto, Y. B. Lin, and P. England. Distributed simulation of PCS networks using time warp. In International Workshop on Modeling, Analysis and Simulation of Computer and Telecommunication Systems - MASCOTS'94, pages 2-7, 1994.

[25] Keith Cheverst, Nigel Davies, Keith Mitchell, and Adrian Friday. Experiences of developing and deploying a context-aware tourist guide: The GUIDE project. In Proceedings of the 6th Annual International Conference on Mobile Computing and Networking MobiCom'2000, Boston, MA USA, August 2000. ACM SIGMOBILE.

[26] Ricardo C. A. da Rocha and Markus Endler. Flexible simulation of distributed protocols for mobile computing. In Proceedings of 3rd ACM International Workshop on Modeling, Analysis and Simulation of Wireless and Mobile Systems - MSWiM'2000, pages 123-126, Boston, MA, USA, August 2000. ACM SIGMOBILE.

[27] Ricardo C. A. da Rocha and Markus Endler. Um simulador de protocolos distribuídos para computação móvel. In Proceedings of the 2nd Brazilian Wireless Communication Workshop, pages 33-48, Belo Horizonte, Brazil, May 2000. (In portuguese).

[28] Dilma M. da Silva, Fábio Kon, and Roy Campbell. Dynamic configuration of a directory service using the ComponentConfigurator framework. In Anais do Workshop de Métodos e Serviços para Computação Móvel, IME-USP, São Paulo, SP, October 2000.

[29] Dilma Menezes da Silva, Marco Dimas Gubitoso, and Markus Endler. Sistemas de informação distribuídos para agentes móveis. In Proceedings of the XXV Brazilian Software and Hardware Seminars (SEMISH'98), pages 125-140, Belo Horizonte, Brazil, August 1998. SBC.

[30] Marcos Aurélio Mendes de Moura. Juggler: Uma infra-estrutura para o gerenciamento de aplicações CORBA tolerantes a falhas. Master's thesis, Departamento de Ciência da Computação, Instituto de Matemática e Estatística, Universidade de São Paulo, São Paulo, SP, March 2001.

[31] M. Endler, D. M. da Silva, and K. Okuda. RDP: A result delivery protocol for mobile computing. In Proc. of the Int. Workshop on Wireless Networks and Mobile Computing (WNMC) at the 20th Int. Conference on Distributed Computing Systems (ICDCS), Taiwan, R.O.C., April 2000. IEEE.

[32] Markus Endler. A protocol for atomic multicast among mobile hosts. In 3rd International Workshop on Discrete Algorithms and Methods for Mobile Computing and Communications (DIAL M'99), pages 56-63, Seattle, Washington, USA, August 1999. ACM SIGMOBILE.

[33] Markus Endler, Dilma M. da Silva, Francisco J. Silva e Silva, Ricardo C. A. da Rocha, and Marcos A. M. de Moura. Project SIDAM: Overview and preliminary results. In Proceedings of the 2nd Brazilian Wireless Communication Workshop, pages 48-64, Belo Horizonte, Brazil, May 2000. 
[34] Markus Endler and Dilma Menezes da Silva. A reliable connectionless protocol for mobile clients. Available in http://www.ime.usp.br/ nendler/sidam/RDP.ps, 1999.

[35] D. Estrin et al. Network visualization with nam, the VINT network animator. IEEE Computer, pages 63-68, November 2000.

[36] Paul A. Fishwick. Simulation Model Design and Execution. Prentice Hall, 1999.

[37] Kenny K. Fok. A simulator for wireless local area networks. Master's thesis, University of Waterloo, Ontario, Canada, September 1997.

[38] FOLDOC - free on-line dictionary of computing. Web Page, 1993. http://ww. foldoc.org.

[39] Geoffrey C. Fox and Wojtek Furmanski. Java for parallel computing and as a general language for scientific and engineering simulation and modeling. Concurrency: Practice and Experience, 9(6):415-425, June 1997.

[40] Brian P. Gallagher. Using the architecture tradeoff analysis method to evaluate a reference architecture: A case study. Technical Report CMU/SEI-2000-TN-007, Software Engineering Institute, Carnegie Mellon University, June 2000.

[41] Erich Gamma, Richard Helm, Ralph Johnson, and John Vlissides. Design Patterns. Addison-Wesley Publishing Company, Inc., Reading, Massachusetts, 1994.

[42] Mark Grand. Patterns in Java, volume 1. John Wiley \& Sons, 1998.

[43] Mark Greis and VINT group. ns tutorial. Web Page. Available at http:// www.isi.edu/nsnam/ns/tutorial.

[44] T.G. Harrison, C.L. Williamson, W.L Mackrell, and R.B. Bunt. Mobile Multicast (MoM) Protocol: Multicast Support for Mobile Hosts. In Proc. 3rd Inter. Conference on Mobile Computing and Networking (MobiCom'97), Budapest, Hungary, pages 151-160, September 1997.

[45] Wendi Rabiner Heinzelman, Joanna Kulik, and Hari Balakrishnan. Adaptive protocols for information dissemination in wireless sensor networks. In Proceedings of the 5th Annual ACM/IEEE International Conference on Mobile Computing and Networking Mobicom'99, pages 174-185, Seattle, Washington, USA, August 1999. ACM.

[46] Ahmed Helmy and Deborah Estrin. Simulation-based 'STRESS' testing case study: A multicast routing protocol. In Sixth International Symposium on Modeling, Analysis and Simulation of Computer and Telecommunication Systems (MASCOTS'98), Montreal, Canada, July 1998.

[47] Alex Hills and David B. Johnson. A wireless data network infrastructure at Carnegie Mellon University. IEEE Personal Communications, 3(1):56-63, February 1996. 
[48] Christopher Ho, Katia Obraczka, Gene Tsudik, and Kumar Viswanath. Flooding for reliable multicast in multi-hop ad hoc networks. In Proceedings of the 3rd International Workshop on Discrete Algorithms and Methods for Mobile Computing and Communications (DIAL M'99) at the Mobicom'99, pages 64-71, Seattle, Washington, USA, August 1999. ACM.

[49] James R. Hodge. A framework for simulating wireless mobile client-server computing. Master's thesis, University of Waterloo, 1996.

[50] Gavin Holland and Nitin Vaidya. Analysis of TCP performance over mobile ad hoc networks. In Proceedings of the 5th Annual ACM/IEEE International Conference on Mobile Computing and Networking - Mobicom'99, pages 219-230, Seattle, Washington, USA, August 1999. ACM.

[51] G. Holzmann. Design and Validation of Computer Protocols. Prentice Hall, 1991.

[52] D. Hong and S. S. Rappaport. Traffic model and performance analysis for cellular mobile radio telephone systems with prioritized and nonprioritized handoff procedures. IEEE Transactions on Vehicular Technology, VT-35, 3:77-92, 1986.

[53] Xiaoyan Hong, Mario Gerla, Guangyu Pei, and Ching-Chuan Chiang. A group mobility model for ad hoc wireless networks. In Proceedings of the 2nd ACM International Workshop on Modeling, Analysis and Simulation of Wireless and Mobile Systems, pages 53-60, Seattle, USA, August 1999. ACM SIGMOBILE.

[54] Yih-Chun Hu and David B. Johnson. Caching strategies in on-demand routing protocols for wireless ad hoc networks. In Proceedings of the 5th Annual ACM/IEEE International Conference on Mobile Computing and Networking - Mobicom'99, pages 231-242, Seattle, Washington, USA, August 1999. ACM.

[55] Norman C. Hutchinson and Larry L. Peterson. The x-Kernel: An Architecture for Implementing Network Protocols. IEEE Transactions on Software Engineering, 17(1):64-76, January 1991.

[56] Tomasz Imielinski and B. R. Badrinath. Mobile wireless computing, solutions and challenges in data management. Communications of the ACM, February 1993.

[57] Jay M. Jacobsmeyer. Capacity of channel hopping stream on cellular digital packet data (CDPD). In Fifth Symposium on Wireless Personal Communications, Blacksburg, Virginia, June 1995.

[58] Per Johansson, Tony Larsson, Nicklas Hedman, Bartosz Mielczarek, and Mikael Degermark. Scenario-based performance analysis of routing protocols for mobile ad-hoc networks. In Proceedings of the 5th Annual ACM/IEEE International Conference on Mobile Computing and Networking - Mobicom'99, pages 195-206, Seattle, Washington, USA, August 1999. ACM. 
[59] David B. Johnson and David A. Maltz. Mobile Computing, chapter 5: Dynamic Source Routing in Ad Hoc Wireless Networks, pages 153-181. Kluwer Academic Publishers, 1996.

[60] David B. Johnson and David A. Maltz. Protocols for adaptive wireless and mobile networking. IEEE Personal Comunications, 3(1), February 1996.

[61] D. R. Kaeli. Issues in trace-driven simulation. Lecture Notes in Computer Science, 729:224-244, 1993.

[62] Brad Karp and H. T. Kung. GPSR: greedy perimeter stateless routing for wireless networks. In Proceedings of the 5th Annual ACM/IEEE International Conference on Mobile Computing and Networking - Mobicom'99, pages 243-254, Seattle, Washington, USA, August 1999. ACM.

[63] Toshihiro Kataoka, Kshirasagar Naik, David S. L. Wei, and Dan He. Crafting a mobile network simulation environment with Java. In Proceedings of the International Conference on Computing and Information - ICCI 98, University of Manitoba, Winnipeg, Manitoba, Canada, June 1998.

[64] Richard A. Kilgore, Kevin J. Healy, and George B. Kleindorfer. The future of Java-based simulation. In Proceedings of the 1998 Winter Simulation Conference, pages 1707-1712, Washington, December 1998. ACM SIGSIM.

[65] D. Lam, J. Jannink, D. C. Cox, and J. Widom. Modeling location management in personal communications services. In Proceedings of the IEEE International Conference on Universal Personal Communications, volume 2, pages 596-601, September 1996.

[66] Averill M. Law and W. David Kelton. Simulation modeling and analysis. McGraw-Hill, New York, 2nd edition, 1991. $759 \mathrm{p}$.

[67] Jinyang Li, John Jannotti, Douglas S. J. De Couto, David R. Karger, and Robert Morris. A scalable location service for geographic ad hoc routing. In Proceedings of the 5th Annual ACM/IEEE International Conference on Mobile Computing and Networking - Mobicom'99, pages 120-130, Seattle, Washington, USA, August 1999. ACM.

[68] L. M. Liljenstam and R. Ayani. MobSim++: An environment for parallel simulation of PCNs. In Proceedings of the SCS World Congress on Systems Simulation (WCSS'97), Singapore, September 1997. Society for Computer Simulation (SCS).

[69] J. G. Markoulidakis, G. L. Lyberopoulos, D. F. Tsirkas, and E. D. Sykas. Mobility modelling in third-generation mobile telecommunications systems. IEEE Personal Communications, pages 41-56, August 1997.

[70] Sergio Marti, T. J. Giuli, Kevin Lai, and Mary Baker. Mitigating routing misbehavior in mobile ad hoc networks. In Proceedings of the 5th Annual ACM/IEEE International Conference on Mobile Computing and Networking - Mobicom'99, pages 255-265, Seattle, Washington, USA, August 1999. ACM. 
[71] Geraldo Robson Mateus and Antônio Alfredo Ferreira Loureiro. Introdução à Computação Móvel. DCC/IM, COPPE/Sistemas, NCE/UFRJ, 1998. 11 ${ }^{a}$ Escola de Computação.

[72] S. Nanda. Teletraffic models for urban and suburban microcells: Cell sizes and handoff rates. IEEE Transactions on Vehicular Technology, 4(42):673-682, November 1993.

[73] Thyagarajan Nandagopal, Tae-Eun Kim, Xia Gao, and Vaduvur Bharghavan. Achieving mac layer fairness in wireless packet networks. In Proceedings of the 5th Annual ACM/IEEE International Conference on Mobile Computing and Networking - Mobicom'99, pages 87-98, Seattle, Washington, USA, August 1999. ACM.

[74] Giao Thanh Nguyen, Randy H. Katz, Brian Noble, and M. Satyanarayanan. A tracebased approach for modeling wireless channel behavior. In Winter Simulation Conference, pages 597-604, 1996.

[75] Sze-Yao Ni, Yu-Chee Tseng, Yuh-Shyan Chen, and Jang-Ping Sheu. The broadcast storm problem in a mobile ad hoc network. In Proceedings of the 5th Annual ACM/IEEE International Conference on Mobile Computing and Networking - Mobicom'99, pages 151-162, Seattle, Washington, USA, August 1999. ACM.

[76] J. Panchal, O. Kelly, J. Lai, N. Mandayam, A. T. Ogielski, and R. Yates. WiPPET, A virtual testbed for parallel simulations of wireless networks. In Proceedings of the 12 th Workshop on Parallel and Distributed Simulation (PADS-98), pages 162-169, Los Alamitos, May 26-29 1998. IEEE Computer Society.

[77] UCLA PCL. GloMoSim - Global Mobile information systems Simulation library. Web Page. http://pcl.cs.ucla.edu/projects/glomosim.

[78] Charles Perkins. IP mobility support. Request for Comments 2002, October 1996. IETF Mobile IP Group.

[79] Kalyan S. Perumalla, Richard M. Fujimoto, and Andrew T. Ogielski. MetateD - A meta language for modeling telecommunication networks. Technical Report GIT-CC-96-32, Georgia Institute of Technology, 1996.

[80] Mike Pidd and Ricardo A. Cassel. Three phase simulation in Java. In Proceedings of the 1998 Winter Simulation Conference, pages 367-371, Washington - USA, December 1998. ACM SIGSIM.

[81] Ramki Rajagopalan, Sridhar Alagar, and S. Venkatesan. MCE: An integrated mobile computing environment and simulation testbed. In USENIX Association, editor, Proceedings of the Second USENIX Symposium on Mobile and Location-Independent Computing, pages 33-46, Ann Arbor, Michigan, USA, April 1995. USENIX.

[82] Mauro Nacif Rocha, Geraldo Robson Mateus, and Soraia Lúcia da Silva. Traffic simulation and the location of mobile units in wireless communication systems. In Anais do $17^{\text {To }}$ Simpósio Brasileiro de Redes de Computadores, Salvador, Bahia, May 1999. 
[83] Elizabeth M. Royer and Charles E. Perkins. Multicast operation of the ad-hoc ondemand distance vector routing protocol. In Proceedings of the 5th Annual ACM/IEEE International Conference on Mobile Computing and Networking - Mobicom'99, pages 207-218, Seattle, Washington, USA, August 1999. ACM.

[84] Jochen Schiller. Mobile Communications. Addison-Wesley, 2000.

[85] M. Schütze, J. P. Riegel, and G. Zimmermann. Psigene - a pattern-based component generator for building simulation. Journal Theory and Practice of Object Systems (TAPOS), 5(2), 1999.

[86] John Scourias and Thomas Kunz. An activity-based mobility model and location management simulation framework. In Proceedings of the 2nd ACM international workshop on Modeling, analysis and simulation of wireless and mobile systems, pages 61-68, Seattle, WA, USA, August 1999. ACM SIGMOBILE.

[87] Atif A. Siddiqi and Thomas Kunz. The peril of evaluating location management proposals through simulations. In Proceedings of the 3rd International Workshop on Discrete Algorithms and Methods for Mobile Computing and Communications (DIAL M'gg) at the Mobicom'99, pages 78-85, Seattle, Washington, USA, August 1999. ACM.

[88] Prasun Sinha, Narayanan Venkitaraman, Raghupathy Sivakumar, and Vaduvur Bharghavan. WTCP: a reliable transport protocol for wireless wide-area networks. In Proceedings of the 5th Annual ACM/IEEE International Conference on Mobile Computing and Networking - Mobicom'99, pages 231-241, Seattle, Washington, USA, August 1999. ACM.

[89] Priyamvadha Thambu and Johnny Wong. An efficient token-based mutual exclusion algorithm in a distributed system. The Journal of Systems and Software, 28(3), March 1995.

[90] Nitin H. Vaidya, Paramvir Bahl, and Seema Gupta. Distributed fair scheduling in a wireless LAN. In Proceedings of the 5th Annual ACM/IEEE International Conference on Mobile Computing and Networking - Mobicom'99, pages 167-178, Seattle, Washington, USA, August 1999. ACM.

[91] Upkar Varshnet and Ron Vetter. Emerging mobile and wireless networks. Comunications of the $A C M, 43(6): 73-81$, June 2000.

[92] VINT group. The network simulator - ns-2. Web Page. http://www .isi .edu/nsnam/ns.

[93] Jennifer Walter, Jennifer Welch, and Nitin Vaidya. A mutual exclusion algorithm for ad hoc mobile networks. In 2nd International Workshop on Discrete Algorithms and Methods for Mobile Computing and Communications (DIAL M'98), Dallas, Texas, October 1998. ACM SIGMOBILE.

[94] Chienwen Wu. A fault tolerant $O(\sqrt{n})$ algorithm for distributed mutual exclusion. In Jim Weeldreyer, editor, Proceedings of the 12th Annual International Phoenix Conference 
on Computers and Communications, pages 175-180, Tempe, AR, March 1993. IEEE Computer Society Press.

[95] Jie Wu and Hailan Li. On calculating connected dominating set for efficient routing in ad hoc wireless networks. In 3rd International Workshop on Discrete Algorithms and Methods for Mobile Computing and Communications (DIAL M'99), pages 7-14, Seattle, Washington, USA, August 1999. ACM SIGMOBILE.

[96] X. Zeng, R. Bagrodia, and M. Gerla. GloMoSim: A library for parallel simulation of large-scale wireless networks. In Proceedings of the 12th Workshop on Parallel and Distributed Simulation (PADS-98), pages 154-161, Los Alamitos, May 26-29 1998. IEEE Computer Society. 